\author{
Universidade de São Paulo \\ Instituto de Física
}

\title{
Estudo magnético de objetos geométricos microscópicos de Co e CoFeSiB amorfo
}

\author{
Rodrigo Mario Calle Huamani
}

Orientador: Prof. Dr. Antonio Domingues dos Santos

Dissertação apresentada ao Instituto de Física da Universidade de São Paulo para a obtenção do título de Mestre em Ciências

Banca Examinadora:

Prof. Dr. Antonio Domingues dos Santos (IF-USP)

Prof. Dr Fernando José Gomes Landgraf (EPUSP)

Prof. Dr. Flavio Garcia (CBPF) 


\section{FICHA CATALOGRÁFICA \\ Preparada pelo Serviço de Biblioteca e Informação do Instituto de Física da Universidade de São Paulo}

Calle Huamani, Rodrigo Mario

Estudo magnético de objetos geométricos microscópicos de Co e CoFeSiB amorfo. São Paulo, 2019.

Dissertação (Mestrado) - Universidade de São Paulo. Instituto de Física. Depto. Física de Materiais e Mecânica.

Orientador: Prof. Dr. Antonio Domingues dos Santos

Área de Concentração: Laboratório de Materiais Magnéticos.

Unitermos: 1. Elementos litografados; 2. Microscopia MOKE; 3. Configuração magnética; 4. Parede domínio; 5 . Microscopia de força magnética. 


\section{University of São Paulo \\ Physics Institute}

\section{Magnetic study of geometric microscopic objects of Co and amorphous CoFeSiB}

\section{Rodrigo Mario Calle Huamani}

Orientador: Prof. Dr. Antonio Domingues dos Santos

Dissertation submitted to the Physics Institute of the University of São Paulo in partial fulfillment of the requirements for the degree of Master of Science

Examining Committee:

Prof. Dr. Antonio Domingues dos Santos (IF-USP)

Prof. Dr Fernando José Gomes Landgraf (EPUSP)

Prof. Dr. Flavio Garcia (CBPF) 



\section{Agradecimentos}

Agradeço a meu orientador Antonio Domingues dos Santos, pela orientação e as sugestões na dissertação.

Agradeço a meus pais Amalia e Abdón, pelo apoio dado nesta etapa acadêmica.

Agradeço aos professores do LMM, ao professor Daniel Cornejo, Luiz Nagamine e Carmen Partiti.

Aos técnicos do LMM, Sergio, Marcelo, Renato, Paulo e Marcos pela ajuda com os equipamentos, desenvolvimento de peças, sugestões, amizade, ensinamentos e compartimento de suas experiências.

Aos amigos e colegas de pós-graduação do laboratório LMM, Gabriel, Karel, Gerson, Fernanda, Francisco, Fernando e Diana pelas discussões e conclusões.

Ao professor de Luís Carlos Sampaio Lima, do CBPF pela gravação de máscaras por meio da técnica de litografia de escrita direta por laser, feitas para a produção de minhas amostras.

Ao professor Alain Quivy, do Laboratório de Novos Matérias Semicondutores pelas medidas de MFM feitas nas minhas amostras.

Ao professor Fernando José Gomes Landgraf e ao laboratório de Microscopia da Escola Politécnica da USP, pelos polimentos nas amostras e as medidas de EBSD.

Agradeço ao Instituto de Física da Universidade de São Paulo, aos professores e aos amigos que conheci.

Agradeço à CNPq, Conselho Nacional de Desenvolvimento Científico e Tecnológico, pelo apoio financeiro durante o período de realização deste mestrado. 



\section{Resumo}

Neste trabalho procura-se compreender o comportamento das configurações magnéticas presentes em objetos micrométricos e filmes finos. Estes estudos foram realizados principalmente através de microscopia de força magnética (MFM) e do efeito Kerr magnetoótico (MOKE). Foi também desenvolvido um procedimento para a obtenção de curvas de histerese a partir de imagens de microscopia MOKE. Para definir o tamanho e a geometria dos objetos empregaram-se as técnicas de litografia por feixe de luz e por feixe de elétrons, e depois para a deposição do material de Co e CoFeSiB amorfo, se fez uso do magnetron sputering. O material assim obtido foi analisado para determinar suas propriedades magnéticas por meio das técnicas do MOKE, magnetrometria de amostra vibrante (VSM), MFM, e microscopia de força atômica (AFM) para o estudo da morfologia dos objetos. Os resultados do MFM e sua interpretação foram apoiados por simulações da estrutura magnética usando o programa Mumax3. Além disso foram analisados as relações entre as propriedades magnéticas e cristalografias de um material de Fe6\%Si por médio das imagens MOKE e as imagens de EBSD.

As medidas das curvas de histereses por VSM foram feitas em filmes preparados nas mesmas condições dos objetos litografados. Elas mostram que não há eixo anisotropia preferencial, portanto, não apresentam uma direção preferencial de magnetização. Com base nas medidas do MFM se encontrou que os objetos de Co policristalino apresentam configurações de estrutura de domínios magnéticos complexas, diferentes comparativamente do material magneticamente mais mole de $\mathrm{CoFeSiB}$ amorfo. Isto se deve as diferenças entre os dois materiais, na anisotropia magnética e magnetostricção. As diferentes geometrias dos objetos estudados apresentaram configurações magnéticas diferentes entre si, fato este, determinado principalmente pela anisotropia de forma. As semelhanças entre objetos da mesma geometria, mas de diferentes materiais mostraram fortes semelhanças, porém com a presença de perturbações locais no caso de Co. O material mole, amorfo, apresenta estados magnéticos ideais e simples, isto é, as tensões mecânicas residuais não geram perturbações magnéticas neste material de baixa magnetostricção. Além disto, nos objetos quadrados a presença de paredes de domínio do tipo cross-tie tem lugar sob certas condições, tendo a espessura do objeto como principal parâmetro. Estes resultados para a parede do tipo cross-tie foram vistos também em simulações micromagnéticas feitas no programa Mumax3.

As estruturas magnéticas foram simuladas, com boa similaridade para a amostra de $\mathrm{CoFeSiB}$, mas encontrou-se discordâncias no caso da amostra de Co, estas discordâncias foram analisadas e se estabeleceu as possíveis causas em cada geometria.

Palavras chaves: Elementos litografados; Microscopia de Força Magnética; Microscopia MOKE; Estrutura de domínio magnético; Parede de domínio magnético. 



\section{Abstract}

In this work the aim is to understand the behavior of the magnetic configurations present in micrometric objects and thin films. This study was developed through the use of magnetic force microscopy (MFM) and magneto-optical Kerr effect (MOKE). Another development was the use of MOKE microscopy images to obtain hysteresis curves. To define the size and geometry of the objects were used laser beam and electron beam lithography techniques, and for the deposition of $\mathrm{Co}$ and amorphous $\mathrm{CoFeSiB}$ materials was used magnetron sputtering. The produced samples were analyzed to determine its magnetic properties by MOKE, vibrating sample magnetometer (VSM), MFM, and atomic force microscopy (AFM) technique for the study of the object morphology. The results of the MFM and its interpretation were supported by simulations of the magnetic structure using the Mumax3 software.

The measurements of the hysteresis loops by VSM were made on films produced under the same conditions of the lithographed objects. They show that there was no overall preferential anisotropy on the surface, this shows the absence of anisotropy in the deposition of the grains, in the case of $\mathrm{Co}$, and therefore do not present a preferential direction of magnetization. Based on the MFM measurements, the polycrystalline Co objects were found to have different configurations compared to the amorphous CoFeSiB magnetically soft material. This is due to the differences in magnetic anisotropy and magnetostriction. The different geometries of the studied objects presented different magnetic configurations between them, this fact is determined mainly by the shape anisotropy. The similarities between objects of the same geometry but of different materials showed strong similarities with the presence of local perturbations in the case of Co. The magnetically soft amorphous material presents ideal and simple magnetic states, due to the fact the residual mechanical stresses do not generate disturbances in this low magnetostriction material. By the other side, in the square objects the presence of cross-tie domain walls takes place under certain conditions, where the thickness of the magnetic object is the main parameter. This kind of domain wall is also seen on the micromagnetic simulations developed using the Mumax3 software.

The magnetic structures were simulated with good similarity to the amorphous $\mathrm{CoFeSiB}$ sample, but disagreements were found in the case of the Co sample. These disagreements were analyzed and the possible causes in each geometry were established.

Key words: Lithographed elements; Magnetic force microscopy; MOKE Microscopy; Magnetic domain structure; Magnetic domain wall. 



\section{Lista de Figuras}

Figura 2-1: Tipos de efeito Kerr magneto-óticos [13] .......................................................................... 6

Figura 2-2: a) Parede de domino tipo Bloch e b) Parede de domínio tipo Néel.[21] ............................... 13

Figura 2-3: (a) Distribuição do vetor de magnetização na superfície de uma parede de cross-tie [24], (b) imagem representativa da distribuição de vetores de magnetização em uma parede de cross-tie [22], (c) imagem da distribuição de carga magnética em uma parede do tipo cross-tie [22].

Figura 2-4: Seção transversal para todas as densidades de energia como uma função da posição ao longo de uma parede simulada do tipo cross-tie [23].

Figura 2-5: Variação da direção da magnetização a através de uma parede de domínio de $180^{\circ}$ [25][27].19 Figura 3-1: Etapas do processo de litografia de escrita por laser, utilizado na obtenção dos objetos

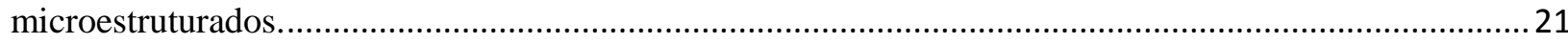

Figure 3-2: esquema do processo de deposição de um magnetron sputtering [30] ................................. 23

Figura 3-3: Esquema de funcionamento de um microscópio de forca magnética MFM [33]....................26

Figura 3-4: Esquema de um magnetômetro de amostra vibrante (VSM). ..............................................2 27

Figura 3-5: Esquema do caminho ótico que percorre a luz no microscópio metelográfico......................... 32

Figura 3-6: Imagens dos estados saturados $\mu$ sat $=\mu($ Hmax $)$ e $-\mu$ sat $=\mu($ Hmin $)$ para um objeto de dimensões Co de $25 \times 60$ um e $60 \mathrm{~nm}$ de espessura e sua distribuição estatística. 34

Figura 3-7: a) Intensidade Kerr polar VS abertura numérica (NA) no ar e no óleo, b) Intensidade Kerr

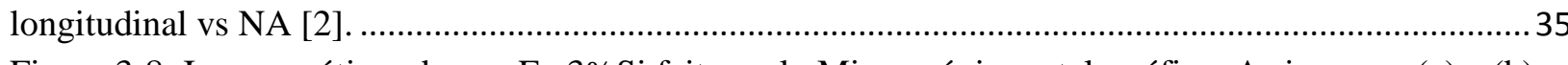

Figura 3-8: Imagens óticas do aço Fe-3\%Si feitas pelo Microscópio metalográfico. As imagens (a) e (b) foram feitas para duas condições de polarização diferentes. A imagem (c) é a diferença entre a imagem (a) e (b). A imagem (d) é a imagem final obtida depois de fazer o filtro adequado. A imagem (e) é o histograma da imagem (c) e a imagem (f) é o histograma da imagem (d). A seta dupla indica a direção da componente de magnetização que é permitido ver pelo contraste magneto-ótico nesta configuração Kerr longitudinal usada.

Figura 4-1: Curva de histereses para duas direções perpendiculares entre si no plano da superfície do filme de $\mathrm{CoFeSiB}$

Figura 4-2: Curva de histereses para duas direções perpendiculares entre si no plano da superfície do filme de Co.

Figura 4-3 A) Imagens MOKE do objeto de Co e seus respectivos histogramas da sua região de interesse para diferentes valores de campo magnético aplicado. B) Curva de histereses obtida pelas imagens Kerr de um objeto de filme fino de Co para diferentes valores do campo $\mathrm{H}$ aplicado.

Figura 4-4: Imagens MOKE para objetos de Co, tratados termicamente, para diferentes disposições angulares, onde $\Theta$ é o ângulo formado pelo eixo maior do retângulo e a direção do campo magnético aplicado. Para 1.a) $\Theta=0^{\circ}$, 1.b) $\Theta=60^{\circ}$ e 1.c) $\Theta=90^{\circ}$. Curvas de histereses obtidas pelas imagens MOKE para diferentes orientações do objeto de Co com respeito a campo magnético 2.a) corresponde a o ângulo de $\Theta=0^{\circ}$, 2.b) corresponde a $\Theta=60^{\circ}$, 2.c) $\Theta=90^{\circ}$ e 2.d) mostra as três curvas de histereses juntas...... 45 Figura 4-5: Imagem Kerr de objetos retangulares de $\mathrm{CoFeSiB}$ onde a) é um estado de remanência antes do tratamento térmico b) e c) são estados de remanência depois do tratamento para quando o campo de 
desmagnetização foi aplicou na direção vertical, e d) e e) são estados de remanência para quando o campo de desmagnetização foi aplicado na direção perpendicular ao eixo de maior comprimento. . .46 Figura 4-6: Imagem Kerr de objetos retangular de Co onde a) e b) são estados de remanência para quando a amostra ficou com seu eixo maior paralelo ao campo de desmagnetização aplicado, e c) e d) são estados de remanência para quando o campo de desmagnetização foi aplicado na direção perpendicular a o eixo de maior comprimento.

Figura 4-7: Imagem de mapa da orientação do grão IPF (Inverse Pole Figure) obtida pelo EBSD e mapa de cores. O quadro de linha clara marca a região que é correspondente à figura 4-9 das imagens de domínio.

Figura 4-8: Imagem Kerr longitudinal mostrando a estrutura de domínios e imagem (IPF)

do EBSD correspondente com seu diagrama de cores. O marco de linha clara relaciona a imagem de domínio com sua imagem de (IPF) na mesma região da superfície da amostra.

Figura 4-9: Imagem Kerr longitudinal mostrando a estrutura de domínios. Esta imagem apresenta sua correspondência com a figura 4-7.

Figura 4-10: Imagem Kerr longitudinal, com contraste magneto-ótico para o caso no qual o contraste mostra a componente de magnetização na direção longitudinal ao plano das chapas. O defeito indicado pela seta, permite a correlação desta imagem com a figura 4-8.

Figura 4-11: Elemento quadrado de $\mathrm{CoFeSiB}$ a) imagem topográfica, b) imagem de MFM c) esquema de micromagnetização obtido por simulação numérica.

Figura 4-12: a) imagem topográfica por AFM de um objeto de Co de $10 \mu \mathrm{m} \times 10 \mu \mathrm{m}$, b) perfil de altura da imagem topográfica de a) mostra um valor de $85 \mathrm{~nm}$ de altura, c) Imagem de fase por MFM do objeto de Co.

Figura 4-13: a) estrutura de domínio ideal de 4 domínios de fechamento de um elemento quadrado b) imagem de MFM mostrando uma estrutura de domínio complexo, onde as setas indicam possível direções de magnetização dos domínios. 58 Figura 4-14: a) imagem de MFM com o esquema da estrutura da parede de cross-tie, b) imagem representativa da distribuição de vetores de magnetização em uma parede de cross-tie [26], c) imagem da distribuição de carga magnética em uma parede de cross-tie [26]. 59 Figura 4-15: Imagem MFM com traços que mostram perfis de nível de sinal onde a) corresponde ao segmento A na imagem, b) ao segmento B, c) a o C e d) a o segmento D. 60 Figura 4-16: Esquema de magnetização dos estados magnéticos no elemento de disco: estado vórtice (a) estado diamante (b) e estado triângulo (c)[46].

Figura 4-17: Imagens de objeto circular de CoFeSiB: (a) imagem topográfica e (b) imagem MFM correspondente.

Figura 4-18: Imagens de objeto circular de Co: a) imagem topográfica $\left(20 x 20 \mu \mathrm{m}^{2}\right)$, b) imagem MFM correspondente, c) e d) mostra possíveis direções da magnetização. 64 Figura 4-19: a) Estado vórtice na parte de acima, esta cebola na parte de baixo, b) detalhes de uma parede vórtice num policristal de $\mathrm{Co}, \mathrm{c}$ ) detalhes de uma parede transversal [49]. .65 Figura 4-20: Imagens do elemento de anel de CoFeBSi a) imagem topográfica e b) imagem de MFM ...66 Figura 4-21: Imagens do elemento de anel de Co a) imagem topográfica, b) imagem de MFM, c) possível disposição radial do sentido da magnetização nos domínios e d) possível orientação circular da magnetização a passar de um domínio ao outro. 
Figura 4-22: Imagens do elemento de triangulo de CoFeBSi a) imagem topográfica, b) imagem de MFM e c) construção de uma estrutura de domínios usando a regra de Van Den Berg........................................68

Figura 4-23: Imagens do elemento de triangulo de Co a) imagem topográfica e b) imagem de MFM ......69 Figura 4-24: Imagens feitas por microscopia Kerr longitudinal, o contraste revela a magnetização a) arranjo de objetos de Co, a linha azul limita os objetos de interesse b) aumento dos objetos de interesse.70 Figura 4-25 a) Imagem de simulação micromagnética de um objeto quadrado de $\mathrm{CoFeSiB}$, os vetores indicam a direção da magnetização, b) a imagem de MFM simulada, correspondente e c) é a imagem de MFM.

Figura 4-26: (a)Imagem de simulação micromagnética de um objeto quadrado de Co, os vetores indicam a direção da magnetização e (b) a imagem de MFM simulada, correspondente.

Figura 4-27: Imagens de simulação micromagnética de objetos retangular de Co, os vetores indicam a direção da magnetização, t é a espessura do objeto, em (a),(b),(c), (e) as dimensões são de 10 Ltro $^{*} 40$ Ltro $^{*}$ t para $\mathrm{t}=6$ Ltro, 8.5 Ltro e $\mathrm{t}=$ Ltro respectivamente, em (d) de 10 Ltro $* 30$ Ltro $* 9$ Ltro e em (e) de 20Ltro*60Ltro*10Ltro. e (f) de 10Ltro*40Ltro*10Ltro, (e) e (f) mostram suas respectivas imagens de MFM.

Figura 4-28: Imagens de simulação micromagnética de objeto quadrado de Co, para diferentes valores de de $\mathrm{K}_{\mathrm{a}}$ (anisotropia uniaxial na direção $\mathrm{Y}$ ). 75

Figura 4-29: (a)Imagem de simulação micromagnética de um objeto de disco de CoFeSiB, os vetores indicam a direção da magnetização e (b) a imagem de MFM correspondente. 76 Figura 4-30: (a)Imagem de simulação micromagnética de um objeto de disco de Co, os vetores indicam a direção da magnetização e (b) a imagem de MFM correspondente. .76 Figura 4-31: : a) Imagem de simulação micromagnética de um objeto triangular de $\mathrm{CoFeSiB}$, os vetores indicam a direção da magnetização e b) a imagem de MFM correspondente.

Figura 4-32: (a) Imagem de simulação micromagnética de um objeto triangular de Co, os vetores indicam a direção da magnetização e (b) a imagem de MFM correspondente.

Figura 4-33: a) Imagem de simulação micromagnética de um objeto em formato de anel de $\mathrm{CoFeSiB}$, os vetores indicam a direção da magnetização e b) a imagem de MFM correspondente. 78 Figura 4-34: a) Imagem de simulação micromagnética de um objeto em formato de anel de Co, os vetores indicam à direção da magnetização e b) a imagem de MFM correspondente. 


\section{Índice}

Capítulo 1 : Introdução ................................................................................................................ 1

Capítulo 2: Fundamentos teóricos...................................................................................................... 3

2.1 Magnetismo em filmes e objetos microscópicos........................................................................... 3

2.2 Filmes fino magnéticos e sua formação .................................................................................. 3

2.3 Efeito Kerr magneto-ótico ...................................................................................................

2.4 Energias envolvidas nos processos magnéticos .......................................................................... 8

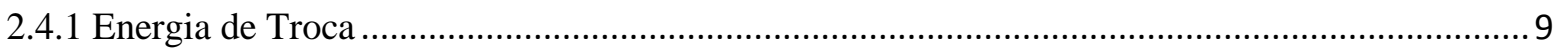

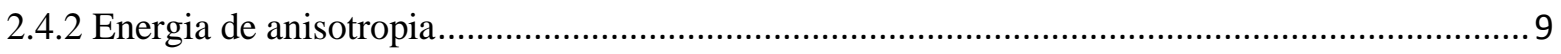

2.4.3 Energia de Zeeman ou magnetostática.................................................................................... 10

2.4.4 Energia de desmagnetização .................................................................................................. 10

2.4.5 Energia magnetoelástica ….............................................................................................. 11

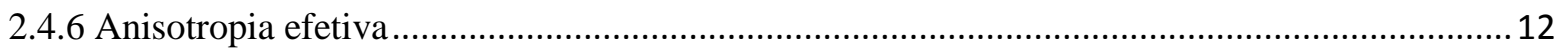

2.5 Estruturas de domínios magnéticos......................................................................................... 12

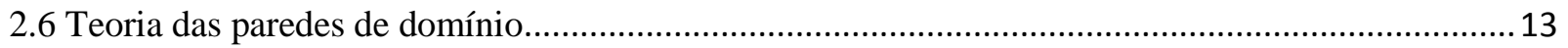

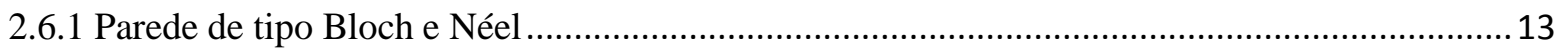

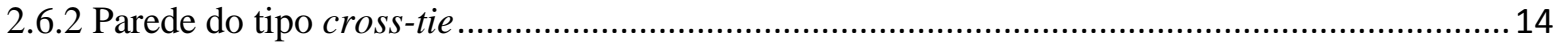

2.6.3 Energia de parede e transições entre tipos de parede …........................................................... 15

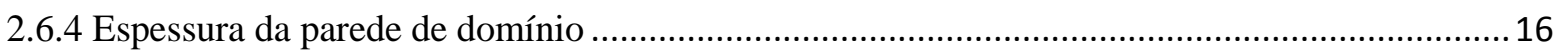

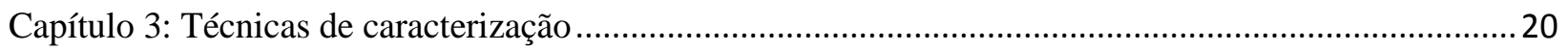

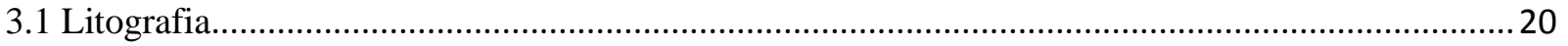

3.1.1 Litografia por feixe de elétrons -e processo de lift-off ........................................................... 20

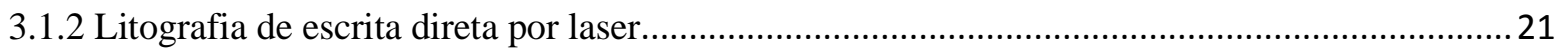

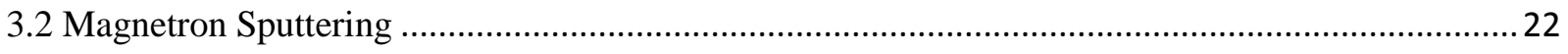

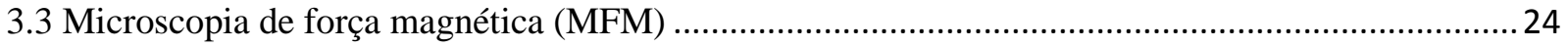

3.4 Magnetômetro de amostra vibrante (VSM) ............................................................................... 27

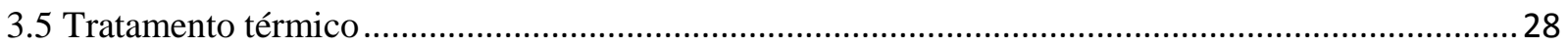




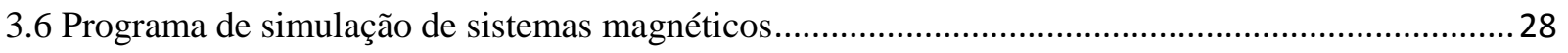

3.7 Microscópio metalográfico adaptado para o MOKE …................................................................... 31

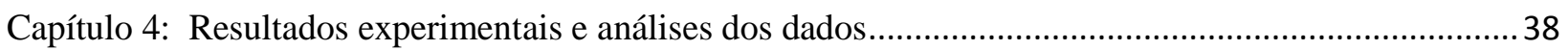

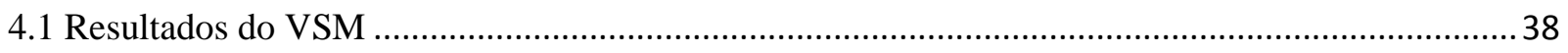

4.2 Curvas de histereses a partir das imagens Kerr no microscópio metalográfi...................................39

4.2.1 Interpretação e modelamento do sinal Kerr ........................................................................... 40

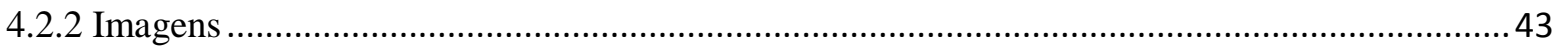

4.2.3 Estudo das propriedades magnéticas e estruturais do aço elétrico Fe6\%Si ...............................48

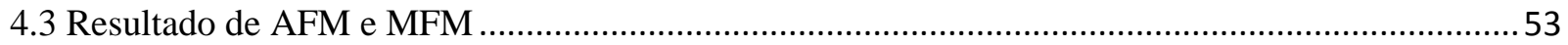

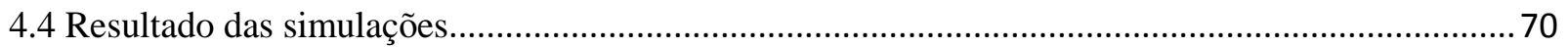

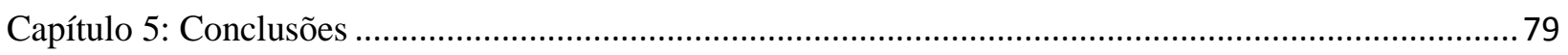





\section{Capítulo 1 : Introdução}

O interesse no estudo dos objetos nano e microestruturados é devido às diferentes configurações magnéticas que se pode encontrar como função de diferentes parâmetros, principalmente da geometria e propriedades microestruturais, morfológicas e magnéticas. E pelo interesse nas suas aplicações tecnológicas como sensores, transdutores e memórias de armazenamento de dados, etc. O material de Co e CoFeSiB , foi escolhido para poder comparar seus estados magnéticos nas amostras preparadas nas mesmas condições, para as mesmas geometrias. Assim se vê a diferença entre um material magneticamente mole (CoFeSiB) e um (Co) que tem anisotropia magnetocristalina e magnetostricção. Nestes materiais microestruturados, por ter a espessura fina, o seu comportamento magnético muda em comparação a um material em bulk.

Os objetos adquirem diferentes configurações de magnetização que dependem tanto de sua geometria como do processo de magnetização. As técnicas empregadas para a sua análise foram o MFM, AFM, VSM e a microscopia ótica por efeito Kerr magneto-ótico (MOKE). No caso dos materiais construídos pela litografia por feixe de luz, a técnica MOKE mostra vantagens de não perturbar o objeto de estudo, ser de rápido acesso e ter uma fácil interpretação do padrão obtido.

O microscópio Kerr magneto-ótico é um equipamento fundamental muito usado no estudo do magnetismo e da spintrônica. Esta técnica permite se obter informação sobre o comportamento magnético em dispositivos na micro e nanoescala. Devido a estas facilidades e pelo fato de poder se selecionar regiões de interesse, foram desenvolvidas técnicas que conseguem obter curvas de histereses a partir das imagens magneto-óticas [1][2]. Estas curvas oferecem informação local do comportamento da magnetização nestes objetos. Assim, possibilitam a melhora na performance de materiais em aplicações e a compreensão na relação entre as propriedades dos materiais e suas geometrias. Neste projeto se reproduz os trabalhos das referências [1] e com ajuda das suas ideias principais se estabelece as condições e limites de aplicabilidade para os quais a resolução das curvas de histereses sejam ótimas. Assim indicando a possibilidade de melhora no processo de medida. Por outro lado as Imagens MOKE do Fe6\%Si também foram analisadas junto com as imagens de EBSD para determinar a relação entre as configurações de domínios e as orientações cristalográficas dos grãos.

No caso dos objetos microestructurados obtido pela litografia e pelo feixe de eletrons, as

análises se centram nas configurações magnéticas possível das diferentes geometrias. Para isto o MFM e AFM resultaram serem técnicas complementares junto com o VSM para a discussão. O MFM dá um mapa dos campos magnéticos espalhados fora da amostra (stray-field), os quais 
estão associados na maioria das vezes a paredes de domínios. O modo como estas paredes se dispõem, junto com o tipo de parede e sua dependência com as dimensões são estudadas por meio de simulações.

Como um dos resultados deste trabalho, foi analisado o comportamento magnético na micro escala do $\mathrm{Co}$ e $\mathrm{CoFeSiB}$, cujas configurações magnéticas de remanência foram interpretadas em base às simulações.

O presente trabalho está ordenado nos seguintes capítulos:

Capitulo 2: Fundamentos teóricos. Neste se explica a física envolvida na formação dos objetos e nas configurações magnéticas, os tipos de energia magnética envolvidas, vistas nos filmes e objetos junto com os tipos de parede que se podem formar. Também se discute a teoria do efeito Kerr magneto-ótico e detalhes instrumentais do equipamento do microscópio ótico.

Capitulo 3 :Técnicas experimentais. Aqui se aborda as técnicas usadas para a caracterização magnética e morfológica, como é o MFM, VSM, AFM. Também se menciona as características do programa de simulação de objetos magnéticos Mumax3.

Capitulo 4: Resultados experimentais e análises dos dados. Mostram-se os resultados, as análises das medidas das diferentes técnicas dando ênfase ao MFM e sua relação com as simulações computorizadas.

Capitulo 5: Conclusões.

Assim os resultados experimentais, junto com as simulações das estruturas magnéticas podem servir de base a estudos posteriores com outros tipos de material magnético. 


\section{Capítulo 2: Fundamentos teóricos}

Nesta secção é descrita a teoria envolvida na produção e formação de filmes finos e objetos de matérias magnéticos. Posteriormente se menciona a teoria do fenômeno de efeito Kerr magneto-ótico envolvida nas técnicas de obtenção de informação magnética. Para poder interpretar os resultados das medidas se estuda a teorias das energias envolvidas na formação de estruturas de domínios assim também a presencia de tipos de paredes de Néel e Cross-tie.

\subsection{Magnetismo em filmes e objetos microscópicos}

$\mathrm{Na}$ atualidade os materiais magnéticos nano e microestruturados tem grande importância tanto no campo de pesquisa como em suas diversas aplicações tecnologias, encontrando se em: sensores, transdutores, memórias de armazenamento, etc [3][4]. O estudo destes sistemas melhora a compreensão dos estados magnéticos e do processo dinâmico da evolução das estruturas de domínios nos materiais, assim como também, estabelece uma base a partir da qual se pode aperfeiçoar suas propriedades, para funções que encontrará lugar em aplicações no campo da eletrônica, microeletrônica, etc.

O interesse no estudo dos elementos microestruturados e filmes finos se deve a seus comportamentos peculiares. No caso dos elementos magnéticos microestruturados (objetos) um dos interesses é poder reproduzir estados magnéticos, ou induzir estados metaestáveis. Estes objetos apresentam uma relevante anisotropia de forma e podem adotar uma variedade de configurações de domínios que depende muito da sua geometria, espessura e propriedades magnéticas. Quanto aos estados metaestáveis desejados, para poder se conseguir precisam da aplicação de um campo magnético $(\mathrm{H})$ adequado, tanto em intensidade como em direção, além de uma geometria específica para o objeto.

Os materiais ferromagnéticos são um campo de estudo ativo devido as suas configurações magnéticas que se podem formar e suas aplicações tecnológicas. Portanto, se selecionou o material de $\mathrm{Co}$ e $\mathrm{CoFeSiB}$ para este estudo. Neste trabalho se dará uma revisão sobre questões gerais dos ferromagnéticos e se fundamentará o objetivo do presente trabalho.

\subsection{Filmes fino magnéticos e sua formação}

Um filme fino está conformado por uma camada ou múltiplas camadas dos materiais de interesse. Podendo, cada camada, ser uma liga ou só um elemento magnético; nestas geometrias

a espessura fica na ordem de dezenas ou centenas de nanômetros. Este material é crescido sobre um suporte, o substrato. O material usado pode ser de elemento puro como o Fe, Ni e Co, ou de 
ligas como permalloy, aço, etc. Para poder proteger o filme ante a oxidação, em muitos casos a amostra é revestida com uma camada fina.

O substrato, tipicamente tem uma espessura na escala de centenas de micrometros. Ao lado de ter a função de servir como suporte do filme, também pode induzir um crescimento epitaxial e determinar a textura do filme dependendo do tipo de substrato usado e do modo como os átomos se depositam. Os mais comuns são o substrato de $\mathrm{Si}$, $\mathrm{Si}$ com camada de $\mathrm{SiO}_{2}$ (amorfo) e o substrato de vidro. Já para a proteção do filme é comum o revestimento com uma fina camada de material transparente, como é o $\mathrm{Si}_{3} \mathrm{~N}_{4}$.

Existem diferentes técnicas para se produzir filmes finos, cada uma possui suas características e limitações na hora de controlar e reproduzir parâmetros tais como a espessura, a microestrutura e a concentração dos materiais. A produção de materiais magnéticos em filmes finos é feito por meio de técnicas como: evaporação física em fase de vapor, evaporação química, sputtering, eletrolítica, por feixe de íons, etc [5-8]. Os filmes finos que crescem sobre substratos terão propriedades estruturais que dependeram do processo de nucleação e crescimento, e estas características estruturais terá efeitos sobre as propriedades magnéticas.

A técnica usada para a preparação de filmes neste estudo foi a técnica de magnetron sputtering, os detalhes da técnica se verá no capitulo 3. No processo da deposição, os átomos dos materiais de interesse ao atingir o substrato formam núcleos dispersos que irão aglomerando e crescendo. Deste modo a morfologia e a microestrutura do filme dependerão da rapidez com que chegam as partículas e de como os núcleos vão formando os aglomerados. Conforme o material é depositado, formam se ilhas que vão se juntando até chegar a recobrir o substrato e formar o filme contínuo.

Pode se apresentar inconvenientes na formação e no resultado dos filmes, este pode ser produzido por impurezas presentes na câmara ou no alvo usado; deste modo, produzindo efeitos locais de deformação na estrutura. A energia cinética dos átomos e o ângulo com que chegam ao substrato também afetarão as características estruturais do filme [9].

As primeiras camadas de crescimento sofrem influência da rede cristalina do substrato, já para filmes de maior espessura e dependendo do processo, o material crescerá formando um cristal ou policristal. No caso do Co forma se um material policristalino com estrutura hexagonal e com empacotamento compacto. Na deposição de ligas e elementos puros, há a tendência de formação de policristais, cujo tamanho de grão dependera da taxa de deposição, da rugosidade do substrato e da temperatura usada [10].

Após a deposição, o material ficará sujeito a tensões residuais aleatórias, que perturbam as propriedades magnéticas como a distribuição de orientações da magnetização. Como as propriedades estruturais e magnéticas dependem do processo de deposição e dos parâmetros de controle da deposição, o bom controle destes parâmetros assegura que o filme não apresente fortes tensões, nem crescimento colunar não desejado. As tensões formadas podem ser 
originadas pela diferencia entre o parâmetro de rede do substrato e do filme e as tensões intrínsecas que proviessem do bombardeio iônico do processo de sputtering. Um parâmetro importante de controle é a pressão, este, além de aportar energia aos íons do gás, também atua como moderador dos átomos ejetados do alvo. Para baixas pressões os átomos neutros pulverizados chegam com maior energia térmica, tendo grande mobilidade no substrato; enquanto que em alta pressão os átomos ejetados são amortecidos pelo gás do plasma, em consequência terão menor mobilidade ao chegar ao substrato. A cinética de crescimento dos grãos e do filme dependerá da pressão e se verá refletida na microestrutura. As tensões residuais e a estrutura do filme estão ligadas à energia das partículas que chegam ao substrato. Por outro lado, tensões presentes nos filmes podem ser relaxadas depois por meio de tratamento térmico a alta temperatura. Também é possível induzir anisotropia uniaxial com ajuda de um campo magnético aplicado durante o tratamento térmico do filme.

As variáveis que afetam a microestrutura do filme fino são: a separação entre o alvo e o substrato, diretamente relacionado com energia com a qual os átomos chegam ao substrato; a potência de pulverização aumenta a energia cinética das partículas e sua mobilidade no substrato; a temperatura do substrato influencia na mobilidade dos átomos na superfície do substrato; e o tipo de substrato usado, através de sua dilatação térmica, textura e imperfeições.

\subsection{Efeito Kerr magneto-ótico}

Técnicas baseadas no efeito Kerr magneto-ótico são capazes de oferecer informação das propriedades magnéticas na superfície de objetos ferromagnéticos, sendo em forma de mapas de magnetização na microscopia, ou para medir curvas de histereses, através da magnetometria. Este fenômeno está baseado na mudança de intensidade e polarização que sofre o feixe de luz incidente quando é refletido na superfície metálica da amostra magnética de interesse.

A técnica tem a vantagem de ser não invasiva. Diferentemente de outras técnicas, como o MFM e a microscopia Lorentz, as imagens Kerr obtidas resultam ser de fácil interpretação sobre a magnetização na superfície e o padrão de domínios magnéticos. Técnicas de microscopia MOKE são amplamente usadas no estudo de filmes finos e sua limitação está dada pela resolução permitida pelos sistemas óticos convencionais.

Na sequência, faremos uma descrição fenomenológica do efeito Kerr com base na teoria clássica do eletromagnetismo. O parâmetro que descreve a resposta do material ante o campo eletromagnético da luz é a permissividade elétrica $\varepsilon$, que no caso de meios não isotrópicos é dado pelo tensor $\varepsilon$.

Dependendo da componente de magnetização que se deseja ver, o sistema é configurado. Assim se tem o efeito Kerr polar, que permite ver a componente de magnetização 
normal ao plano da amostra e paralelo ao plano de incidência; o efeito Kerr longitudinal, para ver a componente paralela à superfície da amostra e ao plano de incidência, e o efeito Kerr transversal, para ver a componente paralela à superfície da amostra e perpendicular ao plano de incidência [11][12].
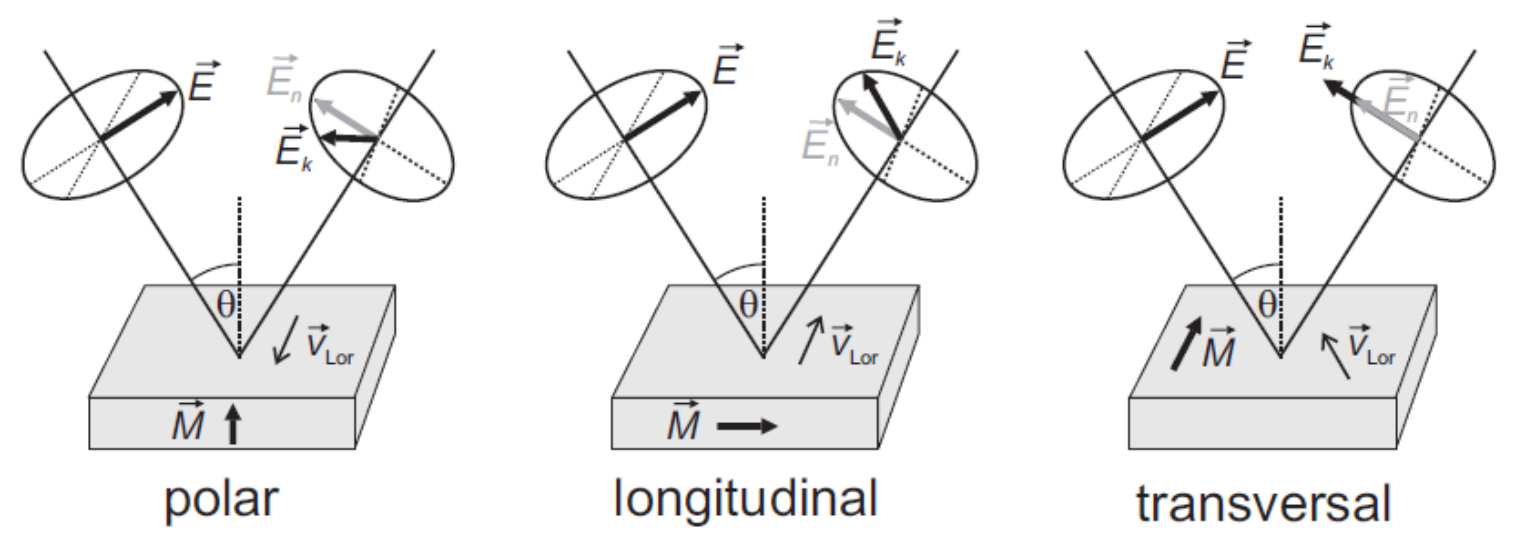

\section{Figura 2-1: Tipos de efeito Kerr magneto-óticos [13]}

O campo elétrico de uma onda incidente é descrito por:

$$
\vec{E}=E_{o s} \vec{s}+E_{o p} \vec{p}
$$

Onde s e p são as direções perpendiculares e paralelas ao plano de incidência da luz e perpendiculares a direção de propagação do campo.

A relação entre a onda incidente e a onda refletida é dada pela matriz R (matriz de Fresnel) [14].

$$
\begin{gathered}
\left(\begin{array}{c}
E_{p} \\
E_{s}
\end{array}\right)^{r}=R\left(\begin{array}{c}
E_{p} \\
E_{s}
\end{array}\right)^{i} \\
R=\left(\begin{array}{ll}
r_{p p} & r_{p s} \\
r_{s p} & r_{s S}
\end{array}\right)
\end{gathered}
$$

Onde o superíndice $\mathrm{r}$ se refere a onda refletida e i à onda incidente. Os elementos da matriz de reflexão $R$ são definidos entre as razoes das amplitudes das componentes do campo elétrico:

$$
r_{p p}=\left(\frac{E_{p}^{r}}{E_{p}^{i}}\right) ; r_{p s}=\left(\frac{E_{p}^{r}}{E_{s}^{i}}\right) ; r_{s p}=\left(\frac{E_{s}^{r}}{E_{p}^{i}}\right) ; r_{s s}=\left(\frac{E_{s}^{r}}{E_{s}^{i}}\right)
$$

Fazendo uso da teoria do eletromagnetismo como é seguida em [14], A equação da onda plana fica: 


$$
n^{2} E_{j}+\sum_{i} \varepsilon_{j i} E_{i}=0
$$

Onde $i, j=(x, y, z)$, n é o índice de refração do meio e $E_{i}$ é a componente do campo na direção i. Esta expressão dá a relação entre os elementos do tensor $\varepsilon$ e os índices de reflexão.

O tensor de permissividade pode ser expresso como [9][14]:

$$
\varepsilon=\varepsilon_{0}\left[\begin{array}{ccc}
1 & -i Q m_{z} & i Q m_{y} \\
i Q m_{z} & 1 & -i Q m_{x} \\
-i Q m_{y} & i Q m_{x} & 1
\end{array}\right]
$$

Onde $Q$ é a constante complexa magneto-ótica do material.

Assim tendo definido os elementos do tensor de permissividade se pode resolver a equação de onda para determinar os coeficientes da matriz de Fresnel. Considerando, respectivamente para o ar e o material magnético, $n_{1}$ e $n_{2}$ os índices de refração dos meios e $\theta_{1}$ e $\theta_{2}$, se obtém os elementos da matriz de reflexão $(\mathrm{R})$.

Os elementos da matriz de reflexão R são:

$$
\begin{gathered}
r_{p p}=\frac{n_{2} \cos \theta_{1}-n_{1} \cos \theta_{2}}{n_{2} \cos \theta_{1}+n_{1} \cos \theta_{2}}+\frac{2 i n_{1} n_{2} \cos \theta_{1} \operatorname{sen} \theta_{2} M_{x} Q}{\left(n_{2} \cos \theta_{1}+n_{1} \cos \theta_{2}\right)^{2}} \\
r_{s s}=\frac{n_{1} \cos \theta_{1}-n_{2} \cos \theta_{2}}{n_{1} \cos \theta_{1}+n_{2} \cos \theta_{2}} \\
r_{p s}=-\frac{i n_{1} n_{2} \cos \theta_{1}\left(M_{y} \operatorname{sen} \theta_{2}+M_{z} \cos \theta_{2}\right) Q}{\cos \theta_{2}\left(n_{2} \cos \theta_{1}+n_{1} \cos \theta_{2}\right)\left(n_{1} \cos \theta_{1}+n_{2} \cos \theta_{2}\right)} \\
r_{s p}=\frac{i n_{1} n_{2} \cos \theta_{1}\left(M_{y} \operatorname{sen} \theta_{2}-M_{z} \cos \theta_{2}\right) Q}{\cos \theta_{2}\left(n_{2} \cos \theta_{1}+n_{1} \cos \theta_{2}\right)\left(n_{1} \cos \theta_{1}+n_{2} \cos \theta_{2}\right)}
\end{gathered}
$$

Onde se vê que $r_{p p}$ é função só da componente da magnetização na direção transversal $\left(M_{x}\right), r_{p s}$ e $r_{s p}$ são funções das componentes polar $\left(M_{z}\right)$ e longitudinal $\left(M_{y}\right)$ da magnetização e $r_{s S}$ é um elemento que não depende da magnetização. 
Neste trabalho o equipamento usado, opera com efeito Kerr longitudinal, assim as expressões de $R$ e $\left(\begin{array}{c}E_{p} \\ E_{S}\end{array}\right)^{r}$ para o efeito Kerr longitudinal se reduz a:

$$
\begin{aligned}
& R=\left(\begin{array}{ll}
r_{p p} & r_{p s} \\
r_{s p} & r_{s s}
\end{array}\right) \\
&\left(\begin{array}{c}
E_{p} \\
E_{s}
\end{array}\right)^{r}=\left(\begin{array}{ll}
r_{p p} & r_{p s} \\
r_{s p} & r_{s s}
\end{array}\right)\left(\begin{array}{c}
E_{p} \\
E_{s}
\end{array}\right)^{i}
\end{aligned}
$$

Reescrever as duas expressões abaixo:

$$
\begin{aligned}
& \left(E_{p}\right)^{r}=r_{p p}\left(E_{p}\right)^{i}+r_{p s}\left(E_{s}\right)^{i} \\
& \left(E_{s}\right)^{r}=r_{s p}\left(E_{p}\right)^{i}+r_{s s}\left(E_{s}\right)^{i}
\end{aligned}
$$

Onde os termos da matriz R passam a ser:

$$
\begin{gathered}
r_{p p}=\frac{n_{2} \cos \theta_{1}-n_{1} \cos \theta_{2}}{n_{2} \cos \theta_{1}+n_{1} \cos \theta_{2}} \\
r_{s s}=\frac{n_{1} \cos \theta_{1}-n_{2} \cos \theta_{2}}{n_{1} \cos \theta_{1}+n_{2} \cos \theta_{2}} \\
r_{p s}=-\frac{i n_{1} n_{2} \cos \theta_{1}\left(M_{y} \operatorname{sen} \theta_{2}\right) Q}{\cos \theta_{2}\left(n_{2} \cos \theta_{1}+n_{1} \cos \theta_{2}\right)\left(n_{1} \cos \theta_{1}+n_{2} \cos \theta_{2}\right)} \\
r_{s p}=\frac{i n_{1} n_{2} \cos \theta_{1}\left(M_{y}\right) Q}{\cos \theta_{2}\left(n_{2} \cos \theta_{1}+n_{1} \cos \theta_{2}\right)\left(n_{1} \cos \theta_{1}+n_{2} \cos \theta_{2}\right)}
\end{gathered}
$$

Os termos $r_{p p}$ e $r_{s s}$ contribuem com a reflexão metálica da luz, enquanto que os termos $r_{p s}$ e $r_{s p}$ são responsáveis de uma ligeira rotação do vetor de campo elétrico quando este é refletido.

\subsection{Energias envolvidas nos processos magnéticos}

A configuração da estrutura magnética, disposição dos domínios, que adquire um objeto é resultado do balanço entre todas as contribuições de energias. A energia total do sistema resulta ser a soma principalmente das energias de troca, magnetostática, de Zemman e de anisotropia; que tem a contribuição da anisotropia magnetocristalina, de forma e magnetoelástica. 


\subsubsection{Energia de Troca}

Para um material ferromagnético (FM) os spins tendem a alinhar seus momentos magnéticos paralelamente para diminuir a energia, isto se deve a um efeito quântico chamado de interação de troca, cuja origem se dá pelo acoplamento de spin dos elétrons desemparelhados no orbital d dos metais de transição [15]. A energia será mínima para o caso onde os momentos sejam paralelos. Esta energia de troca está definida por [15]:

$$
w=-2 \sum A_{i j} \overrightarrow{s_{l}} \cdot \overrightarrow{s_{J}}
$$

Onde $A$ é a constante de troca, sendo $(A>0)$ para o caso de materiais ferromagnéticos. No caso de $(A<0)$ se terá um material antiferromagnético, este tende a ter os spins alinhados antiparalelamente para diminuir sua energia. Finalmente $s_{i}$ e $s_{j}$ se refere aos spins dos átomos na posição i e j, localizados em sítios adjacentes. A soma da equação (1.16) pode ser restringida aos primeiros vizinhos, já que a interação troca é de curto alcance.

\subsubsection{Energia de anisotropia}

A propriedade do material de apresentar uma ou mais direções privilegiadas por ter menor custo de energia para se magnetizar, se chama anisotropia magnética. Um corpo pode estar submetido a vários tipos de anisotropia magnética como são: a anisotropia cristalina, de forma, de superfície e de tensão mecânica.

Energia de anisotropia magnetocristalina

Existem direções de fácil magnetização nos cristais; quando a magnetização se desvia desta direção, chamadas de eixos fácies, isto faz incrementar sua energia. Em ausência de campo externo, a magnetização tende se orientar em um eixo fácil. A origem desta energia está na interação spin orbita [16][17], e é própria do material. Para o caso de um material com estrutura cúbica, a energia de anisotropia é dada por:

$$
W_{a}=K_{o}+K_{1}\left(\alpha_{1}^{2} \alpha_{2}^{2}+\alpha_{2}^{2} \alpha_{3}^{2}+\alpha_{1}^{2} \alpha_{3}^{2}\right)+K_{2} \alpha_{1}^{2} \alpha_{2}^{2} \alpha_{3}^{2}
$$

Onde $\alpha_{1}, \alpha_{2}, \alpha_{3}$ são os cossenos diretores da magnetização com respeito ao eixo fácies, e $K_{o}, K_{1}, K_{2}$ são as constantes de anisotropia de primeira e segunda ordem. Por exemplo, no caso do ferro com estrutura cristalina fcc os eixos de fácil magnetização são (100) e (111) é o eixo de difícil magnetização. Os termos de anisotropia de maior ordem podem ser desprezados, o valor das constantes mostra a dificuldade para desviar a direção de magnetização dos eixos fácies. 
Para um material com estrutura cristalina hexagonal a anisotropia magnética é uniaxial, só possui um eixo de fácil magnetização. O eixo perpendicular ao plano (0001).

A energia magnética de anisotropia uniaxial é dada por:

$$
W_{u}=K_{u 1} \operatorname{sen}^{2}(\theta)+K_{u 2} \operatorname{sen}^{4}(\theta)
$$

$K_{u}$ é a constante de anisotropia uniaxial, e $\theta$ é o ângulo formado entre o eixo fácil e a direção de magnetização, se o ângulo é pequeno só se considera o primeiro termo. Dependendo se $\mathrm{k}>0$ ou k<0 a magnetização em ausência de campo aplicado se orienta paralelamente ao eixo fácil ou perpendicular ao eixo respectivamente. $\mathrm{O}$ cobalto tem estrutura cristalina hexagonal com componentes de anisotropia uniaxial $K_{u 1}=4.1 * 10^{6} \mathrm{erg} / \mathrm{cm}^{3}$ e $K_{u 2}=1.0 * 10^{6} \mathrm{erg} / \mathrm{cm}^{3}$ [16][18].

Os materiais amorfos podem ter energia uniaxial. A anisotropia uniaxial, também pode se induzida por meio de tensão mecânica em uma direção na superfície do filme.

\subsubsection{Energia de Zeeman ou magnetostática}

Quando um campo $\mathrm{H}$ é aplicado a um corpo ferromagnético, este altera sua configuração de domínios fazendo crescer domínios alinhados com o campo externo a expensas dos não alinhados. A energia de interação é dada por:

$$
W_{Z}=-\mu_{o} \vec{M} \cdot \vec{H}
$$

\subsubsection{Energia de desmagnetização}

A energia de desmagnetização está associada à geometria da amostra. Quando um campo é aplicado sobre a amostra, neste se gera polos nos extremos do material, então o próprio material gera um campo em direção oposta ao campo aplicado $(H)$. O campo de desmagnetização $H_{d}$ interno, diminuindo o efeito do $\mathrm{H}$ aplicado. Este campo pode ser visto como o campo criado por uma densidade de cargas magnéticas livres nos extremos da amostra.

O campo de desmagnetização é dado por:

$$
H_{d}=-N M
$$

Onde $\mathrm{N}$ é em geral um tensor, termo de desmagnetização, que depende da geometria do material. No caso de um material isotrópico $\mathrm{N}$ é uma constante que dependerá da razão entre as dimensões geometrias do corpo e M é a saturação da magnetização.

A energia do sistema devido ao campo de desmagnetização é dada por: 


$$
W_{d}=-\frac{1}{2} \mu_{o} H_{d} \cdot M
$$

Esta energia tem sua origem na interação coulombiana dos polos. $W_{d}$ é a energia magnetostática ou de forma e o $H_{d}$ depende da geometria do material. $\mathrm{O}$ sistema tende a minimizar sua energia, diminuindo o número total de polos livres, formando domínios de fechamento.

\subsubsection{Energia magnetoelástica}

As tensões intrínsecas ou externas sobre o material afetam as propriedades magnéticas, em alguns casos pode induzir anisotropias. A magnetostricção é o efeito que liga a magnetização e a tensão mecânica. Neste fenômeno apresenta-se mudança sobre as propriedades magnéticas, como na orientação da magnetização do material, quando este é submetido a tensões externas ou internas e o recíproco; quando devido à ação de um campo magnético o material sofre deformações. A energia ligada a este fenômeno é a energia magnetoelástica. Se sob um corpo se altera seu comprimento, devido à ação de um campo magnético, a razão entre a variação do comprimento e seu comprimento inicial é o parâmetro $\lambda$ que caracteriza a magnetostricção:

$$
\lambda=\frac{\Delta l}{l}=\frac{l-l_{0}}{l}
$$

Onde $l$ é o comprimento do corpo que se deforma, e $l_{0}$ é o comprimento antes de se deformar. $O$ valor de $\lambda$ pode ser na ordem $10^{-6}-10^{-5}$ [17][19]. Se o material atinge a saturação magnética a medida de $\lambda$ passa a ser a magnetostricção de saturação $\lambda_{s}$. Dependendo do material o $\lambda$ pode ser positivo ou negativo. Para materiais cristalinos o valor de $\lambda_{s}$ dependerá da orientação cristalográfica. No caso materiais policristalinos a magnetostricção efetiva é calculada como uma média entre os efeitos magnetostrictivos das possíveis orientações preferenciais dos grãos, cada um com sua orientação cristalográfica. Assim se as orientações dos grãos são completamente aleatórias, a magnetostricção toma uma média sobre todas as direções [17][19].

No caso mais simples de um material com magnetostricção isotrópica a energia associada às tensões é definida como [16][17] [19] [20]:

$$
E=\frac{3}{2} \lambda \sigma \sin ^{2}(\theta)
$$

Onde $\theta$ é o ângulo entre o $M_{s}$ e o estress $\sigma$. 


\subsubsection{Anisotropia efetiva}

Nos filmes finos os átomos que se localizam na superfície representam uma grande porcentagem dos átomos totais do material, sendo maior a porcentagem quando a espessura diminui. Estes átomos pelo fato de estar na superfície sentem forças de ligação diferentes dos átomos no interior do volume. Então o jeito como estes átomos e o filme reagem, sob um campo magnético aplicado é diferente do caso bulk. Este, é um efeito de anisotropia de superfície e depende da espessura.

Nos filmes finos existe contribuição por parte do volume e da superfície, sendo a energia de anisotropia total.

$$
E=\left(K_{V}+\frac{1}{t} K_{s}\right) \sin ^{2}(\theta)=K^{\prime} \sin ^{2}(\theta)
$$

Onde $t$ é a espessura do filme, $K_{V}$ é a constante de anisotropia de volume, $K_{S}$ é a constante de anisotropia de superfície e $K^{\prime}$ é uma anisotropia efetiva. Dependendo do valor de $K^{\prime}$ se terá uma anisotropia perpendicular à superfície do filme se $K^{\prime}>0$ ou paralela no caso de $K^{\prime}<0$.

\subsection{Estruturas de domínios magnéticos}

Os materiais ferromagnéticos são constituídos por muitas regiões, cada região apresenta uma direção determinada. Estas regiões são chamadas domínios magnéticos. Para poder alinhar estes domínios em uma mesma direção e ter um efeito global se precisa da aplicação de um campo magnético que os oriente. A variedade de estruturas de domínios presentes na superfície pode ser explicada tendo em consideração o balanço das energias envolvidas; deste modo, o sistema adquire a configuração de menor energia balanceando todas as possíveis energias. As energias com principal contribuição são a energia de anisotropia magnetocristalina e a energia magnetostática, que leva em conta também a influência dos domínios vizinhos. As regiões que separam os domínios entre si são chamadas de paredes de domínio magnético 


\subsection{Teoria das paredes de domínio.}

\subsubsection{Parede de tipo Bloch e Néel}

Nos objetos magnéticos de filmes finos de dimensões pequenas na escala nanométrica ou micrométrica se forma configurações magnéticas no estado de remanência. Estas configurações dependem da geometria, das propriedades intrínsecas do material, da espessura e da história de como foram magnetizadas.

A estrutura de domínios no objeto adquire a configuração de domínios de menor energia na ausência de campo aplicado, que é o estado de remanência. Aqueles domínios estão separados entre si e limitados por regiões estreitas, chamadas paredes de domínio, de comprimento muito pequeno (na ordem de centenas $\mathrm{nm}$ ), dentro desta região a magnetização muda gradualmente de direção através das camadas de átomos indo da direção de magnetização de um domínio até a do domínio vizinho. A espessura da parede de domínio depende principalmente da competição entre a energia de troca e a energia de anisotropia magnetocristalina. Podem-se classificar as paredes seja pelo ângulo formado entre domínios ou pelo modo como muda a magnetização, assim se tem parede de $90^{\circ}$, quando as magnetizações de um domínio e seu vizinho são transversais entre si e como parede de $180^{\circ}$ quando os domínios tem magnetização anti-paralela. No caso das paredes de $180^{\circ}$, dependendo de como a magnetização muda de um domínio para o outro temos dois tipos principais de paredes:

- Parede de Bloch: Nesta, a transição da direção dos momentos magnéticos se dá girando gradualmente a direção da magnetização e passando pela direção perpendicular ao plano definido pelos domínios.

- Parede de Néel: Nesta, a transição do momento magnético se dá girando gradualmente a direção da magnetização, paralelamente ao plano definido pelos domínios.

(a)

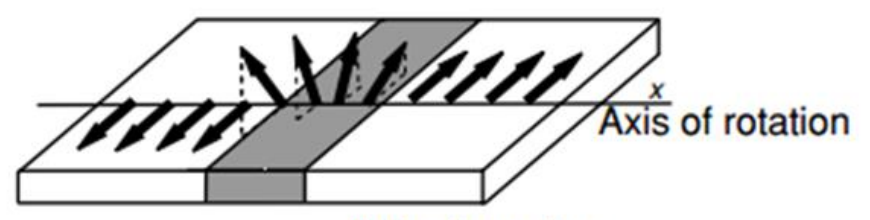

(b)

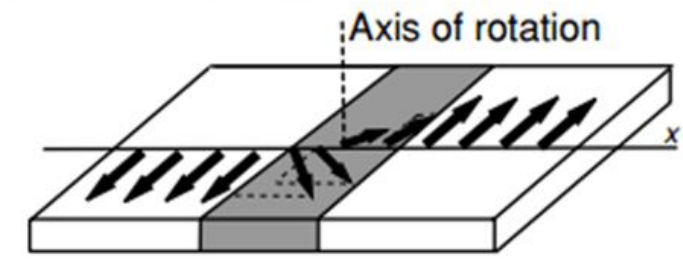

Figura 2-2: a) Parede de domino tipo Bloch e b) Parede de domínio tipo Néel.[21] 
A parede de Néel está presente em filmes de baixa espessura, onde a energia magnetostática devido ao campo desmagnetizante (stray-field) seria maior que a energia de anisotropia e de troca. Este tipo de parede está presente em filmes muito finos, dando-se a transição entre os tipos de parede para uma espessura crítica [22-23]. Tal espessura critica se encontra na ordem de menos de $100 \mathrm{~nm}$.

\subsubsection{Parede do tipo cross-tie}

A parede de domínio de cross-tie é outro tipo de parede presente comumente em filmes finos e foi observado em muitos experimentos com alta resolução [22-23]. Sabe-se que para filmes ultrafinos as paredes passam a ser de tipo Néel, assim a presença de uma parede de crosstie depende principalmente da espessura do filme. A forma como os vetores de magnetização se distribuem nesta parede resulta ser mais complexa que no caso Néel e Bloch, já que se dá em 2 dimensões. Resultados analíticos encontrados na referência [24-25] conseguem descrever a distribuição de magnetização neste tipo de parede.

Na Figura 2-3, apresenta-se o diagrama da distribuição teórica dos vetores de micromagnetização no tipo cross-tie e um esquema da distribuição de carga magnética. Descrevem-se as características deste tipo de parede, onde se tem a parede principal (linha vertical $\mathrm{NM}$ ) e a linhas de Bloch de cross-tie $\mathrm{AB}$ e $\mathrm{CD}$ que são linhas transversais à parede principal. $\mathrm{O}$ modelo mostra que a magnetização muda de direção mais rapidamente perto da linha de Bloch (segmento $\mathrm{AB}$ ) formando o cross-tie no cruzamento com a parede principal. Podemos ver também que o espaço entre linhas de Bloch adjacentes está dividido pela localização de um vórtice no meio. No diagrama a parede principal está subdividida por uma série de linhas de Bloch, sendo estas linhas (BLs) localmente periódicas. Assim, ao longo da parede se tem uma sequência alternada de vórtices circulares e linhas cruzadas.

A parede de cross-tie resulta ter uma menor energia que a parede de Néel a partir de certa espessura do filme, chamada de espessura crítica. Por exemplo, foi encontrado em [26] que o filme de $\mathrm{Co}_{91} \mathrm{Nb}_{6} \mathrm{Zr}_{3}$ tem como valor de espessura crítica $50 \mathrm{~nm}$ e as paredes de cross-tie estão presentes no range de 32.5 a $50 \mathrm{~nm}$. Estruturas de cross-tie estão presentes também em filmes de $30 \mathrm{~nm}$ de cristal de ferro e em $50 \mathrm{~nm}$ de filme de Co. 


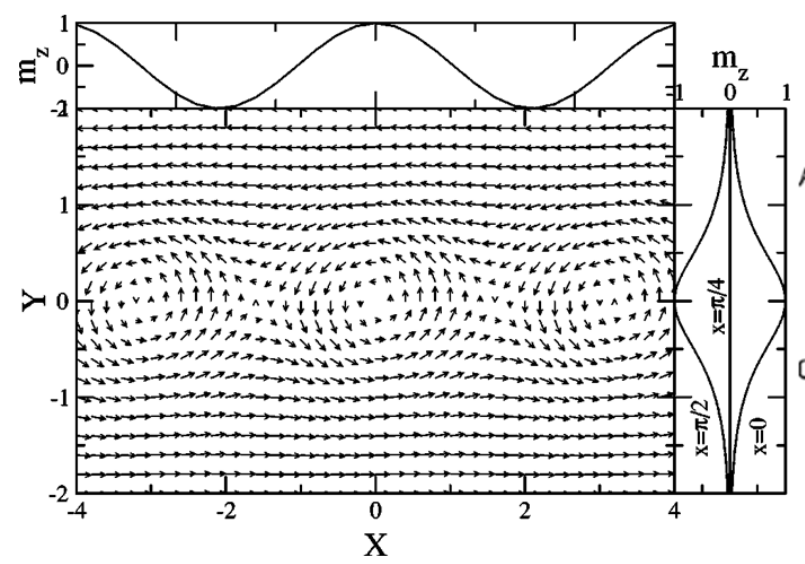

a)

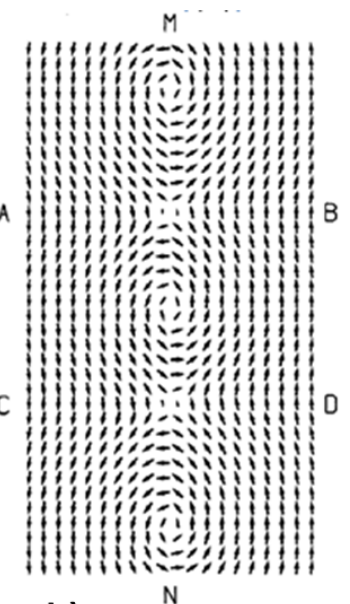

b)

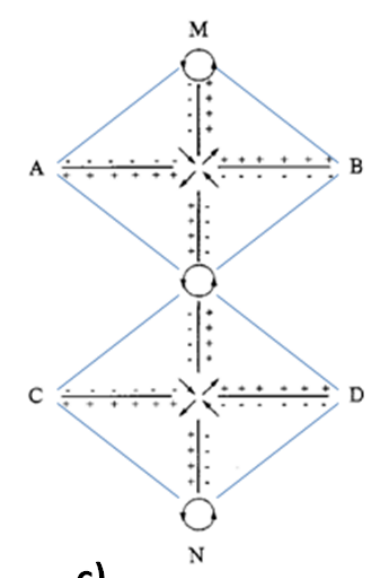

c)

Figura 2-3: (a) Distribuição do vetor de magnetização na superfície de uma parede de cross-tie [24], (b) imagem representativa da distribuição de vetores de magnetização em uma parede de cross-tie [22], (c) imagem da distribuição de carga magnética em uma parede do tipo cross-tie [22].

\subsubsection{Energia de parede e transições entre tipos de parede}

Os estudos e cálculos da densidade de energia envolvida na formação de paredes de domínio em filmes finos e sua dependência com respeito à espessura do filme fornece informação de quando se poderá dar uma transição de tipo de parede de domínio magnético. Sabe-se que os filmes grossos de espessura maiores a $150 \mathrm{~nm}$ ou $200 \mathrm{~nm}$, assim como as amostras bulk tende a formar paredes de Bloch por ser mais estável. Nestas paredes de Bloch o valor da energia e a espessura da parede é resultado do balanço entre a energia de troca e anisotropia. A contribuição da energia magnetostática devido ao stray-field resulta ser desprezível, já que nestas estruturas os polos magnéticos são diminuídos devido a formação de domínios de fechamento. Então a espessura do filme fino é um parâmetro importante que influi sobre a estrutura micromagnética, e também nas transições de tipo de paredes, quer seja de Néel a cross-tie ou de Bloch a Néel [24].

No caso da parede de Néel como os polos se encontram separados de uma distância comparável à espessura da amostra, esta possui um elevado stray-field e a contribuição da energia magnetostática passa a ser significativa na formação da parede, sendo maior que a anisotropia de troca e a magnetocristalina.

A transição de parede Néel para cross-tie se dá porque a energia da parede de cross-tie possui menor energia total que para uma parede de Néel, e estas transições acontecem quando se diminui a espessura do filme. Como foi visto anteriormente, a parede de cross-tie tem uma 
complexa estrutura com alternância entre vórtices e cross-tie, o que dá uma distribuição de energia não uniforme como visto na figura 2-4 [23] ao longo da parede.

Nos cálculos de minimização da energia para obter a configuração de magnetização mais estável, ou metaestável, se considera a contribuição da energia de troca e a energia magnetostática. Dos resultados disto se infere o diagrama de transição de tipo de paredes como foi relatado em [23-24] para o caso de materiais magnéticos moles como o permalloy. Descrevendo a dependência da transição do tipo de parede com a espessura e o tamanho transversal de um objeto retangular. A transição dependerá em menor medida também das propriedades magnéticas da amostra: magnetização de saturação $\mathrm{M}_{\mathrm{s}}$, constante de troca $\mathrm{A}$, constante de anisotropia K. Para saber o efeito de K, na referência [22] se incluiu uma baixa anisotropia no sistema, acrescentando-se o termo de energia de anisotropia uniaxial à energia do sistema. O resultado disto não gerou mudança no diagrama de transição de parede e não mostrou influência sobre outros parâmetros como a espessura crítica de transição. Por outro lado, foi relatado em [23] uma influência da constante de anisotropia uniaxial sobre a periodicidade da parede de cross-tie em filmes magnéticos moles.

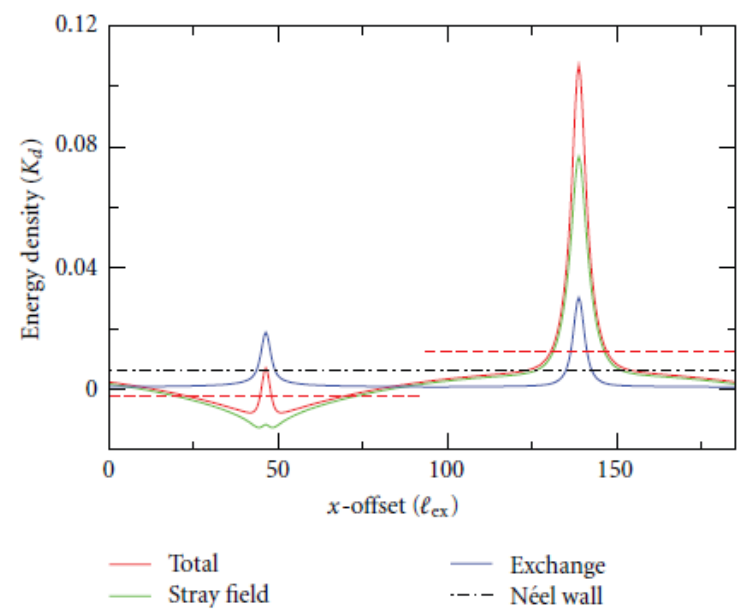

Figura 2-4: Seção transversal para todas as densidades de energia como uma função da posição ao longo de uma parede simulada do tipo cross-tie [23].

\subsubsection{Espessura da parede de domínio}

Descreveremos a determinação da espessura e da energia de uma parede de domínio de tipo Bloch, considerando um modelo de uma dimensão.

A parede de domínio pode se ver como uma sequência de $\mathrm{N}$ momentos magnéticos mudando de direção gradualmente. $\mathrm{O}$ ângulo entre vizinhos próximos é $\Delta \varphi_{i}$, cujo o valor é em média de $180^{\circ} / \mathrm{N}$. 
Os resultados de [17][27] calculam a energia e a espessura de uma parede de Bloch. A espessura da parede de domínio é determinada pelo equilíbrio entre as energias de troca e a energia de anisotropia principalmente. A energia de troca em um material ferromagnético tende a alinhar os domínios magnéticos, isto faz que a mudança do ângulo $\varphi_{i}$ indo de átomo em átomo seja pequeno e a largura da parede seja extensa. Por outro lado, a energia de anisotropia procura alinhar os momentos com as direções de anisotropia, fazendo que a espessura da parede seja a menor possível. O balanço entre estas energias fixa a largura da parede. Na sequência, se descreve um caso idealizado do cálculo para a espessura e energia da parede.

A energia de troca para um par de átomos do mesmo spin é definida por:

$$
\varepsilon_{\text {troca }}=-2 j s^{2} \cos \left(\Delta \varphi_{i}\right)
$$

Onde $\Delta \varphi_{i}$ é o ângulo entre as direções da magnetização adjacentes. Passando ao caso continuo, o $\varphi$ indica a direção da magnetização e o $\Delta \varphi_{i}=\left(\frac{\mathrm{d} \varphi}{\mathrm{dx}}\right) * \mathrm{a}$, assim a energia passa a ser definida como na equação (2.26) [17]. Nesta $\varphi(x)$ muda ao longo da espessura da parede, valido para o caso onde a espessura da parede seja muito maior que o parâmetro de rede (a), $\frac{\mathrm{d} \varphi}{\mathrm{dx}}$ é a taxa de variação a qual a magnetização rota numa posição da parede, $A=2 n j s^{2} / a$ é a constante de troca e tem unidades de $\mathrm{J} / \mathrm{m}$ ou erg/cm. Assim a energia de troca por unidade de volume é:

$$
E_{\text {troca }}=2\left(A / a^{2}\right) \cos \left(\frac{\mathrm{d} \varphi}{\mathrm{dx}} \mathrm{a}\right)
$$

Como o argumento do cosseno resulta ser muito pequeno $\frac{\mathrm{d} \varphi}{\mathrm{dx}} \mathrm{a}$, se faz a aproximação do cosseno e se anula o termo constante, se toma o primeiro termo de $\left(\frac{\mathrm{d} \varphi}{\mathrm{dx}} \mathrm{a}\right)$. Tem-se a energia de troca por unidade de volume:

$$
\begin{gathered}
E_{\text {troca }}=-\frac{2 A}{a}+\left(\frac{A}{a^{2}}\right)\left(\frac{\mathrm{d} \varphi}{\mathrm{dx}} \mathrm{a}\right)^{2} \\
E_{\text {troca }}=A\left(\frac{\mathrm{d} \varphi}{\mathrm{dx}}\right)^{2}
\end{gathered}
$$

A energia de anisotropia é definida por:

$$
E_{A}=k_{u} \operatorname{sen}^{2}(\varphi)
$$

Onde $k_{u}$ é a anisotropia efetiva; que tem em conta a anisotropia cristalina, magnetostática e magnetoelástica.

A energia total da parede por unidade de área será: 


$$
E=\int_{-\infty}^{+\infty}\left[1 \cdot A\left(\frac{d \varphi}{d x}\right)^{2}+k_{u}(\operatorname{sen}(\varphi))^{2}\right] d x
$$

Cada uma das energias gera um torque, a energia de troca e a de anisotropia geram torques em sentido contrário.

Assim, o torque para a energia de troca é:

$\tau_{t r}=\frac{d E_{\text {troca }}}{d \varphi}=A \frac{\partial(\partial \varphi / \partial x)^{2}}{\partial \varphi}=2 A \frac{d \varphi}{d x} \frac{\partial(\partial \varphi / \partial x)}{\partial \varphi}=2 A \frac{d \varphi}{d x} \frac{\partial^{2} \varphi}{\partial \varphi^{2}} \frac{d x}{d \varphi}=2 A \frac{d^{2} \varphi}{d x^{2}}$

E o torque para a energia de anisotropia é

$$
\tau_{a n}=\frac{d E_{A}}{d \varphi}=\frac{d\left(k_{u}(\operatorname{sen}(\varphi))^{2}\right)}{d \varphi}
$$

No equilíbrio os torques chegam a se igualar e se opor.

$$
2 A \frac{d^{2} \varphi}{d x^{2}}+\frac{d\left(k_{u}(\operatorname{sen}(\varphi))^{2}\right)}{d \varphi}=0
$$

Depois de uma manipulação algébrica se chega:

$$
A\left(\frac{d \varphi}{d x}\right)^{2}=k_{u}(\operatorname{sen}(\varphi))^{2}
$$

Isto dá uma relação entre a posição $x$ e o ângulo $\varphi$ na parede. Para o caso mais simples de uma parede de $180^{\circ}$ com anisotropia uniaxial:

A relação entre o X e $\varphi$ mostra a dependência de (2.36). Nesta expressão se pode ver que a largura na parede de domino é formalmente infinita, se pode definir uma largura efetiva da parede, assumindo um valor de $\frac{d \varphi}{d x}$ constante, para a anisotropia uniaxial o $\frac{d \varphi}{d x}$ tem um máximo para $\sqrt{\frac{A}{K_{u}}}$ no centro da parede, como se vê na figura 2-5.

$$
x=\sqrt{\frac{A}{K_{u}}} \operatorname{Ln}\left(\tan \left(\frac{\varphi}{2}\right)\right)
$$

Assim a espessura efetiva para uma anisotropia uniaxial da parede de $180^{\circ}$ é

$$
\delta=\pi \sqrt{A / k_{u}}
$$

A energia armazenada pela parede de $180^{\circ}$ é:

$$
E=4 \sqrt{A k_{u}}
$$


$\mathrm{Na}$ experiência, fatores externos, como as tensões externas podem alterar a espessura e energia das paredes domínios.

Um analise para a energia de uma parede de tipo Néel de $180^{\circ}$ é obtida de [28], assim a energia de uma parede de tipo Néel por unidade de área tendo em conta as contribuições de interação de troca, de desmagnetização e anisotropia é:

$$
\gamma_{N}=A \frac{\left(\pi^{2}\right)}{a}+\frac{1}{2} K a+\left[\frac{\pi a D}{a+D}\right] M_{S}^{2}
$$

Onde $a$ é a espessura da parede e D é a espessura do filme. O resultado acima revela que para filmes muito finos, onde a espessura é muito menor que o comprimento da parede a energia consistirá principalmente da componente de desmagnetização $\gamma_{N}=\pi D M_{S}^{2}$, e o comprimento da parede é determinado só por $A$, e $K$ [27][28].

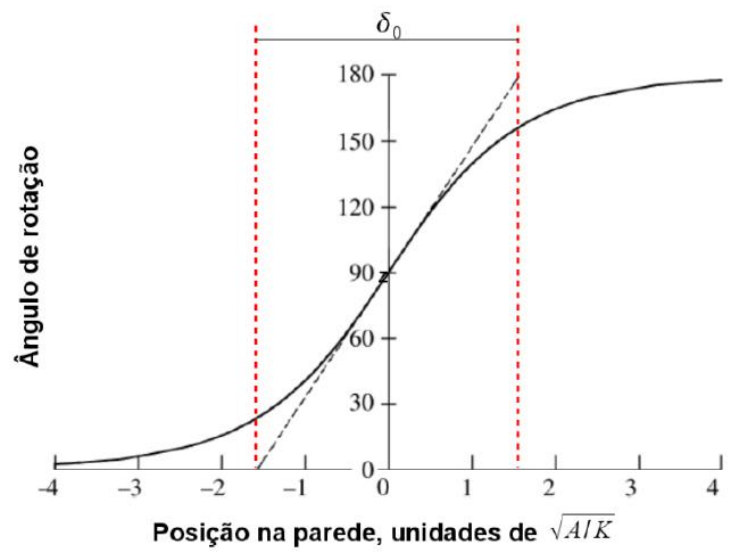

Figura 2-5: Variação da direção da magnetização a através de uma parede de domínio de $180^{\circ}[25][27]$. 


\section{Capítulo 3: Técnicas de caracterização}

Neste capítulo se apresentam as técnicas usadas para a preparação e caracterização das amostras. Se empregou a litografia por laser para desenhar os objetos litografados, a deposição foi feita com o magnetron sputtering. Para a caracterização topografia e magnética dos objetos se fez uso do AFM e MFM, VSM, junto com as imanes MOKE obtidas pelo microscópio metalográfico. Os resultados obtidos por estas medidas foram apoiadas com o uso do programa de simulação de objetos magnéticos Mumax3.

\subsection{Litografia}

A litografia é uma técnica empregada na fabricação de microestruturas, usado especialmente no desenho de circuitos eletrônicos e microeletrônicos. Com esta técnica se consegue desenhar a geometria dos objetos desejados. Neste trabalho se construíram objetos na microescala com a técnica de litografia por feixe de elétrons e por litografia de escrita direta a laser.

\subsubsection{Litografia por feixe de elétrons -e processo de lift-off}

Litografia por e-beam é uma técnica desenvolvida para construir objetos na micro e nanoescala, de tamanho e forma desejados, podendo ser metais ou isolantes crescidos sobre um substrato. Esta técnica possui maior precisão de resolução que a fotolitografia.

O processo de preparação das microestruturas é como se segue. O padrão desejado é desenhado com um feixe de elétrons sobre a superfície de um subtrato revestido com uma camada de resiste sensível ao feixe de elétrons. O material elétron-sensivel pode ser positivo ou negativo. Depois que a região é exposta ao feixe de elétrons o resiste positivo se torna solúvel e pode ser removido por solventes específicos, enquanto que no caso de usar um resiste negativo este tornará insolúvel. No caso de se usar só uma camada de resiste, em geral o material usado é o polimetilmetacrilato (PMMA). Posteriormente à remoção da região sensível do resiste se faz a deposição do metal e o lift-off do filme.

A máscara de resiste é removida depois da deposição do filme, no nosso caso a deposição do material de interesse foi feita com o equipamento de magnetron sputtering. Para a 
remoção final se usa um solvente adequado durante um tempo e temperatura determinada. Depois da remoção, a amostra é lavada em álcool isopropílico (IPA) e secada em fluxo de $\mathrm{N}_{2}$.

Existem também sistemas de duas camadas que usam como resiste o PMMA/DMMAMMA e ZEPS20/PPMA [29], estes sistemas conseguem maior resolução na definição das bordas dos objetos tendo um limite de resolução na borda para microestruturas menores que $100 \mathrm{~nm}$.

Neste estudo, os objetos gravados com litografia são vistos com um microscópio ótico. Sendo que figuras geométricas consideradas tiveram formas quadrada, de disco, triangular e anel, todas com diferentes tamanhos.

\subsubsection{Litografia de escrita direta por laser}

Esta técnica usa um feixe de luz de um laser altamente focalizado para fazer o desenho sobre o material de um substrato, para isto se usa resiste fotossensível podendo ser positivo o negativo. No caso do resiste positivo, a região exposta à radiação será mais solúvel, sendo facilmente removível no passo posterior, deixando uma máscara sobre o substrato. No caso do resiste negativo a região exposta será menos solúvel e a máscara formada após da revelação é o reverso do caso positivo. Depois com o uso de técnicas de deposição, sobre os moldes criados se deposita o material de interesse. A técnica busca ter a melhor resolução aumentando a "profundidade de foco", esta é definida como a capacidade do sistema para manter o foco em um ponto localizado em qualquer altura da espessura do resiste. A técnica tem limitações na resolução que se pode atingir, em comparação a litografia por feixe de elétrons.

a)

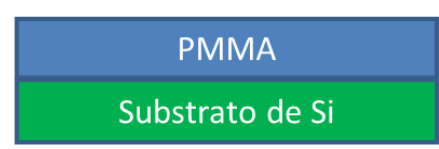

Escrita direta utilizando laser

b)

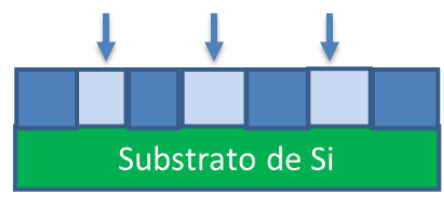

c)

Revelação do PMMA

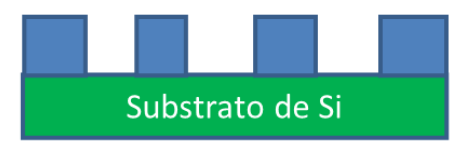

d) Deposição do metal

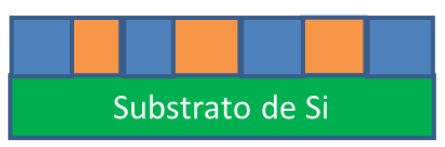

e) Lift-off

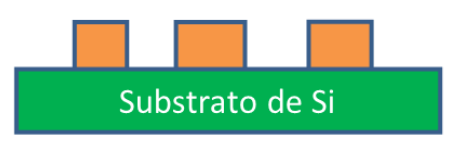

Figura 3-1: Etapas do processo de litografia de escrita por laser, utilizado na obtenção dos objetos microestruturados. 


\subsection{Magnetron Sputtering}

Entre as diferentes técnicas de deposição de materiais sobre substrato para formar filmes finos o Magnetron Sputtering tem uma preferência devido às variedades de materiais que pode empregar para o recobrimento. Os materiais podem ser condutores, cerâmicos ou isolantes com propriedades óticas, elétricas e magnéticas especificas. Esta técnica possibilita o controle de parâmetros com muita precisão, e além disso, fornece resultados com alta reprodutibilidade. A técnica permite ajustar as condições de deposição do filme, tal como a pressão, a potência, temperatura do substrato, e indiretamente, a taxa de deposição que determinaram a espessura, composição e microestrutura da amostra.

O processo de Sputtering está baseado na deposição de um material escolhido, em estado de vapor sobre um substrato, em condições de alto vácuo. O alto vácuo na câmara de deposição

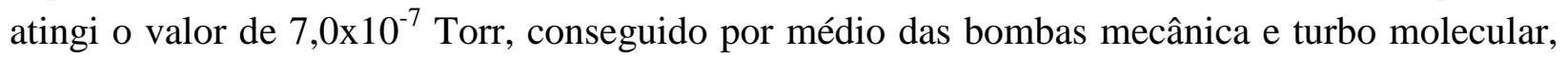
que trabalham em conjunto. Depois a câmara é preenchido com $\operatorname{Ar}(99,999 \%$ de pureza) até uma pressão de entre 1 a 10 mTorr, mantendo um determinado fluxo constante. Nestas condições o gás é submetido a uma alta tensão entre o alvo, material de interesse, e o substrato. Os átomos de Ar se ionizam em Ar+, e os elétrons livres são acelerados em direção ao substrato, ionizando em seu caminho outros átomos de $\mathrm{Ar}$ formando um estado de plasma estável. Os íons $\mathrm{Ar}^{+}$são acelerados em direção ao alvo, transferem energia aos átomos do alvo, que são lançados no espaço e posteriormente vão se depositar sobre o substrato, condensando-se e formando camadas finas. O equipamento tem a faculdade de poder usar até quatro alvos. Estes alvos têm forma de discos de duas polegadas de diâmetro e seis milímetros de espessura. Dependendo do tempo de deposição e da potência aplicada; se podem controlar parâmetros como a espessura e composição do material depositado. Pode se trabalhar com até quatro alvos em simultâneo.

Para a melhora da eficiência do processo a técnica de magnetron sputtering usa um conjunto de ímãs na base do alvo como se vê na figura 3-2. Estes ímãs criam linhas de fluxo de campo magnético fechado. Tais linhas servem como guias para os elétrons (-e) que se movem em espiral, promovendo novas ionizações, fazendo com que o plasma fique confinado no entorno do alvo. Devido ao e- percorrer maior distância, este ioniza maior quantidade de átomos de Ar, aumentando a taxa de deposição.

Para a deposição de matais se usa uma fonte de potência DC. Enquanto que para o caso de alvos isolantes se usa uma fonte de potência RF (rádio frequência) com um ajuste automático de impedância. Os parâmetros usados para a deposição serão detalhados posteriormente. 


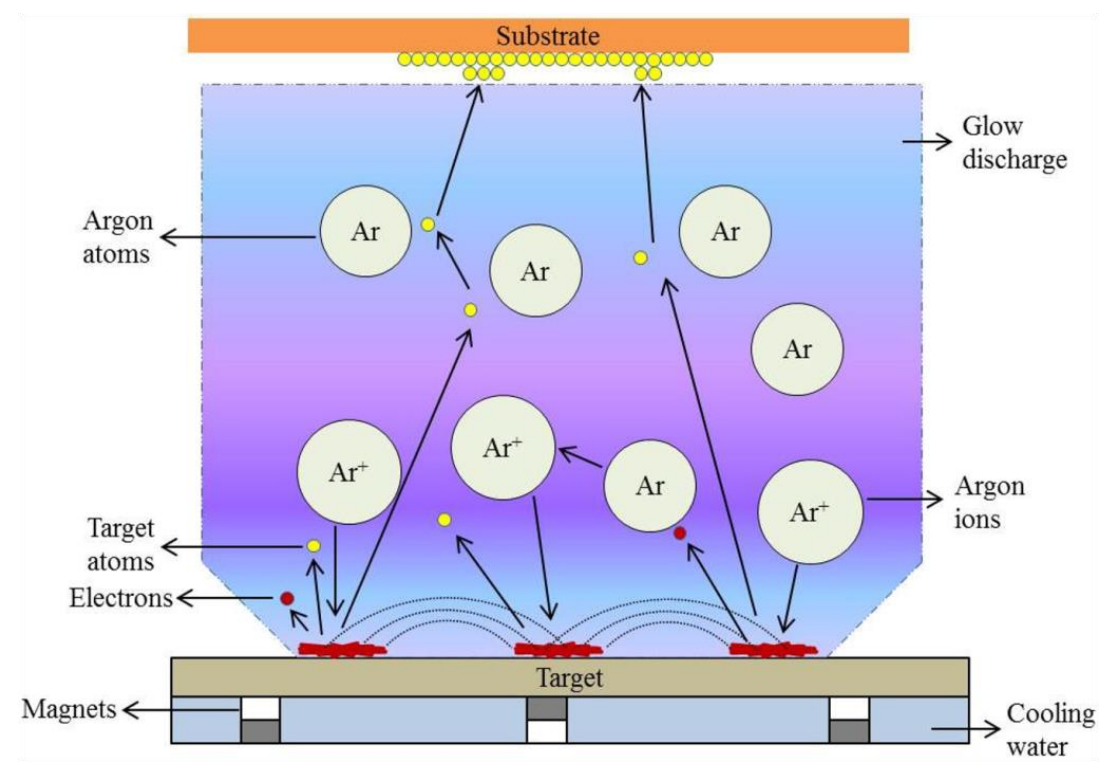

Figure 3-2: esquema do processo de deposição de um magnetron sputtering [30].

Se uso como substrato placas de silício (100) de dimensiones cerca de $10 \mathrm{cmX} 10 \mathrm{~cm}$. Os substratos foram lavadas em acetona, removiendo todas as impurezas orgánicas. Depois foram colados sobre uma porta amostra com peça rotativa, com o propósito de que durante a deposição se conseguisse amostras uniformes e sem efeito de sombras. Os materiais depositados foram feitos em dois conjuntos, em filmes e objetos de Co e filme e objetos de CoFeSiB. No primeiro conjunto a deposição foi feita a temperatura ambiente e no segundo foi feito a baixa temperatura usando nitrogênio líquido, com o propósito de ter amostra amorfa com propriedades magnéticas moles. Posteriormente se recobriu as amostras com uma camada muito fina de $\mathrm{Si}_{3} \mathrm{~N}_{4}$ para os proteger contra a oxidação.

Assim as amostras de Co foram produzidas com o equipamento de magnetron sputtering a partir de um alvo de Co (99,99 \% de pureza). Neste caso, a pressão de base da cámara de vacuo foi de $7 \times 10^{-7}$ Torr e com um fluxo de argônio de $20 \mathrm{sccm}$, a pressão de $2 \mathrm{mTorr}$. Para o CoFeSiB, a pressão de base foi de 3.6X10-7, o substrato foi resfriado na temperatura do nitrogênio líquido, o fluxo de argônio foi de $14 \mathrm{sccm}$ e a pressão de trabalho foi de 3 mTorr.

Os parâmetros da deposição são mostrados na tabela 1:

Tabela 1: Parâmetros usados na produção das amostras.

\begin{tabular}{|l|l|l|l|l|l|}
\hline Alvo & Potência & Tensão & Corrente & $\begin{array}{l}\text { Tempo de } \\
\text { deposição }\end{array}$ & $\begin{array}{l}\text { Espessura } \\
\text { obtida }\end{array}$ \\
\hline & w & V & A & minutos & nm \\
\hline CoFeSiB & 200 & 417 & 0.477 & 8 & $\sim 55$ \\
\hline $\mathrm{Co}$ & 100 & 441 & 0.225 & $18^{\prime} 20$, & $\sim 75$ \\
\hline
\end{tabular}


Após a deposição das amostras estas foram sometidas a um banho de acetona de agitação ultrassônica durante 15 minutos para remover o resiste. Seguido de um banho em alcool isopropilico (IPA) para limpá-las dos residuos de acetona. Em seguida se limpou novamente com IPA em ultrassom por 15 minutos. Ambos processos foram feitos em temperatura ambiente. Depois se submeteu a um fluxo de nitrogênio para secar-las e finalmente foram desidratados a $100^{\circ} \mathrm{C}$, numa estufa.

\subsection{Microscopia de força magnética (MFM)}

O MFM é uma técnica que oferece à possibilidade de sensoriar as linhas de campo de desmagnetização na superfície de amostras magnéticas. Um dos inconvenientes do MFM, é que as imagens não são de fácil e direta interpretação, geralmente elas estão associadas aos campos magnéticos que fluem da amostra (stray-field). Estes campos estão localizados nas paredes de domínios, quer sejam paredes de Bloch ou de Néel, em filmes finos. Esta técnica foi desenvolvida a partir do AFM (microscopia de força atômica) e opera de modo similar a um AFM, tendo como ponta de varredura uma sonda com forma de cone revestida com uma camada fina de material ferromagnético e magnetizado ao longo do seu eixo para interagir com a amostra. O modo de operação é de retrace ou interleave. Primeiro a sonda, que é uma ponta que vibra verticalmente na sua frequência de ressonância, faz uma varredura topográfica em uma linha, no modo tapping (contato intermitente). Depois a ponta é afastada mantendo-se a uma distância constante da superfície (lift mode). Na primeira passagem, há sensibilidade tanto a topografia como aos campos magnéticos gerados pela amostra, enquanto na segunda, apenas aos campos magnéticos. Com esta dupla medida é possível se separar as contribuições mecânica (topografia) e magnética. O processo se repete nas linhas seguintes, até varrer toda a área escolhida. As variações são medidas através da mudança na frequência de ressonância ou na fase da vibração da sonda associada a uma posição (x,y) da área de varredura, isso é salvado pelo computador e processado dando as imagens topográfica e de MFM. O software que foi usado para ver, processar e editar as imagens de MFM é o WSXM [31], que oferece as ferramentas necessárias.

A interação entre a ponta e o campo da amostra gera uma mudança na frequência de ressonância da sonda com respeito da frequência natural de referência. Isto faz com que a amplitude e a fase também mudem. A mudança da fase experimentada pela sonda é proporcional à componente normal do gradiente de força [32][33].

$$
\Delta \emptyset \propto \nabla(\vec{F} \cdot \vec{n})
$$


Baseando se no modelo de [32], se pode ver que a força de interação ponta/amostra pode ser obtida a partir da energia potencial (energia de Zeeman) do campo próprio da amostra e a magnetização da ponta ou vice-versa. Tomando o caso simples, a ponta pode ser modelada como um dipolo com a magnetização na vertical.

$$
F=-\nabla E=\int_{V p} \nabla\left(M_{p} \cdot H_{i}\right) d V
$$

É a força experimentada pela ponta, onde $M_{p}$ é a magnetização da ponta, e $H_{i}$ o campo intrínseco na superfície da amostra. A integral se estende sobre o volume da ponta.

$$
\begin{gathered}
F=\nabla\left(m_{z} \cdot H\right)=m_{z} \frac{\partial H_{z}}{\partial z} \\
\Delta \emptyset \propto \nabla(\vec{F} \cdot \vec{n})=m_{z} \frac{\partial^{2} H_{z}}{\partial^{2} z}
\end{gathered}
$$

Então a mudança de fase detectada provém da variação espacial da componente normal do campo $H$.

Como a força pode ser modelada como uma interação elástica, a constante elástica do cantilever muda seu valor quando se acrescenta a interação magnética ponta-amostra. Assim a constante elástica do cantilever se comporta como se tivesse deslocado até o valor de $c_{F}=c-$ $\partial F / \partial z$, onde $c$ é a constante elástica natural, $\partial F / \partial z$ é a derivada da coordenada perpendicular da força magnética e $c_{F}$ é a nova constante elástica efetiva.

Uma força atrativa fará que a constante $c$ diminuía. Consequentemente a frequência diminuirá e isto mudara a amplitude de oscilação e fase do cantilever, enquanto que uma força repulsiva fará que a constante $c$ aumente.

Uma vantagem do MFM, é que não precisa de amostras com extrema limpeza e se podem fazer estudos da amostra sob campo aplicado. Como é uma técnica indireta, para uma descrição quantitativa da estrutura magnética na superfície, a estrutura magnética da ponta deve ser conhecida. Também se deve ter em consideração a magnetização da ponta, já que esta pode perturbar as amostras muito moles.

A técnica de MFM é uma técnica de caracterização magnética na nanoescala. Os contrastas com boa resolução se devem a divergência da magnetização geralmente nas paredes de domínios. 


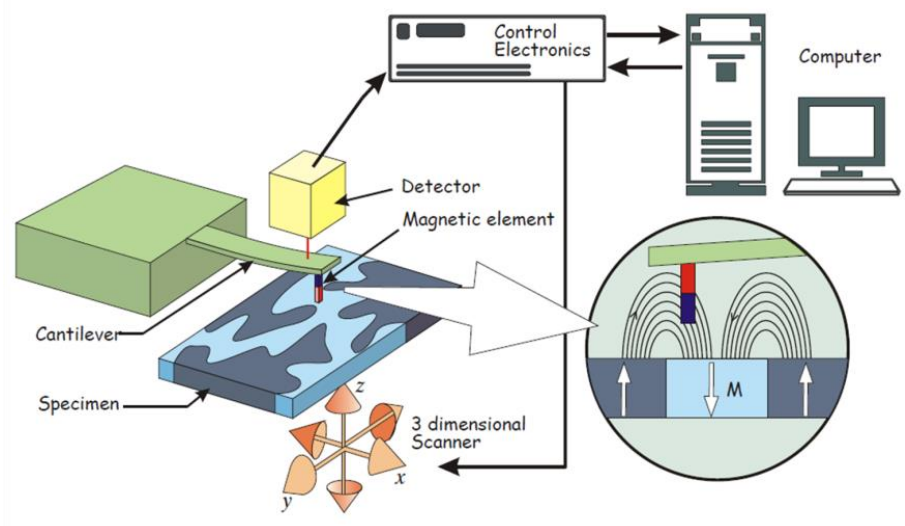

Figura 3-3: Esquema de funcionamento de um microscópio de forca magnética MFM [33].

Reprodução da imagem:

Para ter uma ideia de como é que se formam imagens com esta técnica, é mais fácil fazer o análises de formação da imagem do MFM em uma dimensão de um filme fino levando os parâmetros de magnetização(M) e campo $(\mathrm{H})$ ao espaço de frequências espacial (k), como foi resolvido em [32].

Então, decompõem-se a magnetização $\vec{M}$ em suas componentes de Fourier no plano $(x, y)$.

$$
\vec{M}\left(k_{x}, k_{y}, z\right)=\iint \vec{M}(x, y, z) e^{-i\left(x k_{x}+y k_{y}\right)} d x d y
$$

Se pode chegar a uma relação entre a força e os parâmetros geométricos no espaço $\vec{k}$ partindo de o modelo idealizado como em [32] e as equações de (3.2) e (3.5), isto dá:

$$
\widehat{F_{z}}(\vec{k}, z)=-\mu_{0} M_{t} b S\left(1-e^{-|\vec{k}| t}\right) e^{-|\vec{k}| z} \hat{\sigma}_{e f f}(\vec{k})
$$

A expressão é a forma simplificada de tip transfor function (TTF)[33], onde t é a espessura da amostra e $z$ é a distância ponta-amostra. Se vê que a força é proporcional à magnetização $M_{t}$ da ponta e a carga magnética eficaz $\hat{\sigma}_{e f f}(\vec{k})$ na amostra, junto com fatores de perda geométricas. Então na aproximação de modelo de monopolo para a ponta da sonda; a perda que aparece na força se deve à espessura do filme e à distância ponta-amostra principalmente. Assim para ter uma boa relação sinal/ruído se precisa que a distância $\mathrm{z}$ e a espessura $\mathrm{t}$ devam de ser pequenas. O limite de resolução de um MFM fica determinado principalmente pela combinação de fatores tais como distância ponta-amostra, sensibilidade do instrumento e a geometria da ponta. 


\subsection{Magnetômetro de amostra vibrante (VSM)}

O VSM é uma técnica de caracterização magnética baseada na indução magnética e oferece medidas da magnetização em função de parâmetros, tais como: campo aplicado $(\mathrm{H})$, temperatura (T) e do tempo (t). No processo de medida a amostra ferromagnética é localizada entre dois eletroímãs capazes de gerar campos altos na ordem de kGauss e entre duas bobinas de detecção, o campo é monitorado por um gaussímetro com sensor Hall. A amostra está fixada no extremo de uma haste vertical que é submetida a vibrar por meio de um transdutor a uma frequência determinada de $82 \mathrm{~Hz}$ na direção perpendicular à direção do campo do eletroímã. Devido a vibração da amostra, esta gera uma força eletromotriz $(\mathrm{fem})$ nas bobinas de detecção. Esta voltagem gerada é proporcional à magnetização da amostra e é medida por meio de um equipamento de detecção síncrona (Lock-in amplifier). A constante de proporcionalidade entre o momento magnético e o sinal elétrico no VSM é determinada usando uma amostra padrão de calibração de Ni. Todo o controle de campo e medidas da magnetização é feito por um programa de computador.

Todas as medidas foram feitas em um VSM, marca PAR-EGG (modelo 4500) localizado no Laboratório de Materiais Magnéticos (LMM) do IFUSP.

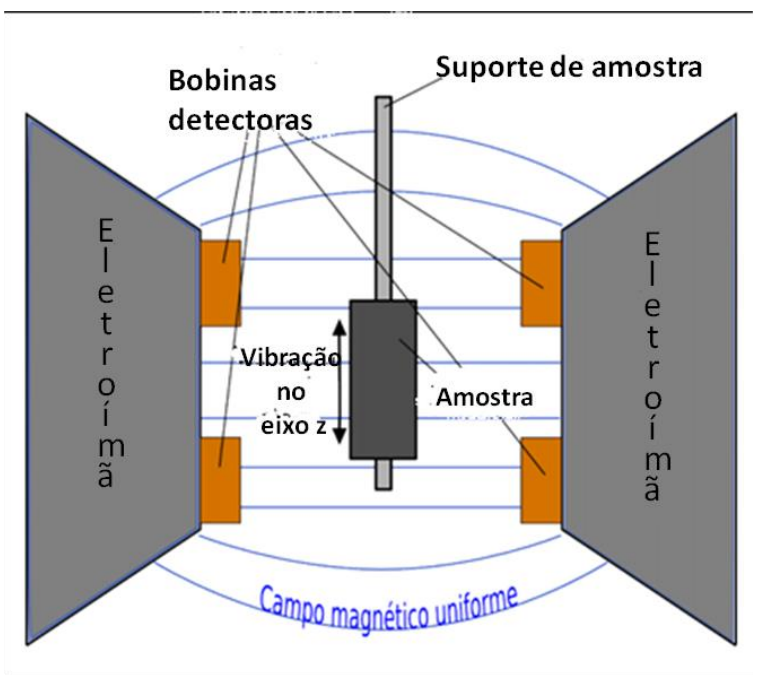

Figura 3-4: Esquema de um magnetômetro de amostra vibrante (VSM). 


\subsection{Tratamento térmico}

Para conseguir amostras com uma direção de anisotropia uniaxial magnética se induziu anisotropia por tratamento térmico. As amostras produzidas por litografia de escrita direta por laser foram submetidas a tratamento térmico sob campo magnético aplicado, se uso o forno do LMM IF USP. O tratamento foi feito dentro de uma câmara de vácuo com pressão de 5,0x $10^{-6}$ Torr, conseguida com ajuda de uma bomba turbo molecular, baixo o campo de um ímã permanente de $5 \mathrm{KOe}$ durante $3 \mathrm{~h}$ a uma temperatura de $350^{\circ} \mathrm{C}$. Para atingir esta temperatura se usou uma razão de aquecimento de $10^{\circ} \mathrm{C} / \mathrm{min}$. Após o tratamento térmico, o resfriamento foi lento, deixando-se o forno resfriar naturalmente.

\subsection{Programa de simulação de sistemas magnéticos}

Para ter uma melhor compreensão das propriedades magnéticas dos objetos e saber o que acontece nas propriedades intrínsecas dos materiais, além dos resultados das medidas, se construíram simulações da configuração micromagnética presentes nas amostras. Para este propósito se usou o programa Mumax3.

O Mumax 3 é um programa que permite simular o comportamento magnético em objetos na nanoescala, ele foi desenvolvido pela Dynamat (Dynamics IF functional Nanomaterials) da Universidade de Genten, Bélgica [34]. Este programa oferece as soluções de configurações magnéticas em sistemas de objetos, também permite o estudo da dinâmica dos processos de magnetização, podendo definir as condições de contorno, como por exemplo, de excitação por um baixo campo ou corrente. Além disso, o programa permite simular curvas de histereses, fazer gráficos, processos da dinâmica da magnetização, imagens de MFM, etc. Ele se diferencia de outros programas, como Oommf que trabalha só com a CPU. As simulações micromagnéticas com o Mumax 3 tem a vantagem de trabalhar em conjunto com a GPU, o que agiliza os processos [34]. O programa usa discretização de diferenças finitas e tem o software de código fonte aberto escrito em linguagem GO e CUDA. Este programa pode rodar com um código escrito em um arquivo scripting Mumax3, com uma linguagem que se parece com um subconjunto da linguagem GO.

Para poder operar no Mumax3, é preciso parâmetros de entradas como, constante de troca, magnetização de saturação, constantes de anisotropia uniaxial e cúbica, tamanho da célula, dimensões do objeto e também é necessário definir as condições experimentais, como o tempo de relaxação, campo magnético aplicado ou corrente de excitação. Uma vez definidos os parâmetros o software faz o cálculo da energia do sistema, que tem termos da contribuição de todas as energias: energia de troca, magnetostática, de anisotropia de forma e outros. Ele discretiza o sistema em células pelo método de diferenças finitas, assim se chega ao resultado de 
$M$ (magnetização) e $H_{e f f}$ (campo efetivo; tem a contribuição de todos os tipos de campo) sobre cada uma das células definidas.

O termo de energia de troca associado a uma célula está definido para seus 6 primeiros vizinhos:

$$
\begin{gathered}
E_{\text {troca }}=-\frac{1}{2} \vec{M} \cdot \vec{B}_{\text {troca }} \\
\vec{B}_{\text {troca }}=2 \frac{A_{\text {troca }}}{M_{\text {sat }}} \sum_{i} \frac{\left(\vec{m}_{i}-\vec{m}\right)}{\Delta_{i}^{2}}
\end{gathered}
$$

Onde $\Delta_{i}$ é a dimensão de uma célula, $\vec{m}_{i}$ é o momento magnético dos vizinhos próximos e $\vec{m}$ é o momento magnético da célula. $\mathrm{O}$ valor de $A$ e $M$ definem o comprimento de troca $L_{\text {tro }}$. Este é um parâmetro importante que determina a distância para o qual a interação de troca no material resulta mais intensa que a interação magnetostática. Este comprimento de troca define o tamanho da célula que vai ser usada na discretização do sistema para as simulações, sendo preferível usar um tamanho de célula menor ou igual a $0.75 * L_{\text {tro }}$. Como se vê na equação (3.9) o $L_{\text {tro }}$ tende a diminuir com o incremento da espessura, já que a energia magnetostática, $K_{d}=\mu_{o} M_{s}^{2} / 2$, incrementa com a espessura.

$$
L_{\text {tro }}=\sqrt{\frac{2 A}{\mu_{o} M_{s}^{2}}}=\sqrt{\frac{A}{K_{d}}}
$$

E o campo efetivo $H_{e f f}$, para cada célula se segue da magnetização inicial.

$$
H_{e f f}=-\frac{1}{\mu_{0}} \frac{\partial E}{\partial M}
$$

O Mumax3 calcula a evolução da magnetização reduzida $\vec{m}(\vec{r}, t)$, que tem valor unitário. Assim o programa parte da derivada de $\mathrm{m}$ com respeito ao tempo, que é proporcional ao torque $\tau$ como se vê na equação (3.11), onde o torque pode ter a contribuição do torque de Landau-Lifshitz, ou de Spin, de Zhang-Li e Slonczewki [35][36]. Uma vez relaxado o sistema, partindo de uma condição inicial definida, este chega a seu valor de mínima energia, então aquele estado de mínima energia definirá a configuração de magnetização do sistema.

$$
\vec{\tau}=\frac{d \vec{m}}{d t}
$$

Torque de Landau-Lifshitz [36][37], no sistema CGS:

$$
\vec{\tau}_{L L}=\gamma_{L L} \frac{1}{1+\alpha^{2}}\left(\vec{m} X \vec{B}_{e f f}+\propto\left(\vec{m} X\left(\vec{m} X \vec{B}_{e f f}\right)\right)\right.
$$


Nesta expressão o $\gamma_{L L}$ é a razão giromagnética, que para o caso do elétron livre $\gamma_{L L}=$ $1.7588 \times 10 \mathrm{~Hz} O e^{-1}$, $\propto$ é o parâmetro de amortecimento, e $\vec{B}_{e f f}$ é o campo efetivo que pode conter os seguintes campos magnéticos: campo externo, campo magnetostático, de Heisenberg Exchange Field, campo de anisotropia magnetocristalina e thermal Field. O primeiro termo dentro do parêntesis representa a interação da amostra com o campo efetivo, já o segundo termo descreve o amortecimento viscoso da magnetização, que evita a prolongação da precessão do momento magnético em torno da direção do campo $\vec{B}_{e f f}$.

O programa está desenhado para usar discretização de diferenças finitas (FD) do espaço em 2D ou 3D com células ortorrômbicas. Entre as células se tem em conta os acoplamentos quantitativos, como interação de troca entre as células, que se limita ao caso de primeiros vizinhos.

Para poder dar uma solução numérica à equação dinâmica da magnetização M (3.12), o programa usa métodos numéricos explícitos de Runge-Kutta (RK4s) para diferentes ordens de convergência, e deste modo soluciona a equação (3.11) de torque. Para isso o programa usa uma função relax () ou run (time), que se encarregará que o sistema tenda a um mínimo de energia e onde se monitora o valor da energia resultante até que o sistema chegue ao estado de mínima energia. Depois se monitora o torque resultante do sistema até que o sistema atinge o critério do erro do torque MaxErr $=10^{-9}$ [36], que é a precisão necessária. Se o sistema está muito perto do equilíbrio existe a possibilidade de que o sistema acabe em um ponto, uma parte plana da energia, um estado metaestável. Nesta condição, o campo efetivo aponta na direção da diminuição da energia. Deste modo se obtém a magnetização média final para cada célula.

Outra vantagem do Mumax3, é que este oferece ferramentas para construir imagens de MFM, podendo partir de imagens que mostram a configuração da magnetização de domínios em termos dos vetores de magnetização, em arquivos de extensão ovf ou monitorando em tempo real enquanto a magnetização evolui no tempo. Depois as imagens de simulação de MFM são apresentadas em 2D.

Para isto o programa calcula a derivada da força de interação entre a ponta da sonda definida e o stray-field presente na superfície, esta força é descrita pela equação:

$$
\frac{\partial F_{z}}{\partial z}=\sum_{i=x, y, z} M_{i}(x, y) \frac{\partial^{2} H_{p, i}(x, y)}{\partial z^{2}}
$$

Nesta expressão o efeito produzido pelo campo da ponta $H_{p, i}(x, y)$ é avaliado na superfície da amostra. 
A ponta pode ser modelada como uma ponta dipolar ou monopolar com afastamento definido pela função off-lift () com respeito a superfície, isto forma produtos de saída proporcionais ao contraste de fase visto nas imagens de MFM.

O Mumax3 oferece também informação sobre a energia total, contribuição dos tipos de energia, das componentes da magnetização dependente do espaço e do tempo, e curvas de histereses.

\subsection{Microscópio metalográfico adaptado para o MOKE}

O microscópio metalográfico foi desenvolvido como uma ferramenta para a observação dos domínios magnéticos; além de ter a função de amplificar a imagem, ele possui um sistema polarizador- analisador que permite mudar o contraste na imagem e desse modo achar um contraste magneto ótico (MO). O sistema ótico deste equipamento está composto por uma série de elementos tais como; uma fonte de iluminação com lâmpada de xenônio, de $150 \mathrm{~W}$, cuja qualidade e estabilização da fonte influencia no contraste e resolução da imagem. Possui também um sistema de lentes, diafragmas, lentes objetivas de diferentes medidas, lente coletora, um polarizador e analisador. Todos estes elementos precisam ficar alinhados e calibrados para um ótimo resultado.

Um elemento muito importante do microscópio e a objetiva. Este elemento é composto por um conjunto de lentes que corrigem as aberrações produzidas no caminho da luz que forma a imagem. Este elemento tem a função de ser um condensador para a luz incidente durante a transmissão, alinhado com os outros componentes e evitando possíveis aberrações, já na reflexão da luz pela amostra a lente serve como uma objetiva para a formação da imagem.

\section{Limite de resolução na objetiva:}

A lente da objetiva tem um limite de resolução dado pelo fenômeno de difração. Quando a luz proveniente de um ponto da amostra atravessa a lente esta gera um padrão de aneles, chamado patrão de Airy. A separação entre duas fontes pontuais será resolvida se o primeiro mínimo de difração de uma imagem de uma fonte pontual cai sobre o máximo do outro. Este limite dá a máxima resolução possível alcançada por um sistema ótico convencional.

A resolução da objetiva dependerá da luz usada e das características da objetiva, sendo dado por [38].

$$
d=1.22 \frac{\lambda}{n \cdot \sin \theta}=1.22 \frac{\lambda}{N A}
$$


Onde $\lambda$ e o comprimento de onda médio, $n$ é o índice de refração do meio ( $n=1$ para o ar), e $\theta$ é a metade do ângulo do cone de luz produzido pela lente. $\mathrm{O} n \cdot \sin \theta=N A$ (abertura numérica) faz referência a capacidade para coletar da luz e resolver detalhes finos da amostra. Valores grandes de NA significa maior ângulo de cone de luz, isso é maior quantidade de fótons chegando de um ponto da amostra e atravessando a lente. Valores altos de $N A$ permite resolver detalhes pequenos.

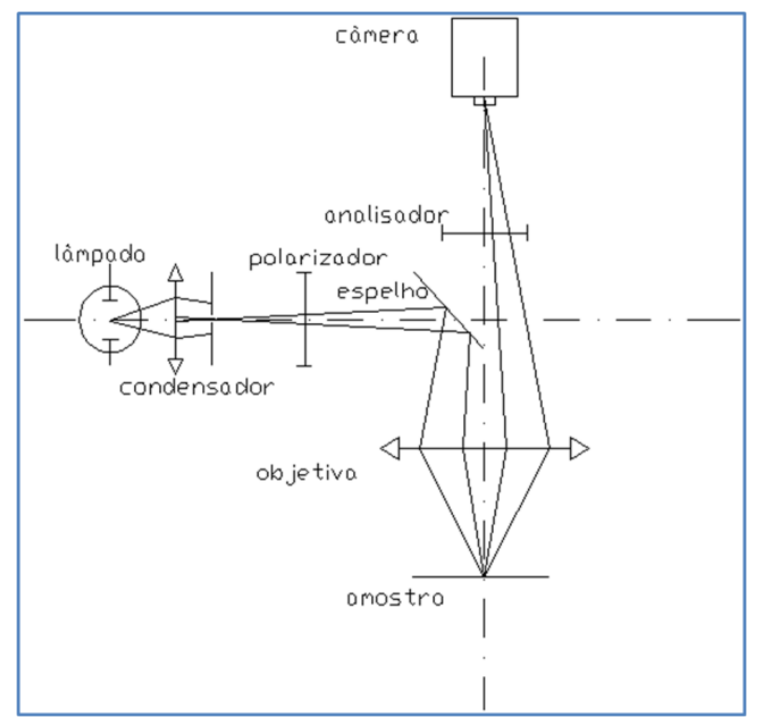

Figura 3-5: Esquema do caminho ótico que percorre a luz no microscópio metelográfico.

\section{Câmera digital}

Para o registro e posterior processamento da imagem se usou uma câmera digital colocada interceptando o caminho da luz que forma a imagem. A câmera digital possui uma matriz de elementos fotossensíveis (pixels). Dependendo se a câmara é de tipo CCD o CMOS, o tempo de resposta dos pixels, a rapidez para gerar carga devido aos fotoelétrons estimulados, difere um pouco; sendo mais rápido para a câmara de tipo CMOS. A qualidade da imagem dependerá da performance da câmera, ou seja, dos parâmetros: tamanho do pixel, área sensitiva(número de pixels* tamanho do pixel), range dinâmico (), ruído de leitura e eficiência quântica $(\mathrm{QE})$ (fração de fótons incidentes que conseguem ativar fotoelétrons, na produção de carga nos fotodiodos, que é dependente do comprimento da onda).

Assim a resolução do sistema dependerá da resolução do sistema ótico e da resolução da câmera. A resolução do sistema ótico é determinada pela configuração dos polarizadores, da centralidade do feixe de luz e da abertura usada para a luz incidente. Enquanto a resolução da câmera é determinada pelo número de pixels, sendo que quanto maior o número de pixels maior será sua capacidade para reproduzir detalhes finos. $\mathrm{O}$ valor numérico do sinal de cada pixel representa o valor médio da intensidade registrada pelo pixel para seu intervalo espacial de 
amostragem. Para poder reproduzir uma imagem ótica sem perder informação é preciso que o intervalo de amostragem da câmera seja menor que a metade da menor característica a ser resolvida pela imagem ótica [1].

Se usou para obtenção das imagens MOKE duas câmeras; a primeira foi uma Samsung, modelor NX3000 de tipo CMOS, tamanho de sensor de 23.5x15.7 mm e tamanho de imagem de $5472 \times 3648$ pixels e sensibilidade ASA de 25.600. A outra câmera usada foi uma Sony com sensor IMX255, tamanho de sensor de $8.45 \times 8.45 \mathrm{~mm}$, sensibilidade de $10^{-3}$ Lux e tamanho de imagem de $704 \times 480$ pixels.

\section{Razão de sinal ruído (SNR)}

Um grande valor de SNR é necessário para uma boa qualidade da imagem de domínios. Os ruídos de maior influência no processo digital presentes na câmara são o ruído de fótons, ruído de fundo e ruído de leitura [2]. Para o cálculo do $S N R$ [1-2].

$$
S N R=\frac{\text { B.QE.S. } t_{\text {exp }}}{\sqrt{\text { B.QE. }(S+I b) \cdot t_{\text {exp }}+B \cdot D \cdot t_{\text {exp }}+N_{r}^{2}}}
$$

Onde $B$ é o numero de pixels da câmara, $t_{\text {exp }}$ é o tempo de exposição ou de integração, $Q E$ é quantum efficiency, $S$ é o fluxo de fótons incidentes, $D$ é a corrente de escuro, $I b$ é o ruído de background e $N_{r}$ é o ruído de leitura [1-2].

Fazendo uma simplificação devido a que o ruído dos fótons é dominante e $D, N_{r}$ são contribuição insignificantes, se chega a (3.16).

O SNR para o caso de domínios magnético alinhado ao longo da direção sensível [1-2].

$$
S N R=\left(\frac{B \cdot Q E \cdot t_{.}}{\sqrt{E}}\right) * \frac{\left(I_{+}-I_{-}\right)}{\sqrt{\left(I_{+}+I_{-}\right)}}
$$

Onde E é a energia dos fótons incidentes, $I_{+}$e $I_{-}$são as intensidades dos domínios magnéticas para os dois estados da imagem alinhados na direção sensível. Da expressão (3.16) do SNR, do primeiro termo se pode ver que uma melhora no sinal se consegue aumentando o tempo de integração $t$, usando uma alta eficiência $(Q E)$ da câmara e tendo uma maior quantidade de bits $B$. O outro termo se refere ao sinal magneto-ótica (MO) e dependerá de como esteja configurado o analisador e da natureza da força do sinal MO da amostra. O efeito MO é melhorado por processamento de imagens. 


\section{Fator de qualidade}

O fator de qualidade $Q$ definido como em [1], será o indicador da separação entre os dois estados magnéticos saturados opostos. Está definido como a diferença dos valores médios do sinal do pixel dos estados magnetizados saturados para ambas as direções de campo aplicado extremo, para o $H$ máximo e $H$ mínimo, dividido pelo desvio padrão da distribuição estatística da imagem de um estado magnético saturado. Quanto maior o valor de $Q$ melhor será para distinguir diferentes estados magnetizados intermédios entre os estados saturados do espécime, atingido por o campo aplicado $(\mathrm{H}=H \max$ e $\mathrm{H}=\mathrm{Hmin})$.

$$
Q=\frac{\mu_{\text {pixel }}(H \max )-\mu_{\text {pixel }}(H \min )}{\sigma_{\text {pixel }}}
$$

Na Figura 3-6 se vê as distribuições estatísticas para dois estados de saturação de magnetização de uma região de interesse da amostra de um objeto de filme fino de Co. No caso ideal na imagem na região de interesse de um estado saturado, deveria ter uma intensidade espacial uniforme. Embora isto não aconteça, devido a ruído presente na toma de dados da imagem, fazendo com que na distribuição estatística o desvio padrão fique maior. Na Figura 3-6, como o desvio padrão é diferente para cada distribuição, se escolhe o maior valor de $\sigma$ dando um valor de $Q=1.992$, isso indica que se podem diferenciar estados de magnetização intermediários entre os dois estados saturados. Um valor de $Q=1$ indicaria que apenas se podem diferenciar os dois estados de saturação. Então se devem melhorar as condições para obter um valor de $Q$ elevado para isso se deve incrementar o número de pixels e incrementar o tempo de exposição.

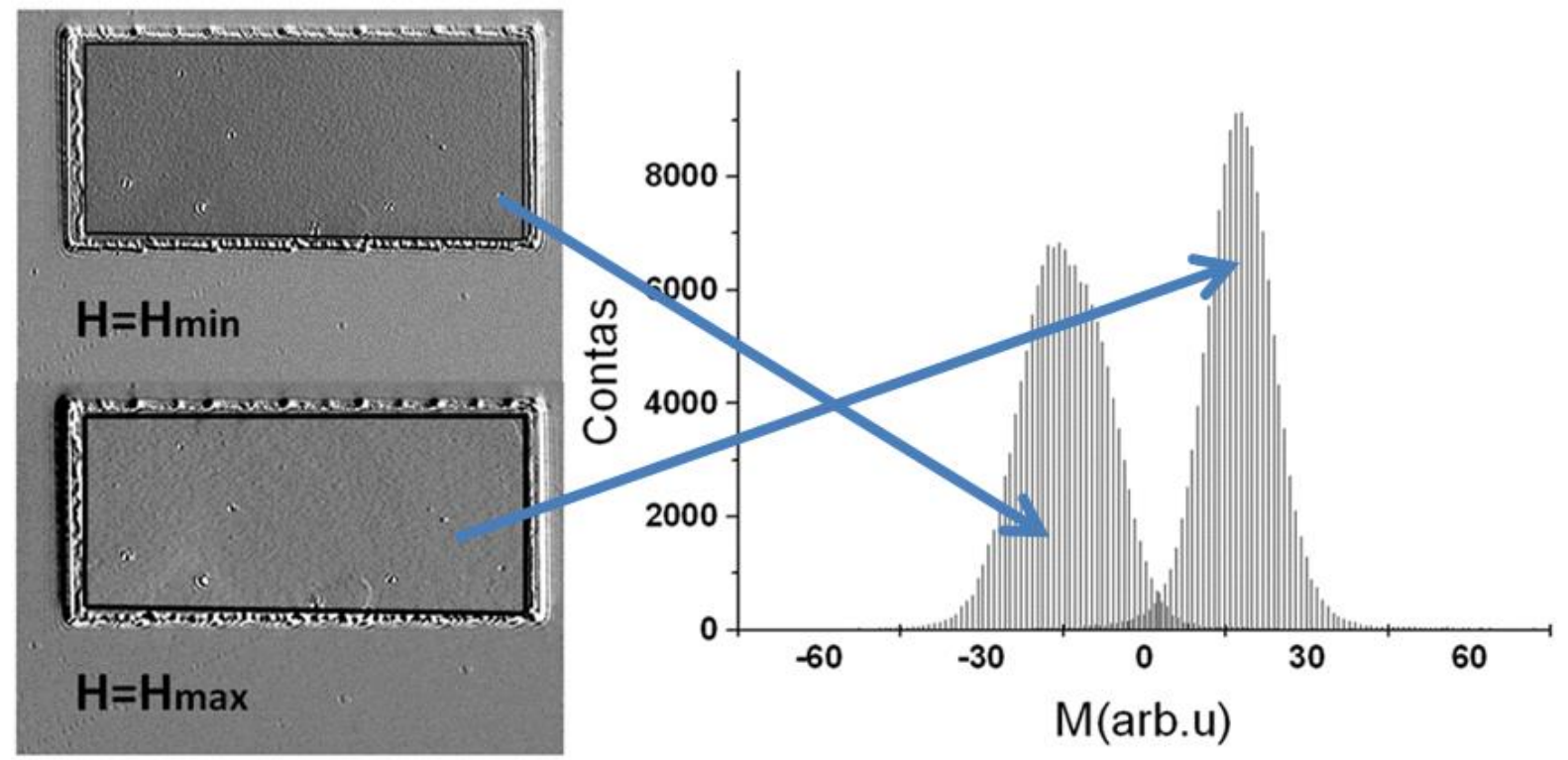

Figura 3-6: Imagens dos estados saturados $\mu \mathrm{sat}=\mu(\mathrm{Hmax})$ e $-\mu \mathrm{sat}=\mu(\mathrm{Hmin})$ para um objeto de dimensões Co de $25 \times 60$ um e $60 \mathrm{~nm}$ de espessura e sua distribuição estatística. 
Dependendo da componente de magnetização; longitudinal, transversal ou polar que se deseja ver no microscópio, este é configurado modificando-se a incidência da luz polarizada que chega à amostra. Para ver as componentes polares da magnetização se configura o sistema para uma incidência praticamente normal da luz polarizada incidente na amostra. Para poder perceber as componentes longitudinais da magnetização, para amostras com magnetização no plano, se escolhe um ângulo de incidência oblíqua para ter melhor sinal Kerr. Como se vê na Figura 3.7 [2] a relação entre intensidade do sinal Kerr refletida e a NA (abertura numérica). O maior sinal de intensidade Kerr longitudinal se consegue usando objetivas de maior NA, onde se pode ver uma faixa de ângulos para a condição de melhor otimização do sistema ótico. Então o sistema ótico se configura para incidência inclinada da luz, para a observação dos domínios no plano da amostra.

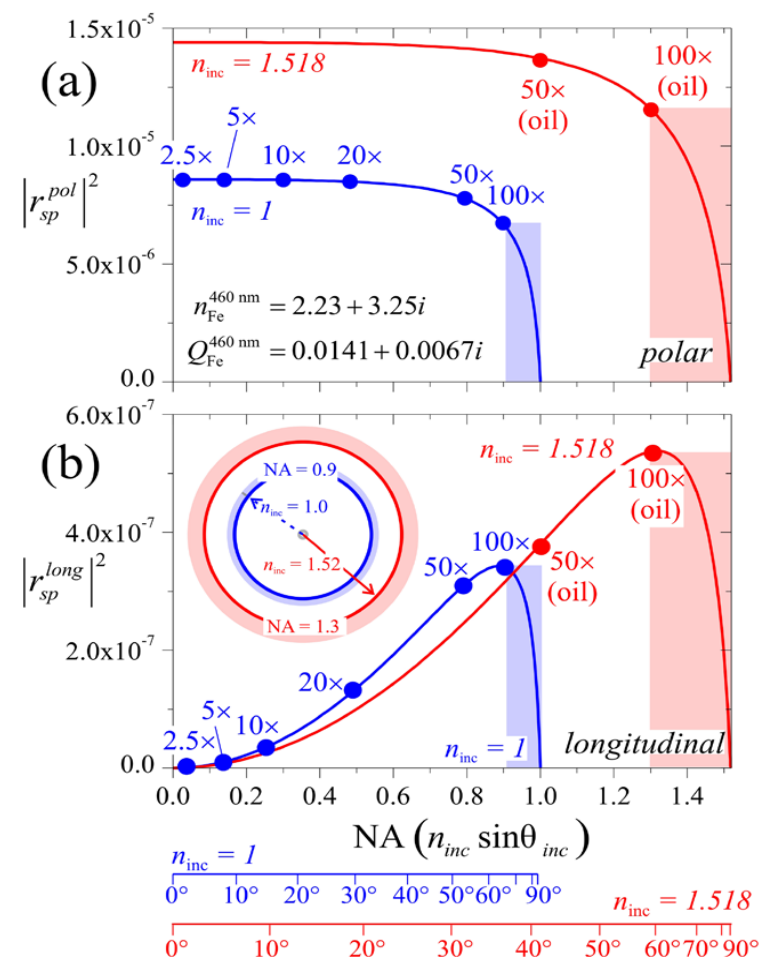

Figura 3-7: a) Intensidade Kerr polar VS abertura numérica (NA) no ar e no óleo, b) Intensidade Kerr longitudinal vs NA [2].

\section{Processamento digital das imagens}

O efeito Kerr é um fenômeno magneto-ótico, que fornece técnicas para o mapeamento das estruturas e configurações de domínios na superfície de materiais. Uma das considerações a ter em conta para um bom resultado é a boa qualidade de polimento da superfície, que dessa maneira reduz os efeitos indesejados de despolarização devido a rugosidade superficial que é 
característico das amostras bulk. Já no caso de amostras com filmes é conveniente não ter muita rugosidade, isto se consegue controlando a deposição.

O processamento de imagens é usado na melhora de observação de domínios, de modo a conservar a informação MO (magneto-ótica) eliminando a informação não magnética. Para isto se utiliza uma série de operações como subtrações entre as imagens, filtros, médias, etc. Uma das maneiras para obter o contraste magneto-ótico é configurando o microscópio para tirar imagens para duas condições de polarização diferentes, isto se consegue manuseando o analisador. Primeiro se tem que assegurar o cruzamento do polarizador e o analisador em $90^{\circ}$, condição de extinção da luz. O polarizador deve estar centrado no centro do caminho ótico da luz incidente para garantir máxima polarização da luz incidente na amostra, então através de um analisador (segundo polarizador) que atua sobre a luz refletida pela amostra é possível separar e registrar a sutil resposta magneto-ótica das duas condições de polarização, deslocando um ângulo pequeno no analisador da condição de extinção para $+\theta\left(+1.5^{\circ}\right)$ e para $-\theta\left(-1,5^{\circ}\right)$ obtendo-se duas imagens com contrastes fracos e invertidos. Com as técnicas de processamento de imagens, usando-se o programa ImageJ, se consegue melhorar e aumentar o contraste magneto-ótico.

Na figura 3-8 se mostra um exemplo do processamento de imagens para melhorar o contraste magneto-ótico. Como exemplo, as imagens (a) e (b) são de um aço elétrico Fe-3\% $\mathrm{Si}$ para uma mesma região em condições de polarização invertidas entre si. A imagem (c) da figura 1 mostra a subtração entre as imagens (a) e (b). Finalmente a imagem (d) é a imagem processada depois de fazer o filtro de subtração de fundo da imagem (c), conseguindo se um forte contraste. A imagem (e) é o histograma da imagem (c) e a imagem (f) é o histograma da imagem (d). A seta dupla indica a direção da componente de magnetização que é permitida ver pelo contraste magneto-ótico nesta configuração Kerr longitudinal usada. Pode-se melhorar a qualidade da imagem incrementando o tempo de exposição na câmera ou mediando sobre um número maior de imagens. 

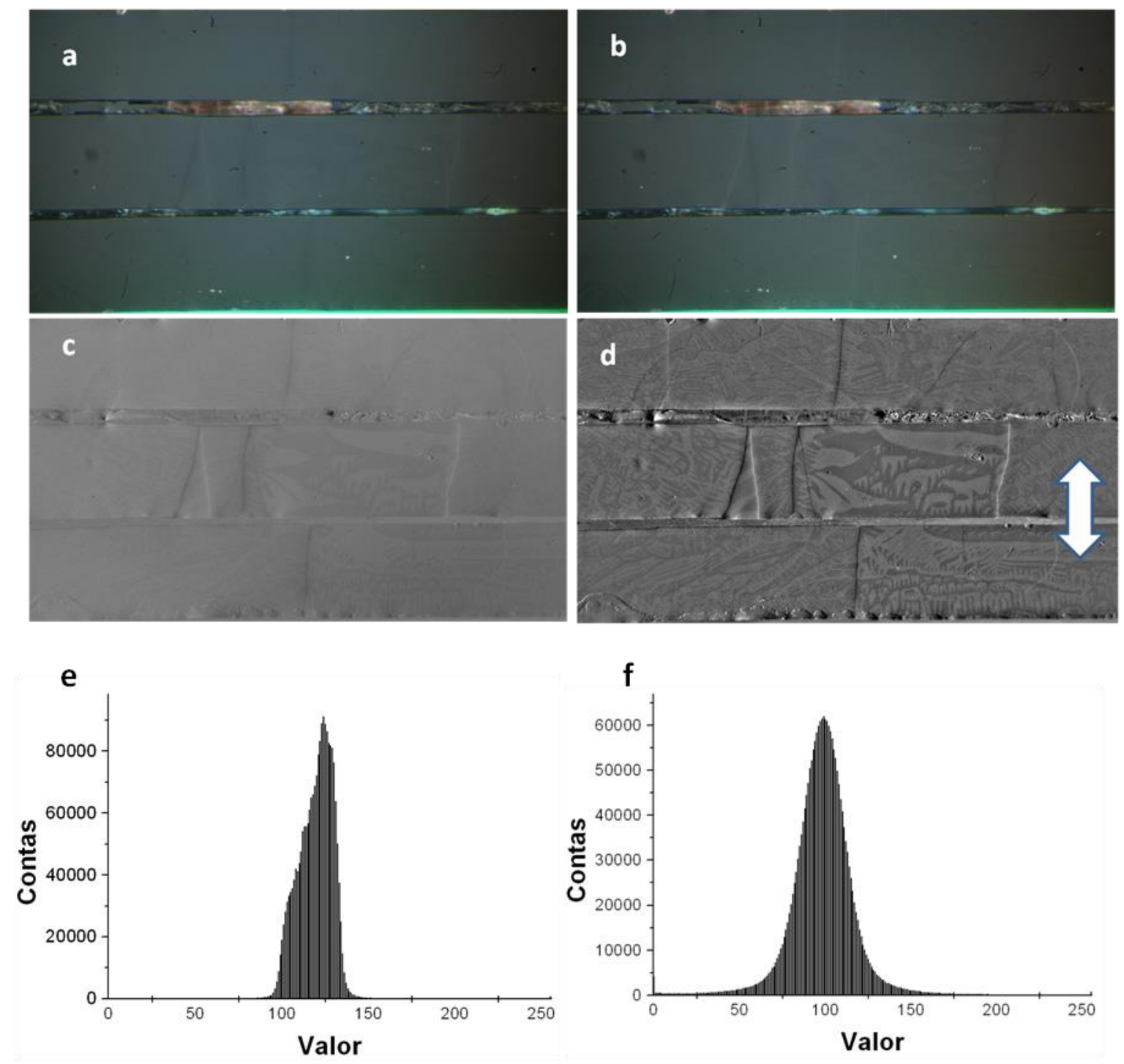

Figura 3-8: Imagens óticas do aço Fe-3\% Si feitas pelo Microscópio metalográfico. As imagens (a) e (b) foram feitas para duas condições de polarização diferentes. A imagem (c) é a diferença entre a imagem (a) e (b). A imagem (d) é a imagem final obtida depois de fazer o filtro adequado. A imagem (e) é o histograma da imagem (c) e a imagem (f) é o histograma da imagem (d). A seta dupla indica a direção da componente de magnetização que é permitido ver pelo contraste magneto-ótico nesta configuração Kerr longitudinal usada.

O outro modo para obter um contraste magneto-ótico é como segue; se leva a amostra a um estado de saturação com ajuda de um campo aplicado, este estado se usará como a imagem de fundo, depois se tira a diferença com a imagem de qualquer outro estado magnetizado mudando o campo aplicado. A subtração das imagens dá o contraste magneto-ótico, o qual é melhorado tomando uma média sobre muitas imagens. 


\section{Capítulo 4: Resultados experimentais e análises dos dados}

Neste capitulo são apresentadas os resultados obtidos das técnicas de caracterização vistas no capítulo 3. Apresenta-se as curvas de histereses de VSM, seguido dos resultados das medidas de AFM, MFM, das imagens MOKE, e como estas podem ser usadas em alguns casos para obter curvas de histereses e os resultados das simulações.

\subsection{Resultados do VSM}

Foram feitas curvas de histereses para os filmes finos de CoFeSiB e de Co por meio do VSM, as medidas foram realizadas com campo aplicado paralelo ao plano da amostra, para dois eixos perpendiculares entre si, no plano da amostra. Foi usada para a medida uma velocidade de varredura do campo de $400 \mathrm{Oe} / \mathrm{min}$.

$\mathrm{Na}$ Figura 4.1, se mostra as curvas de histerese para o material de CoFeSiB, que apresenta campo coercitivo $\mathrm{Hc}=6.4 \mathrm{Oe}$, magnetização remanente $\mathrm{Mr}=2.3 * 10^{-3}$ uem, magnetização de saturação $\mathrm{Ms}=2.7^{*} 10^{-3}$ uem , e na outra direção perpendicular valores de $\mathrm{Hc}=5.1 \mathrm{Oe}, \mathrm{Mr}=8.7 * 10^{-4} \mathrm{uem}, \mathrm{Ms}=2.3 * 10^{-3} \mathrm{uem}$.

Curva de histereses CoFeBSi_1

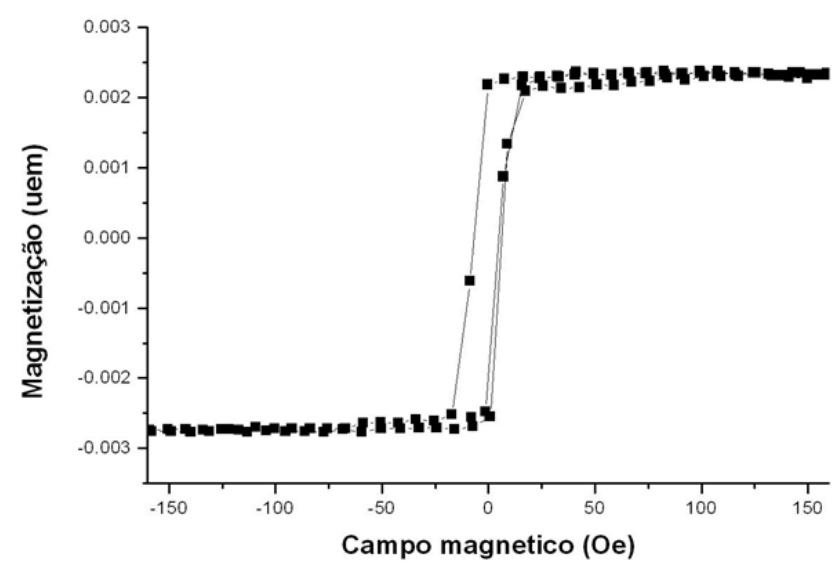

Curva de histereses CoFeBSi_2

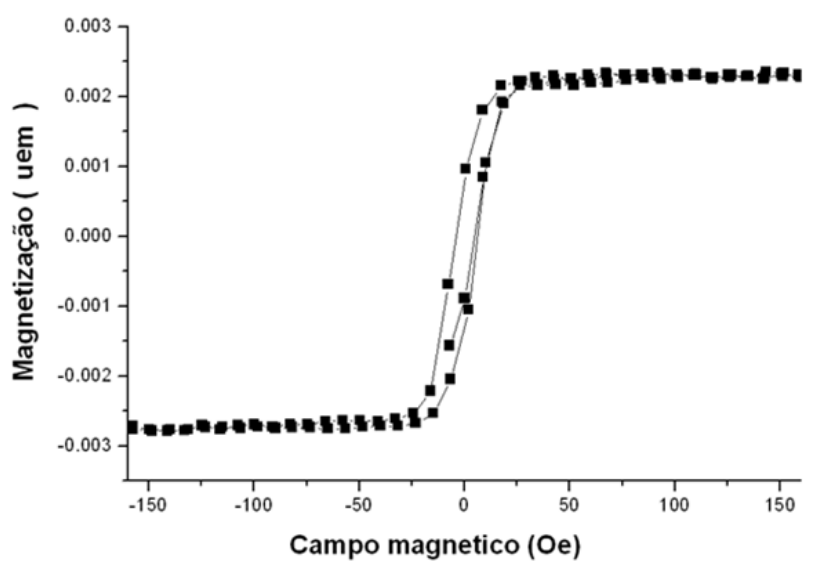

Figura 4-1: Curva de histereses para duas direções perpendiculares entre si no plano da superfície do filme de CoFeSiB.

As curvas de histerese para o filme de Co são mostradas na Figura 4-2. Com campo coercitivo de $\mathrm{Hc}=16 \mathrm{Oe}$, magnetização remanente de $\mathrm{Mr}=5.5^{*} 10^{-3}$ uem e magnetização de saturação de $\mathrm{Ms}=6.7 * 10^{-3}$ uem, e na outra direção de $\mathrm{Mr}=4.5^{*} 10^{-3}$ uem, $\mathrm{Ms}=6.0 * 10^{-3}$ 
e $\mathrm{Hc}=17$ Oe. Com valores muito próximos para as duas direções perpendiculares entre si, o resultado não mostrou diferença significativa entre as curvas para cada material. Isto indica que o material não tem orientação preferencial, ou seja, anisotropia uniaxial, mas uma distribuição aleatória de grãos com anisotropias próprias, dando um efeito não global da anisotropia. Como o material foi depositado sobre um substrato em rotação a deposição foi aleatória, outro fator foi a espessura do filme com valor cerca de $70 \mathrm{~nm}$, a rugosidade e desordenamento dos grãos resulta ser maior. Assim se espera que os objetos litografados que foram depositados sob as mesmas condições que nestes filmes, também apresentem iguais características, o que implica em uma desordem que evite a formação de uma anisotropia uniaxial definida.
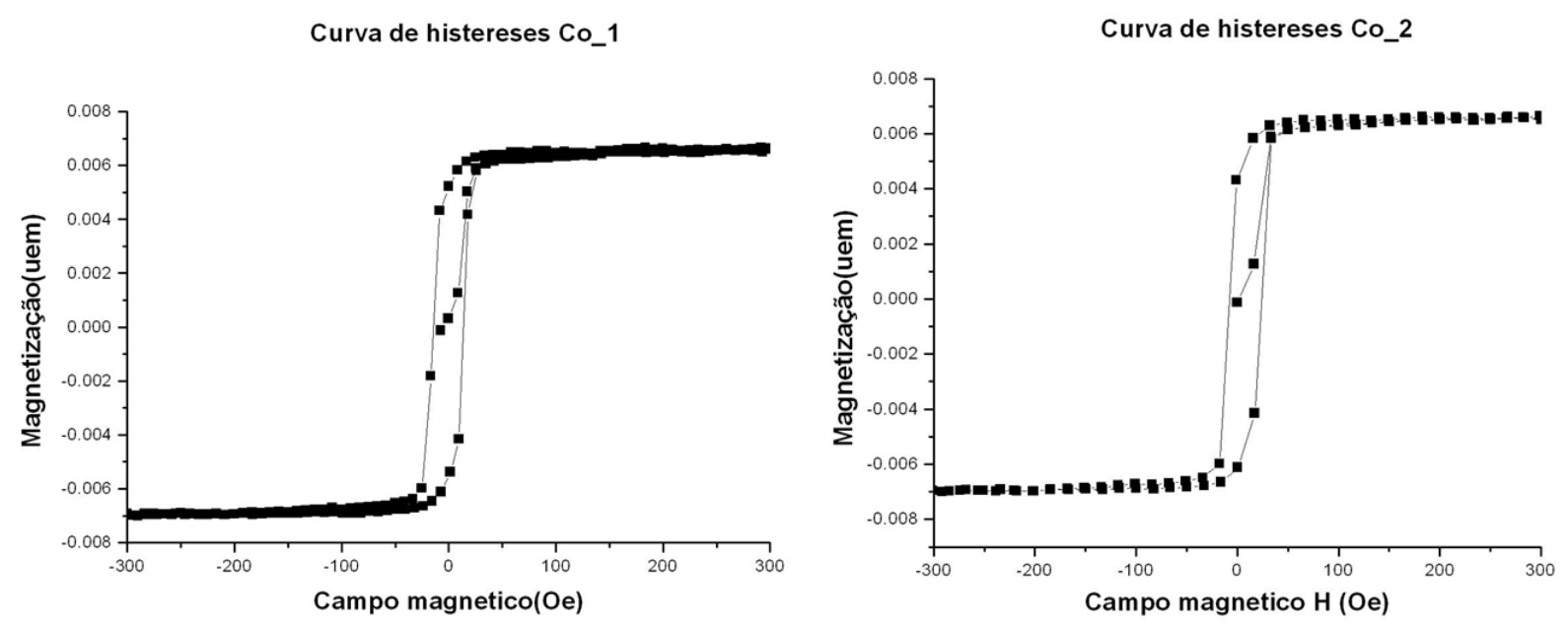

Figura 4-2: Curva de histereses para duas direções perpendiculares entre si no plano da superfície do filme de Co.

\subsection{Curvas de histereses a partir das imagens Kerr no microscópio metalográfico}

$\mathrm{Na}$ literatura se tem desenvolvido diferentes processos e critérios de avaliação para obtenção de curvas de histereses a partir de imagens Kerr magneto-óticas [1-2]. Estes trabalhos estão baseados principalmente na distinção de intensidade entre os estados saturados de magnetização e a otimização da relação sinal/ruído. Como o sinal Kerr geralmente é um sinal muito fraco, muitos autores para poder melhorar o contraste magneto-ótico das imagens fazem uso de filmes de revestimento [2]. A camada depositada sobre a amostra tem a função de amplificar o sinal Kerr por meio do efeito Faraday. Deste jeito o contraste é melhorado e se supera os defeitos de ruído no desejado (aumenta a relação sinal/ruído). No nosso caso não se conta com este tipo de filme. Assim, para melhorar a relação sinal/ruído primeiro se aumentou o tempo de exposição ( a 3 segundos) da câmara para uma abertura muito pequena na entrada de luz incidente do microscópio, se prosseguiu tirando imagens da mesma região, mais em dois estados de polarização diferentes, isso se faz controlando o analisador do microscópio para dois 
estados de polarização simétricos e opostos com referência ao caso onde o analisador esteja completamente cruzado com o polarizador de entrada da luz incidente. Uma vez obtida as médias para estas duas imagens se fazem a subtração e processamento de imagens para aumentar o contraste. De igual modo, se procede a tomada de imagens da mesma região para os outros estados de magnetização, mudando os valores de campo aplicado. Outro modo de superar essa baixa relação sinal/ruído é usando a câmara de alta sensibilidade. Neste caso, o contraste Kerr nas imagens é produzido fazendo a diferença de imagens entre um estado de saturação magnética da amostra e qualquer outro estado de magnetização mediante a mudança do campo magnético aplicado, para diferentes valores de campo entre ambos estados de saturação magnética.

Para uma boa obtenção das curvas, se precisam ter uma boa qualidade da superfície dos objetos com boa resposta magneto-ótica na configuração Kerr longitudinal. Entre muitos dos fatores a ter em conta o uso de uma câmara que tem a função de trabalhar em baixa iluminação foi de muita importância para reduzir o ruído introduzido na aquisição dos dados. Fizeram-se imagens das amostras para diferentes valores de campo magnético aplicado, indo de um estado de saturação de magnetização até o outro estado de saturação nos objetos, mostrando na sequência de imagens a evolução dos domínios magnéticos.

Devem-se tomar em conta muitas considerações no processo de obtenção da curva de histerese, entre eles, o mais importante é a redução de ruído luminoso que atrapalha o contraste nas imagens e uma boa distinção entre os estados saturados de magnetização, neste último se pode conferir na separação entre histogramas das imagens de ambos estados de saturação.

No nosso caso, o microscópio metalográfico tem uma lâmpada de xenônio de $150 \mathrm{~W}$ e é possível ter uma boa iluminação sobre a amostra, com intensidade estabilizada e uniformidade na obtenção da imagem.

\subsubsection{Interpretação e modelamento do sinal Kerr}

Para as correções das imagens, as alterações devidas ao instrumento como as variações da intensidade da fonte, inclinações da amostra, ruído eletrônico, etc, podem ser mitigados, para o caso que o ruído seja continuo e pequeno. Então este background presentes nas imagens pode ser eliminado o seu efeito na curva de histerese subtraindo uma linha contínua (offset) na curva de histerese.

Primeiro se faz a subtração da imagem coletada com respeito a um fundo (background) em comum para todas as imagens de interesse. A imagem de background pode ser a imagem do objeto com um estado magnético uniforme (estado de saturação) de tal modo que na subtração ressalte o efeito magneto-ótico a cada valor de campo aplicado.

O sinal magneto-ótico pode se modelado como nas referências [1-2]. Assim se pode compreender o efeito da subtração. O $S$ é o sinal magneto-ótico, dado pelo sinal médio de 
intensidade feito sobre todos os pixels da região escolhida de interesse sobre a amostra para um valor de campo magnético aplicado.

$$
S(H)=\sum_{(i, j)} I_{i, j}(H) / N_{\text {pixel }}
$$

Onde $I_{i, j}$ é a intensidade do i-eismo, j-esimo pixel; e $N_{\text {pixel }}$ é o numero de pixels totais na região de interesse.

$\mathrm{O}$ sinal $\mathrm{S}$ tem contribuição tanto do sinal magneto-ótico como do sinal de fundo (background), o background se deve a fatores despolarizantes ou à parte não magnética. Para poder filtrar a informação de interesse do sinal MO se subtraí da curva de histerese o offset. Isto se faz, primeiro com a normalização da magnetização [2]:

$$
\begin{gathered}
\lambda=\frac{M}{M_{\text {sat }}}\left\{\begin{array}{l}
+1 \text { se } M=+M_{\text {sat }} \\
-1 \text { se } M=-M_{\text {sat }}
\end{array}\right. \\
S(H)=I_{o} \cdot[1+\lambda k M]
\end{gathered}
$$

Aqui se distingue a parte magnética e a parte não magnética, esta última se pode ver como um offset na curva de histerese, então se conserva a parte magnética fazendo a subtração.

$$
S_{*}(H)=I_{o} \lambda(H) k M \alpha \lambda(H)
$$

Assim o sinal $S_{*}$ é diretamente proporcional a magnetização.

O Processamento para obtenção de curva de histerese é o seguinte. Seleciona-se a região de interesse do objeto, como se vê na figura 3-5. Na seleção se evita a região de borda do objeto já que devido a efeitos de difração, a luz nesta região se despolariza e gera perturbação na hora do processamento das imagens.

Uma vez obtidas as imagens, se subtrai o fundo. Isto pode se conseguir tirando uma média das imagens da região de interesse e subtraindo o fundo, sendo este último a imagem obtida com a aplicação do filtro de media. Outro modo de mitigar o fundo na substrução é construindo um fundo a partir de um filtro linear da imagem na direção X ou Y. Deste modo se ajuda a eliminar a tendência de aumento de intensidade de cada ponto (pixel) nas imagens ao dirigir-se na direção X ou Y. Este fundo é devido a variações de luminosidade no microscópio ou a não horizontalidade da fixação da amostra.

Da imagem que se obtém depois de fazer a subtração de fundo, extrai se a distribuição estatística das intensidades dos pixels da imagem (histograma) e sobre esta distribuição se faz a conta da equação (4.1), dando o valor do sinal S, que é proporcional a magnetização, para o campo $\mathrm{H}$ aplicado. Repete-se o processo para todos os valores de campo $\mathrm{H}$ requeridos. $\mathrm{Na}$ figura 4-3 se mostra um exemplo de curva de histereses obtido dos histogramas de intensidades das 
imagens de uma amostra com objeto de filme fino de Co de $30 \mu \mathrm{m}$ x70 $\mu \mathrm{m}$ para diferentes valores de campo $\mathrm{H}$ aplicado.
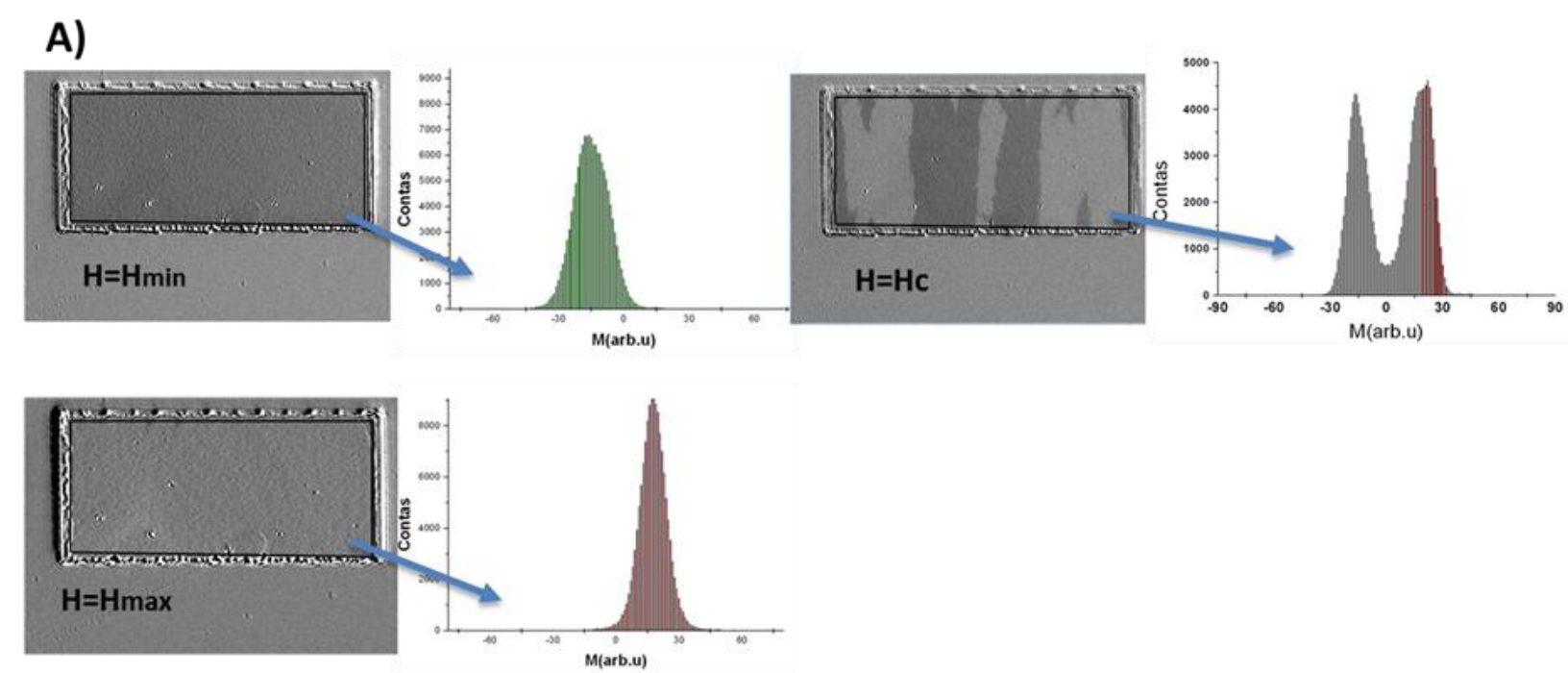

B)

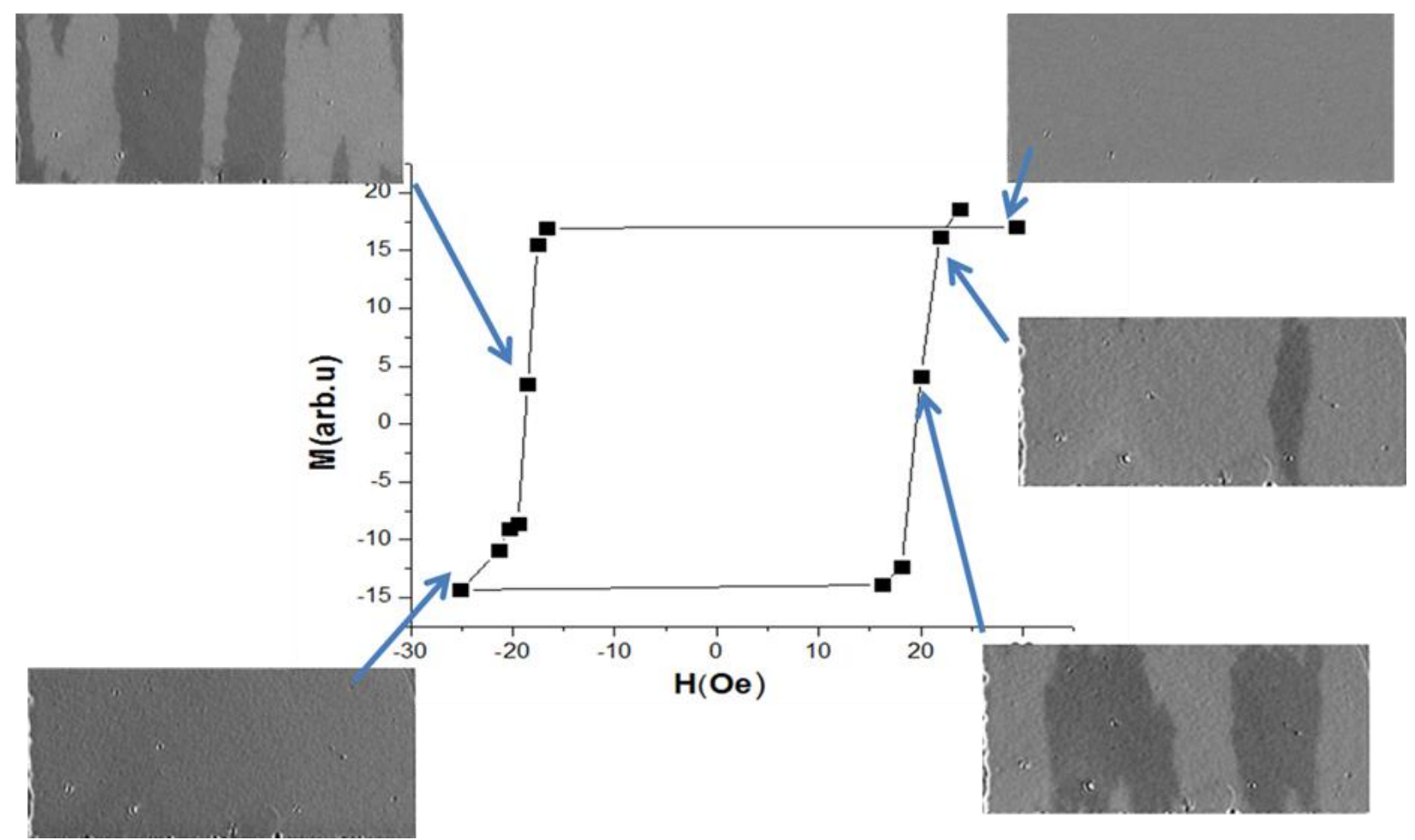

Figura 4-3 A) Imagens MOKE do objeto de Co e seus respectivos histogramas da sua região de interesse para diferentes valores de campo magnético aplicado. B) Curva de histereses obtida pelas imagens Kerr de um objeto de filme fino de Co para diferentes valores do campo $\mathrm{H}$ aplicado. 
Parâmetros críticos usados para garantir uma boa sequência da caracterização magnética:

Angulo relativo entre o analisador e o polarizador (1 grau).

Tempo de exposição do microscópio (3 segundos).

Área de interesse capturada da amostra $(30 \mu \mathrm{m} \times 70 \mu \mathrm{m})$.

Número de imagens coletados que foram mediadas (16).

\subsubsection{Imagens MOKE obtidas dos objetos litografados por feixe de luz de Co e CoFeSiB.}

As medidas de MOKE foram feitas por médio do microscópio metalográfico e posteriormente se obtiveram as curvas de histereses. Se observaram amostras de objetos de Co e $\mathrm{CoFeSiB}$, estas foram submetidas a tratamento térmico com campo magnético aplicado perpendicular a direção de maior comprimento dos objetos retangulares para induzir anisotropia. Nestes elementos se podem ver nas curvas de histereses as diferentes preferências em atingir a magnetização de saturação com respeito à direção de campo aplicado. No caso do $\mathrm{CoFeSiB}$ se fizeram tratamentos térmicos, mas devido ao seu fraco sinal Kerr não foi possível determinar uma curva de histerese. A pesar disso se conseguiu estimar o valor de seu campo coercitivo a partir de suas imagens Kerr.

Na Figuras 4-4 se mostra as curvas de histereses normalizadas e medidas nas direções de campo aplicado de $\Theta=90^{\circ}, 60^{\circ}$ e $0^{\circ}$ com respeito ao eixo de maior comprimento do objeto retangular para a amostra de Co de dimensões de $35 \mu$ mx60 $\mu$ m tratadas termicamente. As curvas de histerese mostram uma sutil direção de fácil magnetização de saturação, próprio de amostras com anisotropia uniaxial. Confirma-se a presença de anisotropia uniaxial.

Como as amostras foram submetidas a uma indução de anisotropia por tratamento térmico, se esperava que os momentos magnéticos ficassem orientados na direção do campo aplicado. Embora nestas imagens, se confirma a presença de uma anisotropia uniaxial fraca, esta anisotropia é dirigida ao longo da direção de maior comprimento do elemento demonstrando que a anisotropia de forma é predominante, o campo desmagnetizante tende a ser menor na direção de maior comprimento. A pesar de que o objeto ter anisotropia magnetocristalina hexagonal e ter recebido um tratamento térmico com direção de campo perpendicular ao lado de maior comprimento, o qual faria que os momentos magnéticos ficassem orientados na direção do campo aplicado. Apesar disso o elemento prefere magnetizar-se na direção do maior comprimento, demonstrando a importância da anisotropia de forma. Além disso, a magnetização prefere ficar paralela ao plano da superfície. Passando para elementos de outras dimensões de $35 \mu \mathrm{mx} 100 \mu \mathrm{m}$, o comportamento é similar. Sempre se prefere a direção de maior comprimento como direção de anisotropia, com a exceção mudança de ligeiras variações nos valores de $H_{c}$. 
Os valores de campo coercitivo resultam serem próximos uns dos outros para as diferentes disposições angulares do objeto retangular de Co, em relação a direção do campo $\mathrm{H}$. Por outro lado a diferença se vê no valor de campo de saturação da magnetização. No caso do material orientado na vertical $\Theta=0^{\circ}$, eixo de maior comprimento alinhado com o campo $\mathrm{H}$, esta se satura a um campo menor de aproximadamente $\mathrm{Hs}=24 \mathrm{Oe}$, enquanto que uma disposição na horizontal $\Theta=90^{\circ}$, campo $\mathrm{H}$ perpendicular ao eixo de maior comprimento, dá $\mathrm{Hs}=41$ Oe. No caso de objeto disposto no ângulo de $60^{\circ}$, dá o valor de $\mathrm{Hs}=35 \mathrm{Oe}$, que é um resultado intermediário entre o caso horizontal e vertical.

Assim esta técnica mostra a curva de histerese com parâmetros característicos diferentes para os diferentes ângulos, após o tratamento térmico.

Tabela 2: Relação entre o angulo de orientação do eixo maior do elemento com o campo (H) e o Campo coercitivo $\left(H_{c}\right)$ e de saturação (Hs).

\begin{tabular}{|l|l|l|}
\hline Ângulo $(\Theta)$ & Campo coercitivo $(\mathrm{Hc})$ & Campo de saturação (Hs) \\
\hline $90^{\circ}$ & $25 \mathrm{Oe}$ & $41 \mathrm{Oe}$ \\
\hline $60^{\circ}$ & $21 \mathrm{Oe}$ & $35 \mathrm{Oe}$ \\
\hline $0^{\circ}$ & $20 \mathrm{Oe}$ & $24 \mathrm{Oe}$ \\
\hline
\end{tabular}

No caso do CoFeSiB os campos coercitivos são da ordem de Hc 6 Oe. 


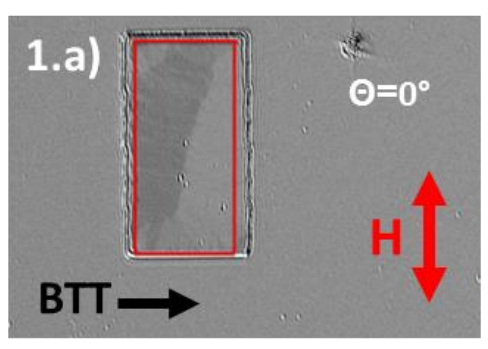

2.a)

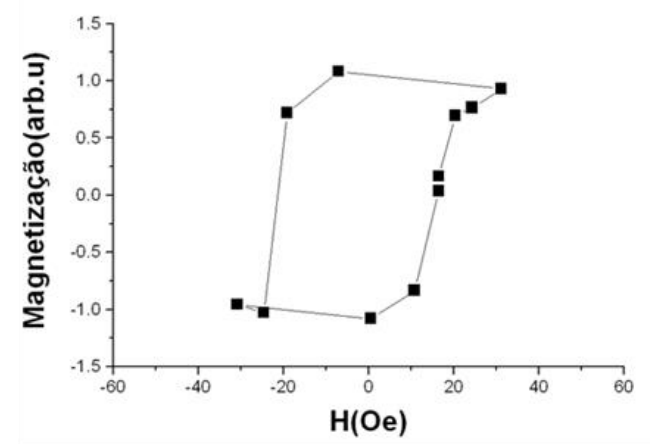

2.c)

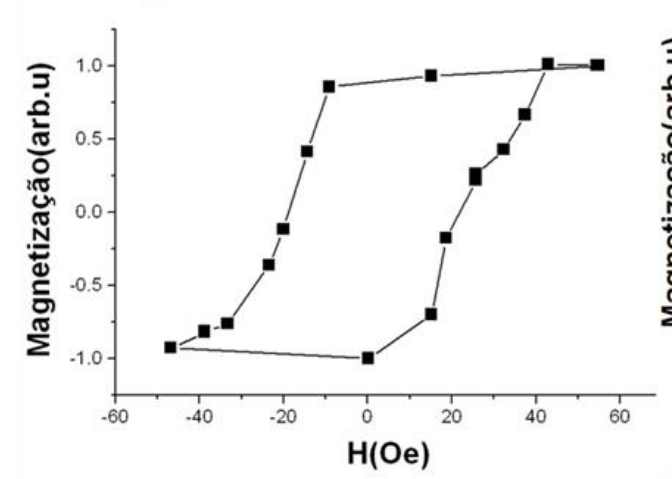

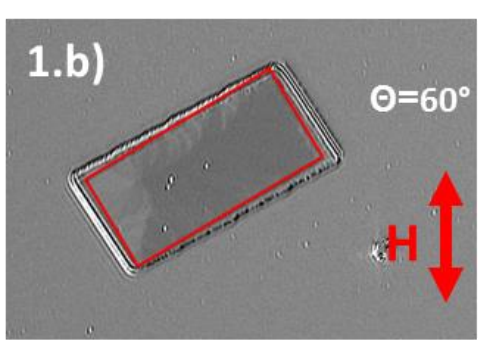

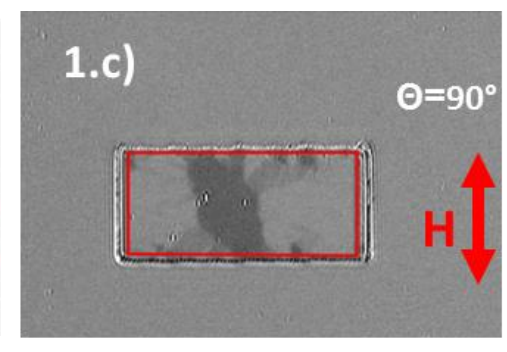

2.b)

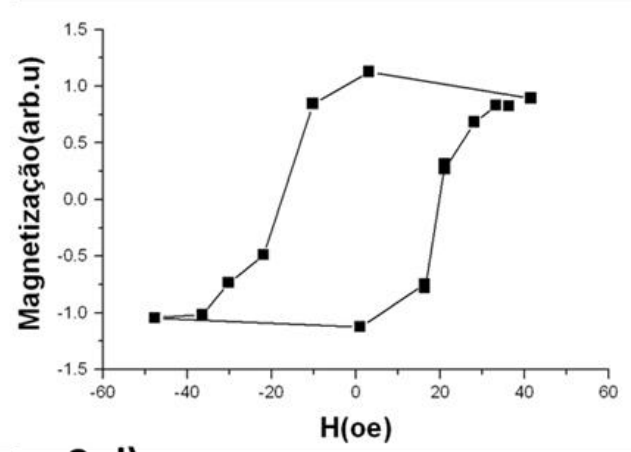

2.d)

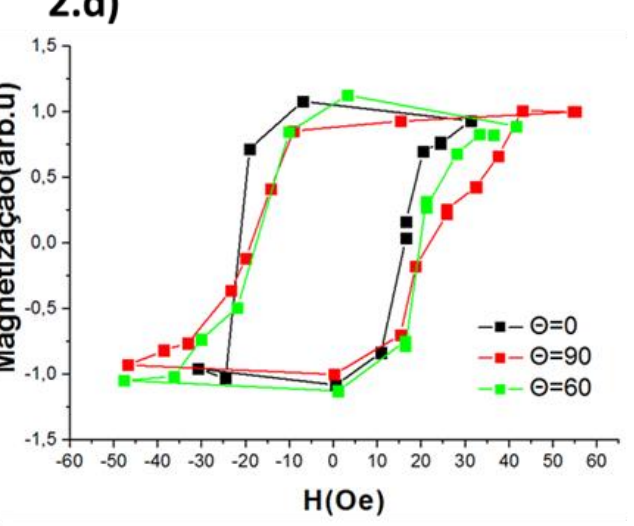

Figura 4-4: Imagens MOKE para objetos de Co, tratados termicamente, para diferentes disposições angulares, onde $\Theta$ é o ângulo formado pelo eixo maior do retângulo e a direção do campo magnético aplicado. Para 1.a) $\left.\theta=0^{\circ}, 1 . b\right) \theta=60^{\circ}$ e 1.c) $\theta=90^{\circ}$. Curvas de histereses obtidas pelas imagens MOKE para diferentes orientações do objeto de Co com respeito a campo magnético 2.a) corresponde a ôngulo de $\Theta=0^{\circ}, 2 . b$ ) corresponde $\mathbf{a} \Theta=$ $\left.60^{\circ}, 2 . c\right) \Theta=90^{\circ}$ e 2.d) mostra as três curvas de histereses juntas.

Os resultados sugerem que se a resolução e os processamentos das imagens forem melhorados, será possível ter um estudo das anisotropias observando as curvas para diferentes ângulos do campo aplicado no objeto. Deste modo se revelaria se as amostras têm anisotropia uniaxial, se se trata de uma anisotropia forte ou fraca, ou de outro tipo.

Por outro lado, as imagens MOKE mostram as configurações da magnetização e podem dar uma ideia da dinâmica dos domínios. Na figura 4-5 e 4-6 se pode ver o estado de remanência nos objetos, este se atingiu por médio de campos magnéticos alternando de direção. No caso dos 
objetos $\mathrm{CoFeSiB}$, figura 4-5, as estruturas são bem definidas, com faixas retangulares, paredes retas de $180^{\circ}$ e $90^{\circ}$, para ambas direções de orientação do objeto, mostrando um caminho regular da magnetização e do fluxo fechado. Isto mostra uma predominante anisotropia de forma para as distintas geometrias. Na figura 4-5 a), se pode ver um objeto sem tratamento térmico, neste a configuração de domínio é de quatro domínios de fechamento. Depois do tratamento térmico com campo $\mathrm{H}$ aplicado na direção perpendicular ao comprimento maior se vê que as estruturas de domínios se direcionam e se orientam seguindo $\mathrm{H}$, figura 4-5 b) e d). Assim se tem no estado de remanência formação de domínios com estruturas serpentadas e domínios de fechamento nas bordas, como se vê na figura 4-5. As figuras c) e d) foram obtidas para melhorar o contraste das figuras b) e d) respectivamente por meio de outro modo de operação, modificando o analisador do microscópio.

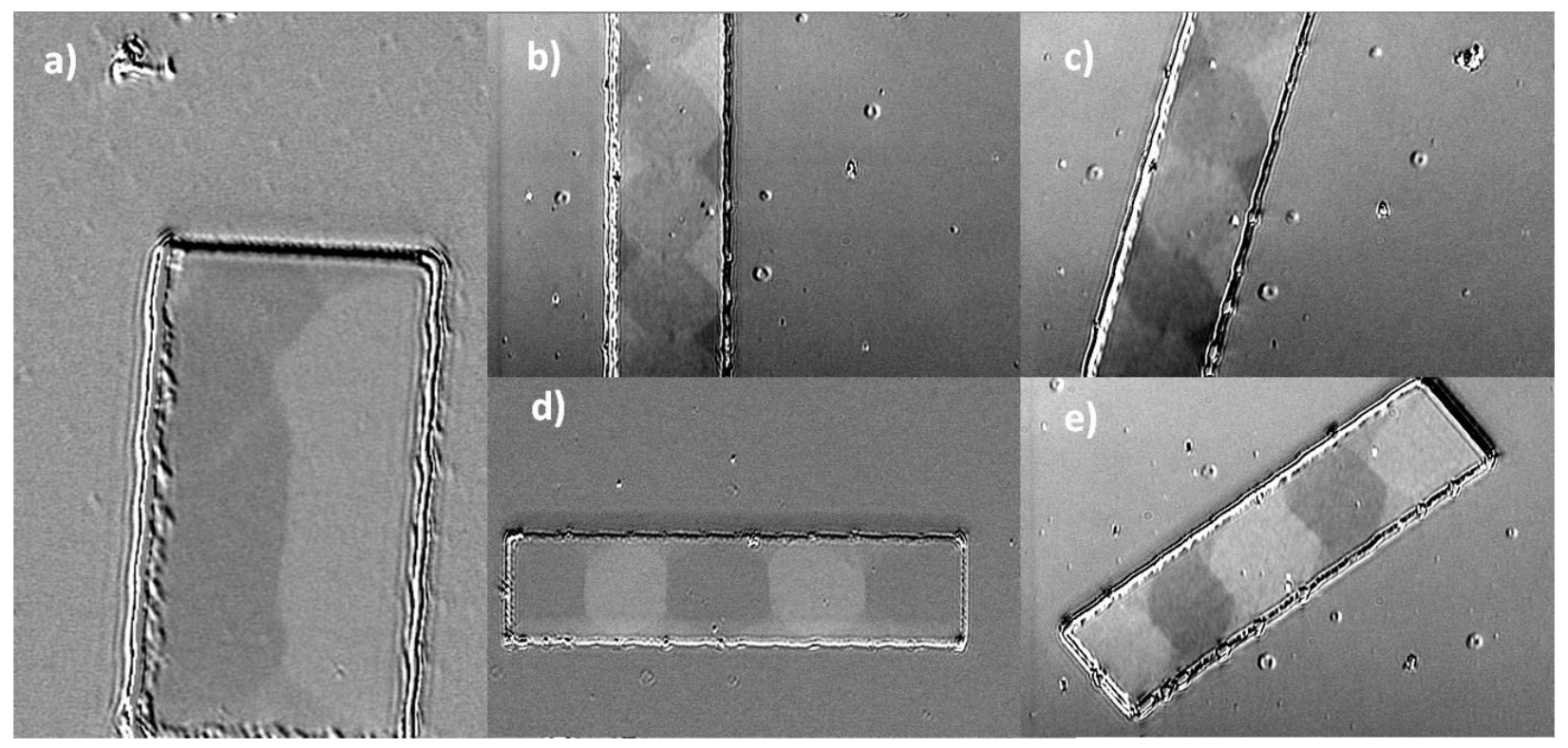

Figura 4-5: Imagem Kerr de objetos retangulares de CoFeSiB onde a) é um estado de remanência antes do tratamento térmico b) e c) são estados de remanência depois do tratamento para quando o campo de desmagnetização foi aplicou na direção vertical, e d) e e) são estados de remanência para quando o campo de desmagnetização foi aplicado na direção perpendicular ao eixo de maior comprimento.

Já no caso do Co cristalino, figura 4-6, a forma das paredes de domínios é desordenada com irregularidade de um processo para outro na hora de deixar na remanência. Estas características diferem do $\mathrm{CoFeSiB}$. Como o Co é um material cristalino, o filme é formado por policristais e se tem anisotropia cristalina e magnetostricção. Os efeitos da magnetostricção são consequência das imperfeições e tensões, quer seja devido a impurezas, inclusões ou aquelas geradas nas bordas, criando pontos de armadilhamento na hora da formação da estrutura de domínios. 
A estrutura de domínios da figura 4-6 a) foi conseguida com um campo $\mathrm{H}$ aplicado em um objeto na direção paralela ao comprimento maior, para desmagnetiza-lo. Esta figura mostra paredes de domínio irregulares, com configurações que mudam de um processo para outro e não um padrão de domínios de fechamento como se esperaria das simulações com essas dimensões. Nestes objetos as impurezas influenciam a magnetização, sendo pontos de ancoragem (pinning) ou barreiras para a reversão da magnetização. Isso se apresenta em maior medida nas regiões das bordas dos objetos. Além disso, também se encontrou que no estado de remanência é possível e muito frequente a formação de um só domínio, isto por causa do baixo campo de desmagnetização da amostra, que não impede ter uma magnetização de um só domínio. Outra disposição da amostra, na figura 4-6 c, mostrou um comportamento similar, a diferença no comportamento de $\mathrm{M}$ vs $\mathrm{H}$ de ambas disposições a) e c) se pode ver em suas curvas de histereses, figuras 4-4 a) e c), respectivamente. As figuras 4-6 b) e d) foram obtidas para melhorar o contraste de a) e c) respectivamente por meio de outro modo de operação, modificando o analisador do microscópio.

Para ambas as disposições das amostras figura 4-6 a) e c), sua dinâmica de domínios com o campo magnético aplicado, mostrou que este tende a nuclear domínios no sitio dos pontos de pinning, que são pontos de nucleação devido aos defeitos na borda dos objetos. Isto é seguido de uma inversão de domínios, por deslocamento de parede de domínio de $180^{\circ}$, conforme se aumenta o campo. Se observa também a formação de paredes de domínio irregulares ondulantes, que são devido ao caráter policristalino do filme, onde cada um de seus grãos tem uma direção de eixo fácil. Assim se tem a energia de interação de troca e a energia magnetostática presentes pela formação de polos em cada grão. A configuração de domínios tende a minimizar ambas as energias, fazendo com que as paredes sejam onduladas. 


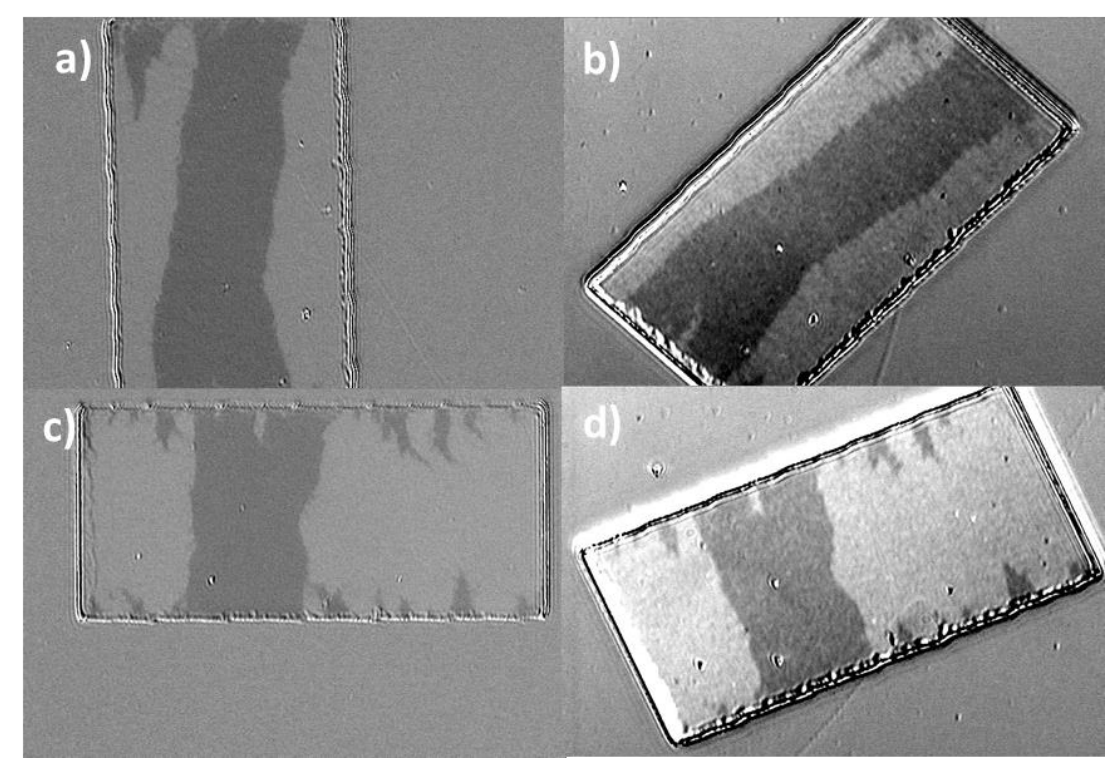

Figura 4-6: Imagem Kerr de objetos retangular de Co onde a) e b) são estados de remanência para quando a amostra ficou com seu eixo maior paralelo ao campo de desmagnetização aplicado, e c) e d) são estados de remanência para quando o campo de desmagnetização foi aplicado na direção perpendicular a o eixo de maior comprimento.

\subsubsection{Estudo das propriedades magnéticas e estruturais do aço elétrico Fe6\% Si}

Se usou a técnica Electron backscattering diffraction (EBSD) e MOKE para o estudo das propriedades microestruturais cristalográficas e magnéticas do aço elétrico de Fe-6\%Si.

A variedade de estruturas de domínios presentes na superfície da amostra pode ser explicada tendo em consideração o balanço das energias envolvidas, o sistema adquire a configuração de menor energia, balanceando todas as possíveis energias [39]. As energias com principal contribuição são a energia de anisotropia magneto-cristalina e energia magnetostática, onde se leva em conta também a influência dos domínios vizinhos.

A energia magneto-cristalina é definida como a energia necessária para magnetizar o cristal em relação a um eixo fácil que no caso do aço elétrico não orientado (NOES) Fe-\%6Si, se encontra na direção (100), e o eixo (111) é quem tem maior energia [39]. A energia de anisotropia é definida por

$$
E_{a}=k_{1}\left(a_{1}^{2} a_{2}^{2}+a_{2}^{2} a_{3}^{2}+a_{3}^{2} a_{1}^{2}\right)+k_{2} a_{1}^{2} a_{2}^{2} a_{3}^{2}
$$

onde $\mathrm{k}_{1}$ e $\mathrm{k}_{2}$ são constantes de anisotropia cúbica e $\mathrm{a}_{1}$, $\mathrm{a}_{2}$ e $\mathrm{a}_{3}$ são cossenos diretores [39]. 
Um conceito empregado para o estudo de domínios magnéticos é a densidade de polos magnéticos [39] relacionada com a energia magnetostática, que por sua vez, é definida como $E_{m}=5.40 * 10^{4} I_{s}^{2} w \sin \beta^{2}$ [39], onde $\beta$ é o ângulo de desvio do eixo principal, que se encontra mais próximo da superfície, $w$ e a largura do domínio e $I$ é uma constante . É possível se estimar que para maiores valores do ângulo $\beta$, os domínios tenderiam a ser mais estreitos e ter uma estrutura mais complexa para poder diminuir a energia. A influência dos grãos vizinhos sobre a estrutura de domínios necessita também ser levada em conta. A densidade de polos magnéticos nas bordas dos grãos é definido por $\omega=I_{S}\left(\cos \theta_{1}-\cos \theta_{2}\right)$ [39], onde $\theta$ é o ângulo entre a magnetização e a normal ao contorno de grão. Quanto maior a diferença entre os ângulos $\theta_{1}$ e $\theta_{2}$, mais a energia magnetostática incrementa na região intergranular, tornando a estrutura de domínios complexa. Por outro lado, para pequenas diferenças se terá uma continuidade da estrutura de domínios através da fronteira entre os grãos [39].

$\mathrm{O}$ aço elétrico de $\mathrm{Fe}-6 \% \mathrm{Si}$ possui excelentes propriedades magnéticas moles, tais como zero magnetostricção, alta permeabilidade magnética, baixa perda de núcleo em transformadores/geradores e possibilidade de trabalhar em altas frequências [40], estas propriedades dependem fortemente da textura [41]. Trabalhamos com aço Fe-6\% Si de espessura de $100 \mu \mathrm{m}$ e com uma direção de laminação paralela à superfície de observação. O material foi cortado e disposto de maneira a poder estudar o lado do corte, onde as tensões mecânicas são mitigadas. A amostra foi embutida em baquelite e em seguida, passou por um processo de polimento, necessário para a observação de domínios. O polimento foi feito com pasta de diamante de $9 \mu \mathrm{m}$ diâmetro, durante 10 minutos; seguido com pasta de $6 \mu \mathrm{m}$, durante 15 minutos; posteriormente com diamante de $3 \mu \mathrm{m}$, durante 9 minutos; diamante de $1 \mu \mathrm{m}$, durante 8 min e finalmente com uma solução de sílica durante $6 \mathrm{~min}$. Depois do polimento foi lavado em ultrassom durante 30 minutos em álcool isopropílico a $30^{\circ} \mathrm{C}$, para remover possíveis resíduos de sílica. A superfície da amostra ficou muito lisa revelando os contornos dos grãos e mantendo pequenos resíduos de sílica. Para a remoção desta silica, se fez uma primeira tentativa de limpeza por meio de remoção pelo plasma de argônio do sistema de Sputtering, durante 10 minutos, com potência de $20 \mathrm{~W}$ e uma segunda durante 40 minutos, a uma potência de $30 \mathrm{~W}$. Com este procedimento, observou-se uma melhora significativa na superfície lisa do aço elétrico, uma diminuição de riscos profundos e remoção de resíduos de sílica, se estabelecendo como uma opção para limpeza de superfície das amostras.

As imagens da técnica de Electron backscatter diffraction (EBSD) foram feitas com step size de $2.5 \mu \mathrm{m}$ e área de varredura de $600 \times 600 \mu \mathrm{m}^{2}$. Vale ressaltar que os pontos de medida são hexagonais com o tamanho determinado pelo step size. Os mapas oferecidos pelo EBSD são de IPF + IQ, ou seja, revelam a orientação dos grãos (IPF) e também a qualidade do padrão de difração no spot de medição (IQ). Neste caso, pontos onde há defeitos (como contornos de grão, deformações ou falhas no polimento) se tornam escuros. A figura 4-7, mostra uma variedade de orientações cristalográficas indo de grão a grão com seu respectivo mapa de cor. Também se marca com linhas claras a região que é correspondente na imagem de domínios da figura 4-9 
para ver a relação entre as orientações cristalográficas e a estrutura de domínios em cada grão da amostra.

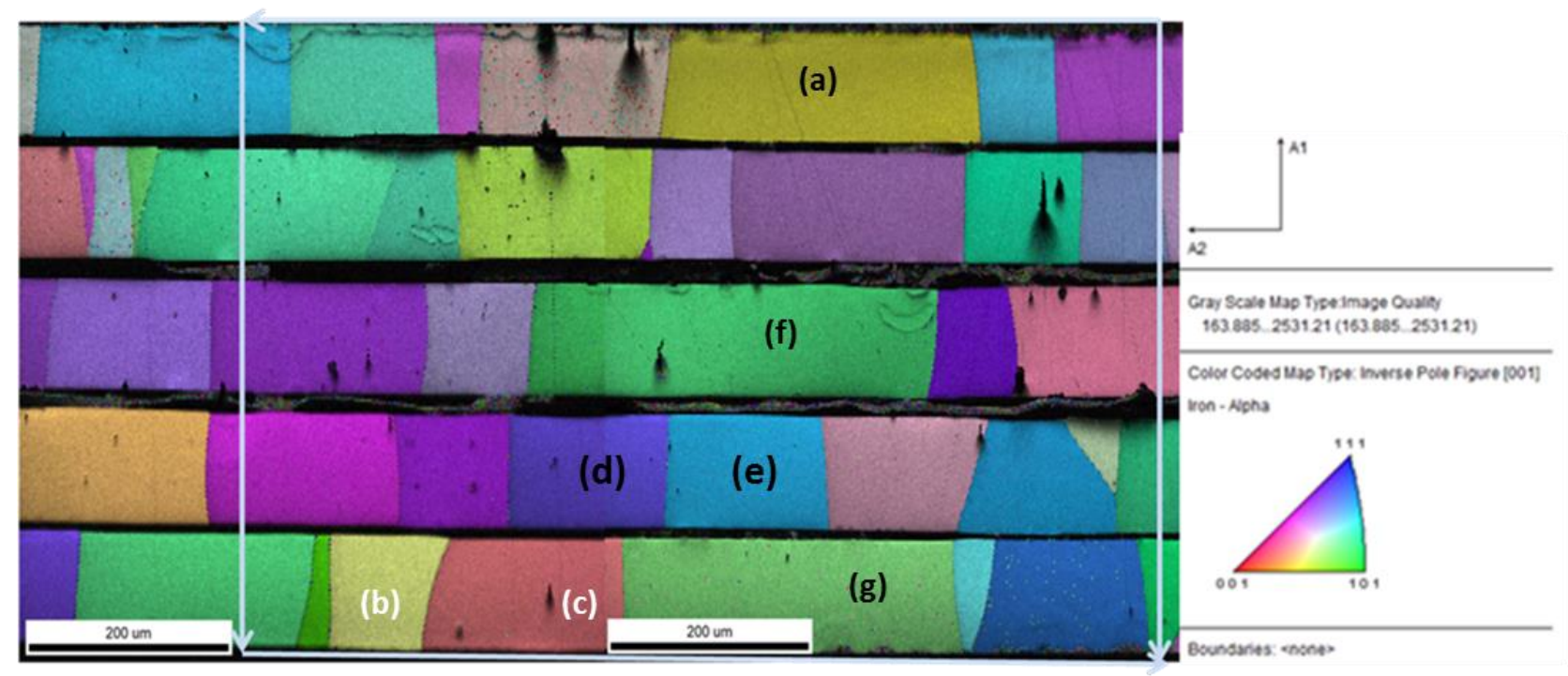

Figura 4-7: Imagem de mapa da orientação do grão IPF (Inverse Pole Figure) obtida pelo EBSD e mapa de cores. $O$ quadro de linha clara marca a região que é correspondente à figura 4-9 das imagens de domínio.

Como se busca a correspondência entre as orientações cristalográficas dos grãos no mapa IPF com a sua respectiva estrutura de domínios, foram feitas observações da estrutura de domínio, através uso do efeito Kerr magneto-ótico.

As imagens Kerr magneto-óticas feitas com o microscópio metalográfico na configuração Kerr longitudinal mostram variedades de estruturas de domínios magnéticas nos diferentes grãos. Os grãos mostrados na superfície são de tamanho variado, limitados pela superfície de laminação e os contornos de grão, marcados pelo processo de polimento, como se vê nas Figuras 4-8, 4-9 e 4-10.

As imagens Kerr magneto-óticas mostram uma variedade de estruturas de domínios entre os diferentes grãos. Na Fig 4-8 o grão (a) tem o plano de observação próximo à direção (100), de seus planos na superfície. Neste caso, a magnetização dos domínios tende a se alinhar na direção de algum eixo fácil principal, devido à anisotropia magnetocristalina. Assim, o eixo pode estar muito próximo à superfície. A estrutura de domínios nesta parte da figura tem uma forma simples, com formas alongadas e largura grande, para minimizar a energia de anisotropia. A mesma estrutura de domínios se observa nos grãos (a), (b) e (c) da figura 4-8, os grãos apresentam texturas próximas ao plano (100) com eixos fáceis muito próximos da superfície da amostra. Na figura 4-8 na parte superior os grãos têm orientações de seus planos próximos à direção (111), com eixos difíceis de magnetização e uma maior densidade de polos magnéticos mostrando uma estrutura de domínios na superfície complexa e ramificada com largura de 
domínios pequena. Esta estrutura é necessária para diminuir a energia magnetostática devido à densidade de polos magnéticos. Os grãos (d) e (e) da figura 4-9 com textura próxima a (111) também apresentam estrutura de domínios complexa.

Na fig. 4-9 os grãos (f) e (g) com orientação próxima a direção (101) apresentam estrutura de domínios intermediária, não tão complexa como se vê no grão (f). Neste caso, os domínios são faixas finas e alongadas com terminação em forma de ponta. No grão (g), há uma estrutura de domínios alongados, mas subdivididos e com larguras pequenas.

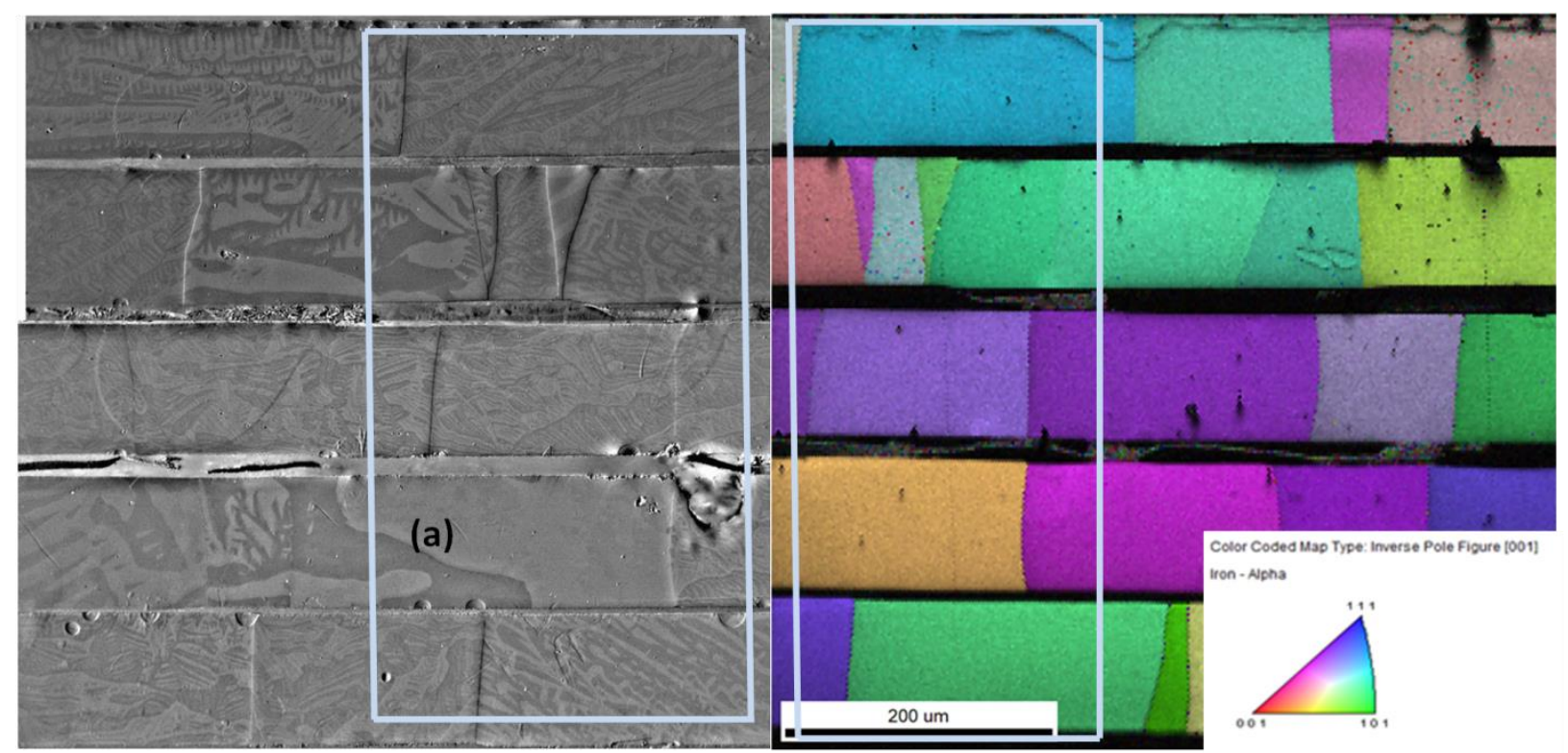

Figura 4-8: Imagem Kerr longitudinal mostrando a estrutura de domínios e imagem (IPF) do EBSD correspondente com seu diagrama de cores. $O$ marco de linha clara relaciona a imagem de domínio com sua imagem de (IPF) na mesma região da superfície da amostra. 


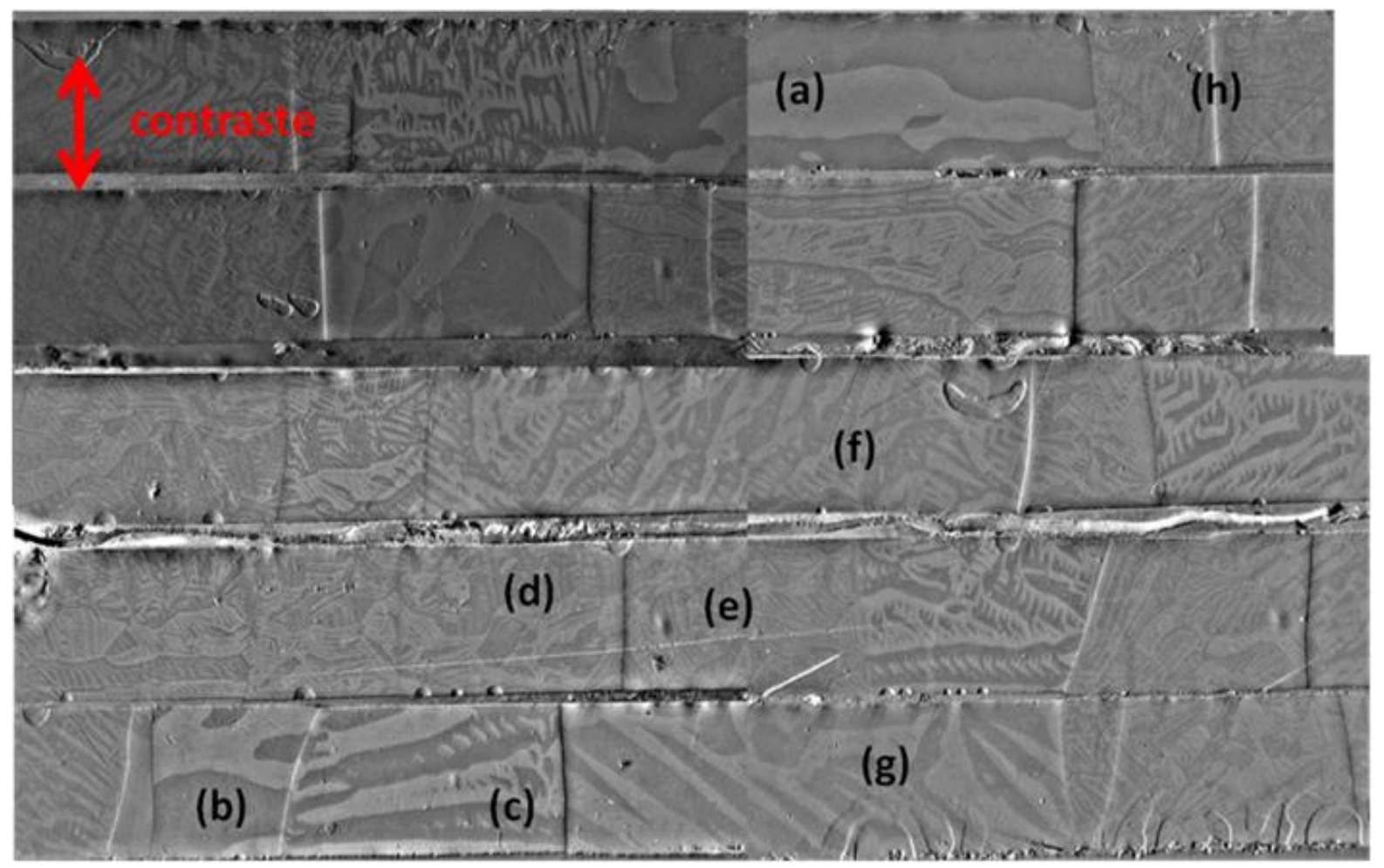

Figura 4-9: Imagem Kerr longitudinal mostrando a estrutura de domínios. Esta imagem apresenta sua correspondência com a figura 4-7.

Na Figura 4-9 se observa uma continuidade dos domínios ao atravessar a fronteira entre os grãos (b) e (c). Esta continuidade é devida aos eixos fácies de magnetização dos grãos vizinhos terem pequena diferença de direção cristalográfica, minimizando os polos magnéticos livres e a energia magnetostática na fronteira. Também na figura 4-9 se pode ver a continuidade de domínios ramificados entre grãos (d) e (e) vizinhos com orientação próxima a (111). No entanto, na figura 4-9, temos também, na fronteira dos grãos (a) e (h) uma mudança brusca de estrutura de domínios, que é devido a uma grande diferença entre os eixos cristalográficos e fáceis de magnetização de cada grão, já que isso gera densidade de polos magnéticos e para diminuir a energia magnetostática os domínios adquirem estruturas complexas.

A Figura 4-10 foi obtida girando-se a amostra de $90^{\circ}$ em relação ao eixo de polarização do microscópio ótico. Esta figura mostra o contraste magneto-ótico para o caso no qual a componente da magnetização observada pelo efeito Kerr fica na direção longitudinal, ao longo das chapas. A forma dos domínios é muito semelhante ao das imagens anteriores, onde o contraste magneto-ótico era mais forte. Isto indica que as componentes perpendiculares ao comprimento das chapas são mais significativas, revelando que os domínios tem forte magnetização na direção perpendicular às chapas do aço elétrico. 
Parece que no processo de fabricação do material há um favorecimento aos grãos que têm uma orientação próxima a direção (111), com estrutura de domínios complexa. Assim, poucos grãos apresentam orientação (100).

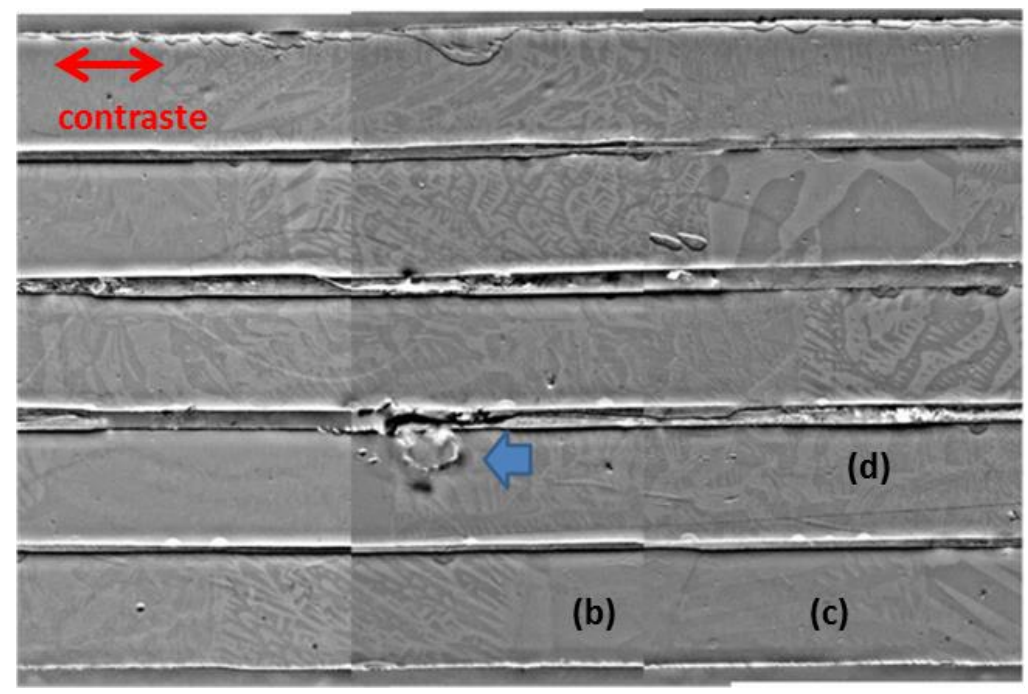

Figura 4-10: Imagem Kerr longitudinal, com contraste magneto-ótico para o caso no qual o contraste mostra a componente de magnetização na direção longitudinal ao plano das chapas. $O$ defeito indicado pela seta, permite a correlação desta imagem com a figura 4-8.

\subsection{Resultado de AFM e MFM}

As imagens de MFM mostraram mais detalhes que outras técnicas, superado as outras quanto a resolução e além disto, confirmaram os perfis de paredes de domínios encontrado nas simulações e resultados analíticos [22-26][28][42-43] feitos em filmes finos.

Foram feitas medidas de AFM e MFM de alta resolução sobre os objetos de distintas geometrias de filmes finos de material de $\mathrm{CoFeSiB}$ e Co de alta resolução, preparados por magnetron sputtering, apresentados no capítulo 3. Para as medidas se empregou um equipamento da marca Bruker com controlador Nanoscope V e software de estabilização de imagens ScanAsyst do Laboratório de Novos Materiais Semicondutores (LNMS) do IF USP, sob a coordenação do Prof. Alain Quivy, que auxiliou nas medidas.

Como ponta sensora, foi usada uma MESP-V2 da Bruker, que é constituída de Si dopado com antimônio e revestida com uma fina camada de Co-Cr. O raio nominal da ponta é de $35 \mathrm{~nm}$. A camada de Co-Cr é um material ferromagnético que atua interagindo magneticamente com a amostra. Antes de fazer as medidas, a ponta foi submetida a um campo magnético vertical de um ímã, para alinhar os momentos magnéticos e dessa forma melhorar as interações durante as medidas. 
As amostras foram deixadas na remanência e as medidas foram feitas em ausência de campo magnético. Usa-se a imagem de fase do MFM por mostrar melhor resolução. As varreduras foram de 512 pontos por linha dando uma boa resolução, com lift de $120 \mathrm{~nm}$. As imagens obtidas foram tratadas com o software WSxM, um software livre com muitas ferramentas para análises, filtrados, etc.

Em seguida, mostraremos as imagens de AFM e MFM sobre os distintos objetos e descreveremos suas características e propriedades.

\section{Elemento em formato de quadrado}

As imagens de AFM sobre o objeto quadrada de CoFeSiB mostra uma superfície lisa com exceção de algumas impurezas no topo e defeitos nas bordas. Estes defeitos são produzidos pelo processo de litografia realizado. Como se fizeram a deposição do $\mathrm{CoFeSiB}$ ou Co sobre uma só camada de resiste sensível, no momento de tirar o resiste, após a deposição do material, o resiste localizado na borda arrasto junto a ele parte do material na borda. Outra consequência do processo de litografia é a formação curvada das bordas do quadrado, já que a precisão da técnica é limitada. Ainda assim um perfil de altura sobre a superfície mostrou uma baixa variação de altura o que demonstra que o processo de deposição foi de boa qualidade e com baixa quantidade de impureza.

Assim, se selecionou a superfície dos objetos, discriminando as bordas para obter alguns parâmetros estatísticos da rugosidade da superfície. As imagens de AFM mostraram superfícies planas. Com o software WSxM se determinou a rugosidade media $\left(R_{m}\right)$ que é definida como o desvio de altura sobre o valor médio de $\bar{z}$ na superfície. O $R_{m}$ é definido como:

$$
R_{m}=\frac{1}{N} \sum_{i=1}^{N}\left|z_{i}-\bar{z}\right|
$$

Onde $z_{i}$ e a altura no ponto i e $N$ é o número total de pontos da imagem. Outro parâmetro importante é a rugosidade média quadrática, definida como a raiz da soma dos quadrados dos desvios de $z_{i}$ com respeito a $\bar{z}$. É uma forma de medir a variação de $\mathrm{z}$ tendo em conta picos e vales na superfície.

$$
R_{r m s}=\sqrt{\frac{1}{N} \sum_{i=1}^{N}\left(z_{i}-\bar{z}\right)^{2}}
$$

Os resultados mostram que para todos os objetos de Co com exceção do anel, a rugosidade média é baixa estando na ordem de $1 \mathrm{~nm}$ e a rugosidade média quadrática $R_{r m s}$ está entorno de $1.5 \mathrm{~nm}$, o que demonstra uma boa qualidade de superfície conseguido pela deposição. Outros parâmetros são mostrados na tabela 3 . 
Tabela 3: Parâmetros morfológicos para a amostra de Co.

\begin{tabular}{|l|l|l|l|l|l|}
\hline & Altura máxima & Altura media & \multicolumn{1}{|c|}{$R_{r m s}$} & $R_{m}$ & $\begin{array}{l}\text { distância } \\
\text { pico- } \\
\text { pico(pp) }\end{array}$ \\
\hline disco & $15 \mathrm{~nm}$ & $0 \mathrm{~nm}$ & $0.9 \mathrm{~nm}$ & $0.6 \mathrm{~nm}$ & $22.8 \mathrm{~nm}$ \\
\hline quadrado & $46,2 \mathrm{~nm}$ & $0 \mathrm{~nm}$ & $1.5 \mathrm{~nm}$ & 0.75 & $60 \mathrm{~nm}$ \\
\hline triangulo & $15 \mathrm{~nm}$ & $0 \mathrm{~nm}$ & $1.2 \mathrm{~nm}$ & $0.81 \mathrm{~nm}$ & $22.1 \mathrm{~nm}$ \\
\hline
\end{tabular}

A figura 4.11 apresenta resultados de medidas de MFM para um objeto quadrado com dimensões laterais de $10 \mu \mathrm{m}$. O perfil de altura feito sobre a imagem topográfica de AFM do quadrado revela uma altura em torno de $55 \mathrm{~nm}$, a mesma altura foi encontrada para os outros elementos, o que é esperado por ser o mesmo processo de deposição. Já a imagem magnética obtida no modo MFM do quadrado no estado de remanência mostrado da figura 4-11b revela linhas de contraste (claro e escuro a cada lado das linhas que passam pela diagonal), estas linhas estão associadas a paredes de domínios de tipo Néel de $90^{\circ}$. Pode-se inferir uma estrutura de quatro domínios com um fluxo de magnetização de fechamento. A Figura $4.11 \mathrm{c}$, obtida por simulação numérica, também mostra um esquema da direção da magnetização em cada domínio. Esta estrutura é de se esperar neste material magneticamente mole, onde os domínios de fechamento se formam para diminuir os polos livres e assim também diminuir a energia magnetostática associada. A estrutura magnética está dominada pela anisotropia de forma, o que é próprio de um material magneticamente mole.

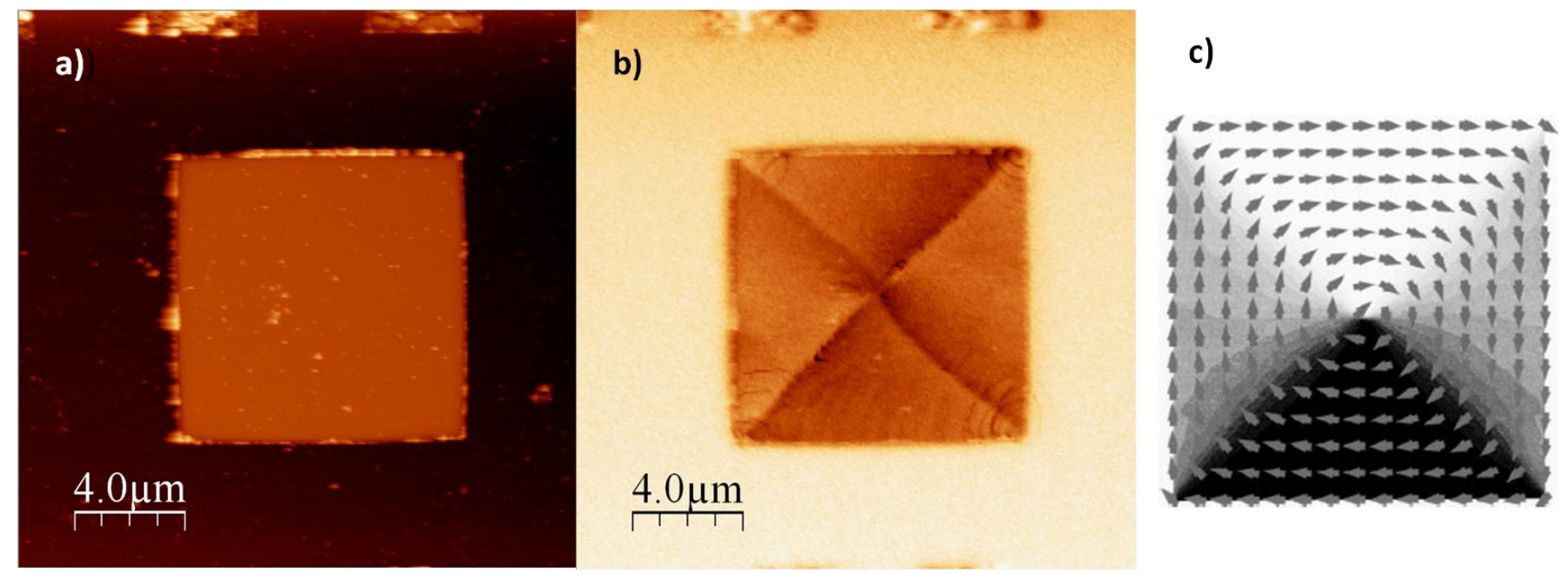

Figura 4-11: Elemento quadrado de CoFeSiB a) imagem topográfica, b) imagem de MFM c) esquema de micromagnetização obtido por simulação numérica.

Outra característica da imagem de MFM que tem diferença com o caso ideal visto em Figura 4-11(c) é a leve curvatura presente ao longo das paredes visto na Figura 4-11 (b), onde pode se ver que as paredes se curvam para o lado claro da linha da parede. A presença disto se 
deve à perturbação da ponta sobre a amostra, como foi analisado nos trabalhos [44][45] visto para o caso de materiais magneticamente moles e sonda de pontas rígidas e magneticamente imperturbáveis. Nestes casos o campo magnético da ponta interage com a amostra localmente, perturbando a magnetização da amostra. Assim a força de interação experimentada pela sonda se deve a magnetização da própria amostra, como também ao efeito induzido pelo campo da ponta sobre esta. $\mathrm{O}$ efeito se pode ver como segue, quando a ponta se aproxima de um domínio, esta induz uma carga magnética sobre o material mole. Se a ponta se aproxima de uma parede, a carga induzida na amostra interage com a estrutura da parede, fazendo que a parede se curve como se mostra na imagem de MFM. A parede do tipo Néel, pode ser vista como um conjunto de dois planos de cargas opostas, sobre seus lados.

Enquanto para o material amorfo, mole magneticamente, de $\mathrm{CoFeSiB}$, os domínios são determinados pela anisotropia de forma, para o $\mathrm{Co}$, devemos considerar sua anisotropia magnetocristalina e magnetostricção. Estas propriedades fazem uma diferença na configuração dos domínios observados, como se verá em seguida.

Na figura 4-12 temos a imagem topográfica de um objeto quadrado de Co de 10x10 $\mu \mathrm{m}^{2}$, um perfil de altura do objeto revela um valor de $85 \mathrm{~nm}$ de espessura, mostra também uma superfície muito lisa e uniforme com a exceção de algumas impurezas, porém não atrapalharam o resultado da imagem de MFM. Como imagem de MFM, se escolheu a imagem do sinal de fase por ter menor ruído e artefatos. É sabido que é preferível uma superfície sem impurezas já que estas introduzem um erro local de altura na amostra que provoca erros locais na medida do strayfield. Mostra-se também a correspondente imagem de MFM na figura 4-12c, mostrando uma estrutura complexa de domínios e com tipos de paredes diferentes daquelas na figura 4-11b.

Já que o MFM somente pode registrar o stray-field, mediante a interação entre a sonda magnética usada e o gradiente de campo nas componentes perpendiculares do stray-field na amostra. Se tem relatado nos trabalhos de [42][43] que para uma melhor interpretação das imagens de MFM, se acompanha com outros tipos de imagem como imagem Kerr, ou de Lorentz para poder reconstruir a distribuição de magnetização e ter confiabilidade nos resultados. No caso do quadrado, a análise dos resultados das imagens MFM se apoiaram nas conclusões de [22][23] e simulações que serão vistas na secção 4.4. Antes de fazer uma análise sobre esta estrutura de domínios do MFM, se verá o que acontece numa estrutura ideal, magneticamente mole, com nenhum defeito e livre de tensões que podem induzir anisotropia. Assim a estrutura de domínio em estado de remanência do objeto idealmente mole com formato quadrado dessas dimensões $(10 \mu \mathrm{m} \times 10 \mu \mathrm{m})$ estará governada por uma estrutura de fechamento de quatro domínios com paredes de $90^{\circ}$. A estrutura resultante é um balanço entre a energia de troca e a energia magnetostática, esta última é devido ao campo de desmagnetização ou de forma, assim a configuração magnética está governada pela anisotropia de forma. Nesta estrutura ideal, vista na Figura 4-13a, as paredes de domínios para tal espessura do filme são paredes de tipo Néel de $90^{\circ}$ e possuem um vórtice no centro do quadrado. Na figura 4-13b se mostra a imagem MFM com uma possível direção de magnetização dos domínios, se vê também a configuração complexa de 
domínios na remanência, depois de ter sido desmagnetizado com campo alternado. Então, a imagem pode se ver como uma inclusão, sobre uma estrutura de fechamento figura 4-13 a), de uma parede de domínio vertical e curvada no lado direito, dentro do quadrado e outra no centro. Isto pode ser devido a presença de uma anisotropia uniaxial nessa direção. Esta presença de anisotropia local também pode ser responsável pela existência da parede de domínio de tipo cross-tie que se vê com baixa resolução da figura 4-13. Assim o padrão dessa parede faz correspondência com uma parede tipo cross-tie, identificada e vista nos resultados de [22][23] entre imagem MFM e diagramas de resultados analítico e simulações correspondentes [26, 4647]. Na figura 4-14 se vê um diagrama de cross-tie correspondente a imagem de MFM, onde se pode ver que este tipo de parede apresenta contrastes claros e escuros ao longo da parede vertical, com respeito a folha.
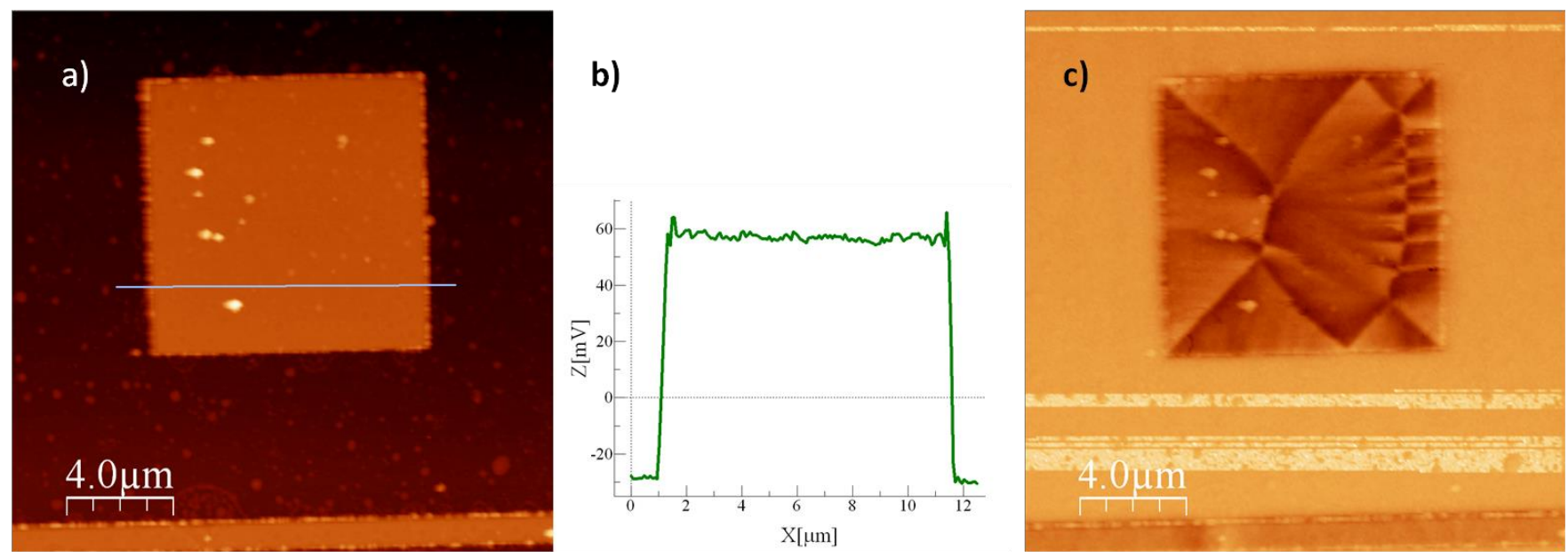

Figura 4-12: a) imagem topográfica por AFM de um objeto de Co de $10 \mu \mathrm{m}$ x10 $\mu \mathrm{m}$, b) perfil de altura da imagem topográfica de a) mostra um valor de $85 \mathrm{~nm}$ de altura, c) Imagem de fase por MFM do objeto de Co. 

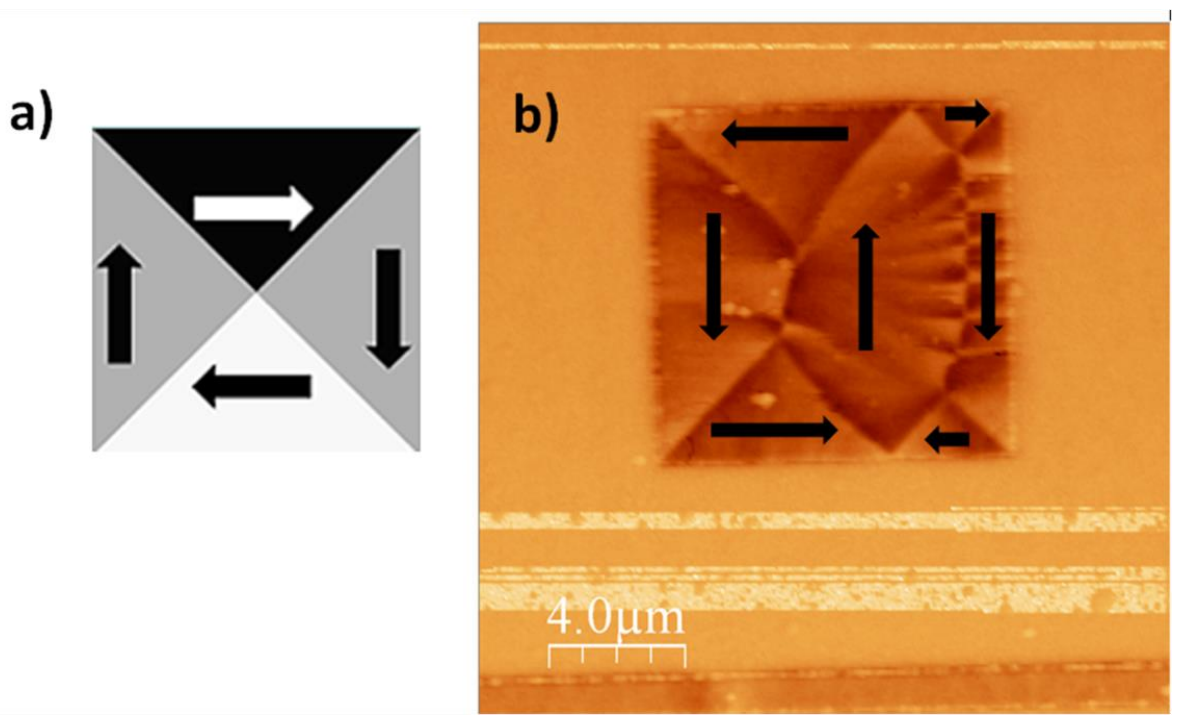

Figura 4-13: a) estrutura de domínio ideal de 4 domínios de fechamento de um elemento quadrado b) imagem de MFM mostrando uma estrutura de domínio complexo, onde as setas indicam possível direções de magnetização dos domínios.

O contraste claro e escuro na parede de cross-tie é devido à força de atração e repulsão experimentada pela ponta da sonda metálica do MFM. Porém o sistema não foi perturbado consideravelmente pelo campo da ponta e se mostrou que o sinal atrativo é mais forte que o sinal repulsivo, isto se pode ver na intensidade na área relativamente maior da cor clara com respeito ao escuro e no perfil de altura na Figura 4-15. Então na figura 4-13 se mostra a imagem de MFM e um esquema proposto da configuração da magnetização. As setas indicam uma possível direção de magnetização dos domínios, mostrando um fechamento do fluxo de magnetização. Também se vê romboédros localizados na parede vertical (com repeito a folha) e ressaltados na Figura 4-14, são modelos de cross-tie dentro das paredes. Um só cross-tie visto no MFM está formado de 4 segmentos: escuro e branco em cada lado da parede e com contraste invertido com respeito a parede.

Quando se faz a correspondência entre o modelo de cross-tie e o cross-tie visto no MFM se localiza as paredes transversais AB e CD chamada de linha de Bloch. Cada ponto crosstie é localizado no centro do romboédro, onde dois segmentos claros e escuros se unem. Os pontos de vórtice se localizam entre dois pontos cross-tie a uma distância equidistante. No MFM se observa uma alteração na simetria do cross-tie com respeito a diagonal menor dos romboédros, esta diferença nos comprimentos de um romboédro ao outro pode se dever ao processo de desmagnetização do objeto. Também se viu que as linhas de Bloch foram estáveis sob a influência do campo magnético da ponta. 

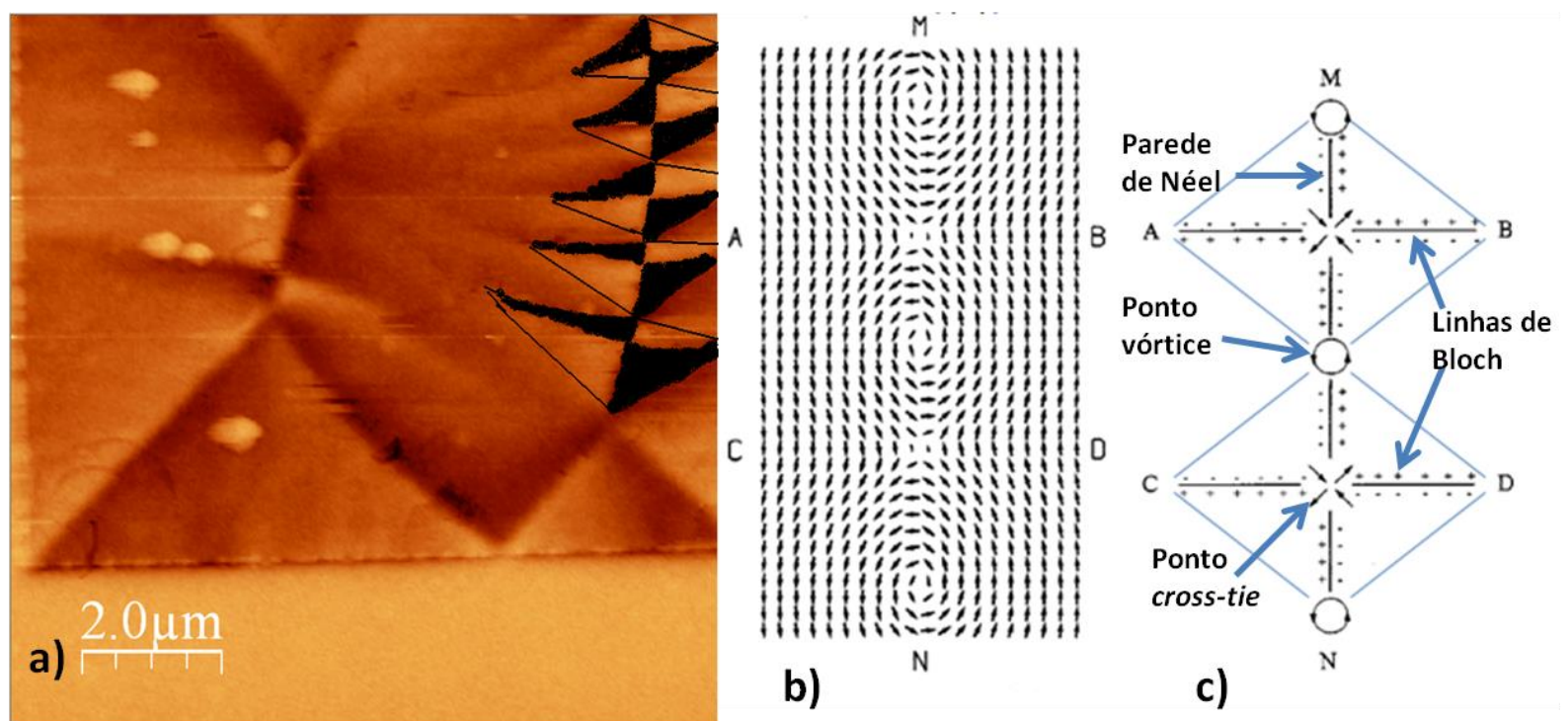

Figura 4-14: a) imagem de MFM com o esquema da estrutura da parede de cross-tie, b) imagem representativa da distribuição de vetores de magnetização em uma parede de cross-tie [26], c) imagem da distribuição de carga magnética em uma parede de cross-tie [26].

Para poder entender o contraste observado pelo MFM na parede se faz uma descrição da interação entre o campo da ponta e a amostra. Para isso se pode ver no diagrama figura 4-14 b) e c)[42] a distribuição dos vetores de magnetização e da carga magnética. Na região afastada da parede principal, segmento $\mathrm{MN}$, a magnetização se mantém paralela ao atravessar transversalmente as linhas de Bloch, enquanto que na região mais perto à parede transversal e ponto cross-tie, a magnetização mostra uma mudança progressiva na sua direção, ao atravessar as linhas de Bloch, até chegar a formar o ponto cross-tie, esta mudança na magnetização é própria de uma parede Néel, então na região de variação de magnetização como se menciona em [22] se pode ver como um lugar de densidade de carga magnética $\rho_{\text {mag }}$, onde a carga magnética está associada à divergência da magnetização, $\quad \rho_{\text {mag }}=\nabla$. M . Os sítios onde se apresenta concentração de carga são: na parede de Néel de $90^{\circ}$, na parede principal e nas regiões próximas a linha de Bloch do cross-tie (x), esta carga surge do fluxo de Néel [23] no núcleo da parede, eles são cancelados pela magnetização vizinha mais distante do centro da parede. Enquanto que na região do vórtice a variação da magnetização cai rapidamente ao afastar-se da parede principal. Levando em consideração essa distribuição de carga, pode-se entender o contraste visto nas imagens. As cargas geram fluxo fechado entre o positivo e o negativo e produzem um stray-field com uma forte componente normal ao plano do filme de Co, o qual é detectado pela ponta magnética do MFM. Então, o resultado da interação da ponta, que foi magnetizada na direção z, e o stray-field produz o contraste claro e escuro na imagem MFM.

Na Figura 4-15 se pode ver os perfis de nível de sinal das linhas azuis indicadas na imagem de MFM. Como a ponta do MFM está magnetização verticalmente, isto tem um efeito sobre a medida dos campos, embora a perturbação gerada pela ponta situada a uma distância de 
$120 \mathrm{~nm}$ sobre a amostra não afeita significativamente os resultados. A ponta magnetizada durante a varredura gera uma distribuição de carga magnética que faz que o campo de atração seja um pouco maior que o campo de repulsão isto pode se ver no perfil de sinal na fronteira entre domínios.

O perfil A e B mostra uma leve mudança da intensidade ao atravessar a parede de Néel de $90^{\circ}$, o comprimento da transição se estimou desde um ponto profundo até o pico, dando o valor de $260 \mathrm{~nm}$, aproximadamente. O perfil de força é associado com a distribuição de densidade de carga magnética, e se pode considerar a parede de Néel $90^{\circ}$ como uma capa dipolar com a espessura de $260 \mathrm{~nm}$. Os segmentos C e D que atravessam a parede principal do cross-tie, também mostram uma distribuição de carga similar.
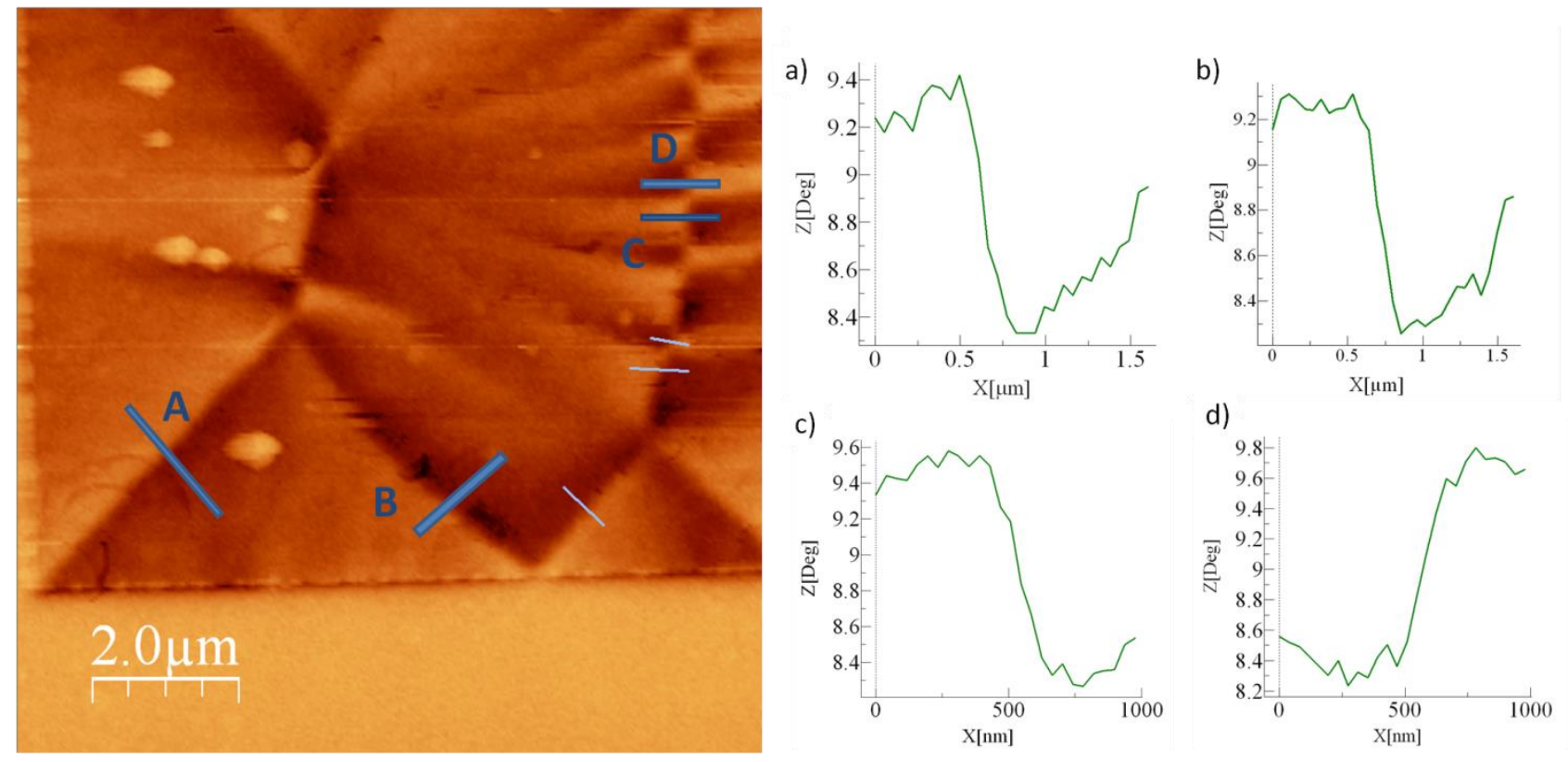

Figura 4-15: Imagem MFM com traços que mostram perfis de nível de sinal onde a)
corresponde ao segmento A na imagem, b) ao segmento $B$, c) a o C e d) a o segmento D.

Em termos de energia total a configuração de domínios que se forma na superfície do objeto de Co é como segue: Na região das diagonais do objeto e favorável a formação de paredes de Néel de $90^{\circ}$ por ter menor custo de energia, evitando polos livres e fechando com fluxo de magnetização na borda. Enquanto que na região central do objeto (com respeito a folha) parede de tipo cross-tie, por requerer menor energia para se formar, é preferido em vez de uma parede de Néel de $180^{\circ}$. Na parede vertical localizado na esquerda se forma um só um ponto de cross-tie (ou antivortice) e na parede vertical da direita se forma uma cadeia de vórtices e antivortices com mudanças livres em sua periodicidade. Esta mudança no comprimento da sua periodicidade é devido a perturbações em seu entorno em comparação com um cross-tie periódico, com um comportamento regular, visto em filmes finos e em simulações que assumem não limitação nos extremos, ou seja, sem efeito de bordas. Então as flutuações locais da anisotropia, induzida 
possivelmente pelo estresse formado durante a deposição do filme faz que se formem aquelas paredes verticais, e estas paredes preferem o formato cross-tie por custar menor energia que a parede de Néel de $180^{\circ}$.

O custo de energia para formar uma parede cross-tie resulta ser mais favorável que para Néel de $180^{\circ}$, isto se deve principalmente ao termo de energia magnestostática [23] que tende a aumentar com o aumento da espessura de filme. No gráfico da energia da Figura 2-4 se vê a distribuição da densidade de energia ao longo da parede de cross-tie (eixo principal), esta distribuição não resulta ser uniformo, mostrando um aumento muito grande perto região de um ponto cross-tie em comparação com o caso da parede de Néel, onde se vê uma distribuição uniforme, e uma diminuição da densidade de energia no centro e entorno de um vórtice. Assim a formação da parede de cross-tie se deve principalmente a um menor custo na formação do ponto de vórtice.

\section{Elemento em formato de disco}

O objeto com forma de disco, não apresenta uma configuração magnética fácil de predizer. Nos estudos da magnetização deste elemento foram encontradas configurações distintas em seu estado magnético de remanência [46]. O estado fundamental nas dimensões tratadas de $10 \mu \mathrm{m}$ não resulta ser um estado magnético uniforme, e se requer calcular a energia magnetostática nas bordas do disco, tendo o inconveniente de gerar singularidades no potencial magnético [46].

Entre as características desta geometria se tem que quando o tamanho do disco incrementa, incrementa também a energia magnetostática (linearmente com a espessura e com o diâmetro) [47][48]. Nos estudos e resultados obtidos das simulações e observações experimentais deste elemento em materiais magnéticos moles como o permalloy [46] mostram que o estado de vórtice resulta ser o estado de menor energia (estado fundamental) na remanência. Além do estado de vórtice, também se observaram e estudaram outros estados de baixa energia como o estado C, S descritos na referência [46]. A formação destes estados dependerá do processo de desmagnetização como de possíveis defeitos, ou impurezas que fixem tais estados. Foram relatados também estados metaestáveis, como o estado triângulo e o diamante [46]. O estado triângulo se caracteriza por ter dois vórtices localizados na borda, e o estado diamante é formado por dois vórtices dentro do disco. Porém, eles não resultam ser estados de mínima energia, como o estado vórtice. Estes estados podem ser nucleados no processo de relaxação de magnetização do estado saturado ao diminuir o campo aplicado. Na Figura 4-16 pode se ver à configuração de magnetização de diferentes estados, possíveis. 


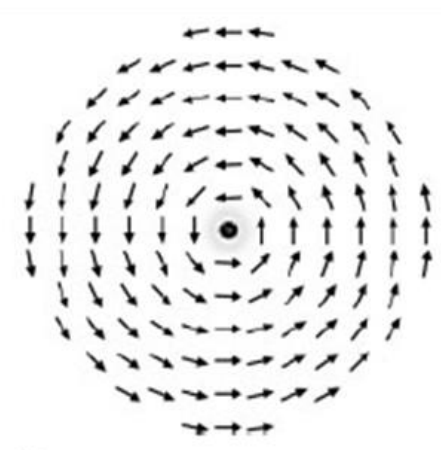

(a)

Figura 4-16: Esquema de magnetização dos estados magnéticos no elemento de disco: estado vórtice (a) estado diamante (b) e estado triângulo (c)[46]

Voltando ao estado vórtice, este é o estado fundamental e se caracteriza por ter os vetores de magnetização em uma distribuição circular, possuindo um vórtice no centro (zona de singularidade). No lugar do núcleo, devido ao custo de energia para girar os spins, a magnetização está fora do plano. O custo de energia magnetostática determinará o tamanho do núcleo [48]. Um esquema da distribuição dos vetores de magnetização no estado vórtice se pode ver na Figura 4-16a). Os vetores de micromagnetização giram em sentido horária ou anti-horário dependendo da história de sua magnetização, com respeito ao centro do disco, enquanto no centro os vetores são perpendiculares ao plano do disco. No caso de materiais com anisotropia cristalina, ou anisotropia uniaxial. Estas propriedades podem influenciar na configuração magnética do disco, seu efeito distorce o caso isotrópico formando configurações complexas. Como por exemplo, no caso de um disco de Co FCC epitaxial, que pode ser visto em [47] se observa na região central, a formação de uma estrutura de quatro domínios de fechamento, próprio de uma anisotropia cúbica. Enquanto que na adjacência da circunferência se observa uma configuração de estado vórtice. Assim, a configuração da magnetização do disco é um resultado entre o balanço das energias de troca e magnetostática, afetada pelas restrições geométricas do disco.

Nas Figuras 4-17 e 4-18, pode se ver as imagens topográficas e por MFM dos objetos com forma de disco, de CoFeSiB e Co. Estas, revelam uma altura de $55 \mathrm{~nm}$ para CoFeSiB e de $75 \mathrm{~nm}$ para o Co e diâmetro entorno de $10 \mu \mathrm{m}$. Baseado na teoria encontrada na literatura se pretende interpretar as imagens de MFM. Já que a técnica só pode mostrar componentes perpendiculares de stray Field ao plano do filme, lugar onde diverge a magnetização e com alta densidade de carga magnética. Então a imagem de MFM da amostra de CoFeSiB mostra uma pequena região escura no centro do disco, esta região escura é correspondente a um vórtice, que é um ponto de divergência da magnetização. A imagem revela o estado vórtice que é o estado magnético de energia mínima presente para geometria de disco. O objeto de CoFeSiB apresenta uma estrutura de tipo vórtice, e é de esperar que esta amostra não presente efeito de anisotropia induzida pelo estresse, já que é uma a amostra muito mole magneticamente e de baixa 
magnetostricção. Ou seja, o efeito devido às tensões durante a formação do objeto não geram anisotropia local magnética no objeto.

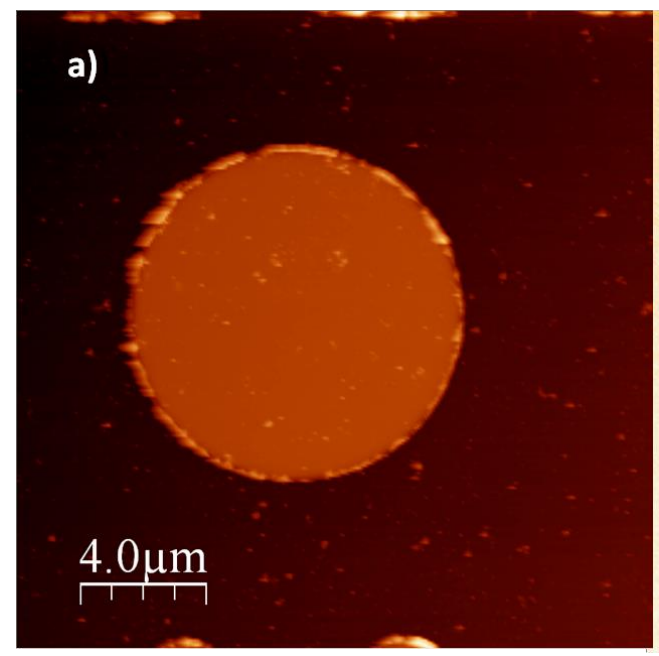

b)

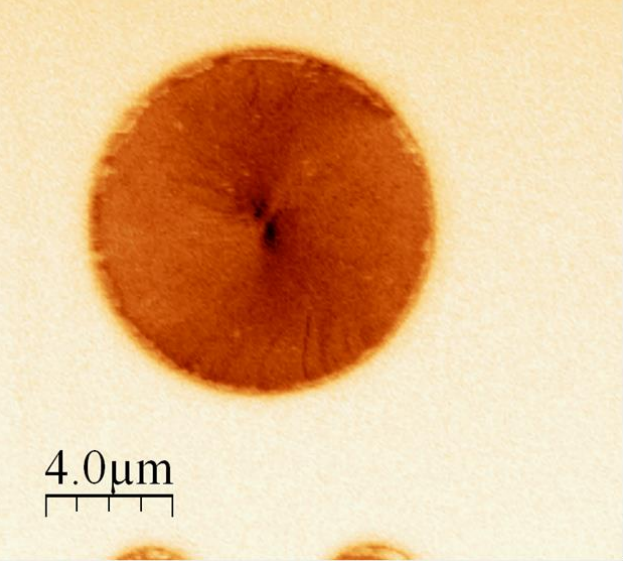

Figura 4-17: Imagens de objeto circular de CoFeSiB: (a) imagem topográfica e (b) imagem MFM correspondente.

No caso do disco de Co, sua imagem de MFM resulta ser complexa, Figura 4-18. O estado de remanência visto no MFM mostra duas linhas de contrastes que separa duas regiões. Estas linhas são interpretadas como paredes de domínios, uma se localiza na região de separação entre o segundo e tecer quadrante do círculo passando muito perto do centro do disco. Esta linha se refere a uma parede de domínio que passa de clara para escura, da parte superior para a inferior. A outra linha passa de clara para escura na região inferior onde a parede é vertical e curvada. Vê-se no centro do círculo, que os contrastes das paredes se invertem. Também se vê pequenas manchas de contraste na borda da região do terceiro quadrante do disco. Estas manchas podem ser os riples de magnetização, que estão presentes em amostras com irregularidades como as policristalinas. As diferenças encontradas da configuração magnética entre estes dois materiais se devem ao fato que o Co é um material cristalino com anisotropia magnética e magnetostricção.

As linhas curvadas com contraste são paredes de domínios separando duas claras regiões, isto mostra um distanciamento do estado vórtice ou outro estado esperado pela teoria. Uma possibilidade para a interpretação desta imagem seria a magnetização em cada região girar em sentidos contrários Figura 4-18 d), mas neste caso haveria a formação de fortes polos magnéticos livres. Outra possibilidade seria que a magnetização siga um sentido circular com mudanças bruscas de direção da magnetização nas paredes como se vê na Figura 4-18c), sendo esta parede de tipo Néel. Esta alternativa parece mais aceitável, mas por não ser uma configuração padrão, não é possível defini-la completamente. 


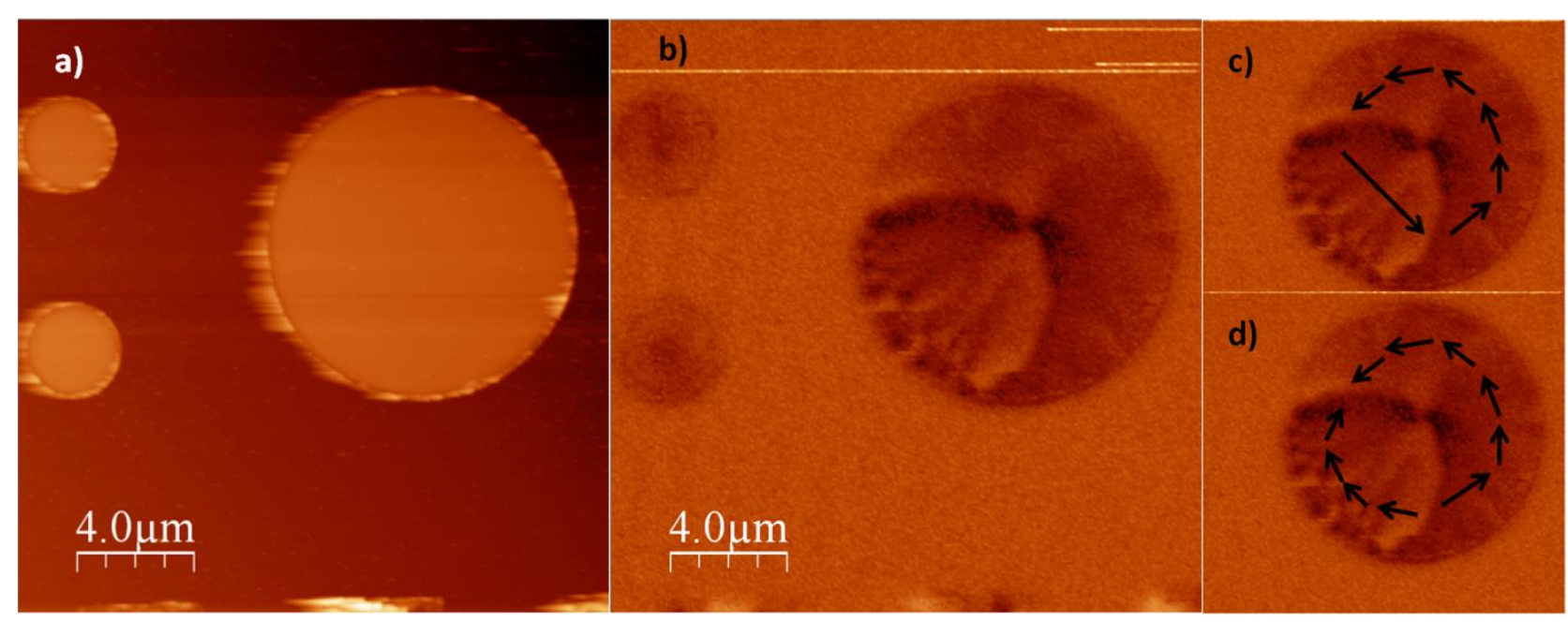

Figura 4-18: Imagens de objeto circular de Co: a) imagem topográfica $\left(20 \times 20 \mathrm{~mm}^{2}\right)$, b) imagem MFM correspondente, c) e d) mostra possíveis direções da magnetização.

\section{Elemento em formato de anel}

Neste objeto, a configuração de magnetização é resultado do balance entre a energia magnetostática e a energia de troca. Na literatura [48] [49] tem se encontrado observações experimentais e resultados numéricos para material magnético mole (permalloy) nos estados de menor energia, que são o estado vórtice e o estado de cebola [49]. Na Figura 4-19 (a)se pode ver os estados vórtice e cebola. No estado de vórtice de um anel, o custo de energia resulta ser mais baixo que no elemento de disco devido a não existência do núcleo do vórtice, que é energeticamente custoso. O estado de cebola, estado metaestável, é um estado de alta remanência. Neste estado a magnetização em cada lado da metade do anel tem sentidos opostos. No caso do estado cebola se podem apresentar dois tipos de paredes. Parede de tipo vórtice e transversal, Figura 4-19 b) e C), separando as duas regiões de magnetização opostas. A parede a se formar depende da energia. Assim, a energia de troca favorecerá uma magnetização uniforme, formando paredes de domínio transversal, enquanto que a energia magnetostática favorecerá um fluxo fechado e a aparição de paredes do tipo vórtice. 


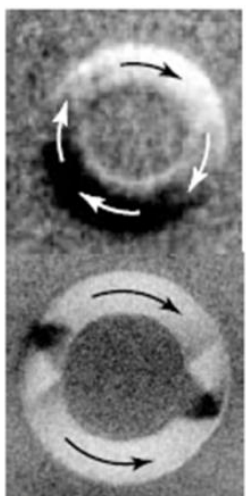

(a)

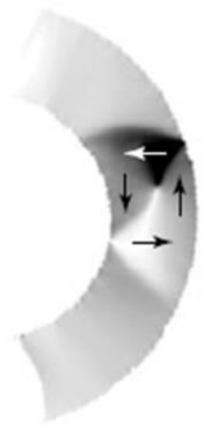

(b)

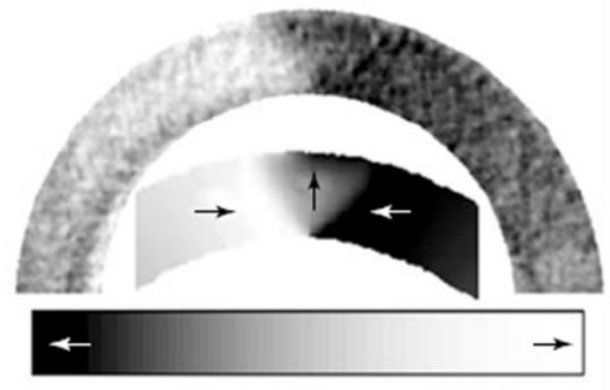

(c)

Figura 4-19: a) Estado vórtice na parte de acima, esta cebola na parte de baixo, b) detalhes de uma parede vórtice num policristal de $\mathrm{Co}$, c) detalhes de uma parede transversal [49].

Considerando as dimensões geométricas do anel, o caso da parede de tipo vórtice está presente quando o objeto anel tem uma espessura e largura grande, que favorece a preponderância da energia magnetostática. No caso de filme muito fino e largura estreita a parede a se formar é de tipo transversal [48].

$\mathrm{O}$ anel de $\mathrm{CoFeSiB}$ visto na Figura 4-20 mostra uma topografia com impurezas do resiste nas suas bordas que se estende sobre a superfície e atrapalha o sinal de MFM, esta dificuldade como se mencionou se deve ao fato de ter sido usado só uma camada de resiste. A partir da imagem de AFM, fez-se um perfil de altura, que revelou as dimensões de $55 \mathrm{~nm}$ de espessura para $\mathrm{CoFeSiB}$ e de $75 \mathrm{~nm}$ para o $\mathrm{Co}$, diâmetro de $10 \mu \mathrm{m}$, e uma largura do anel de 2.16 $\mu \mathrm{m}$, aproximadamente. Como a espessura e a largura do anel são relativamente grandes, se esperaria um estado de tipo vórtice. Por outro lado na imagem de MFM se podem ver faixas escuras fracas que cruzam o anel, mas elas podem ser devidas a rugosidade e impurezas do resiste na borda do objeto, que não foram removidas durante o processo de revelação. Visto isto, se pode dizer que devido ao material ter baixa magnetostricção, o estresse não produz efeitos significativos, assim a configuração de domínio do anel é um estado vórtice. 


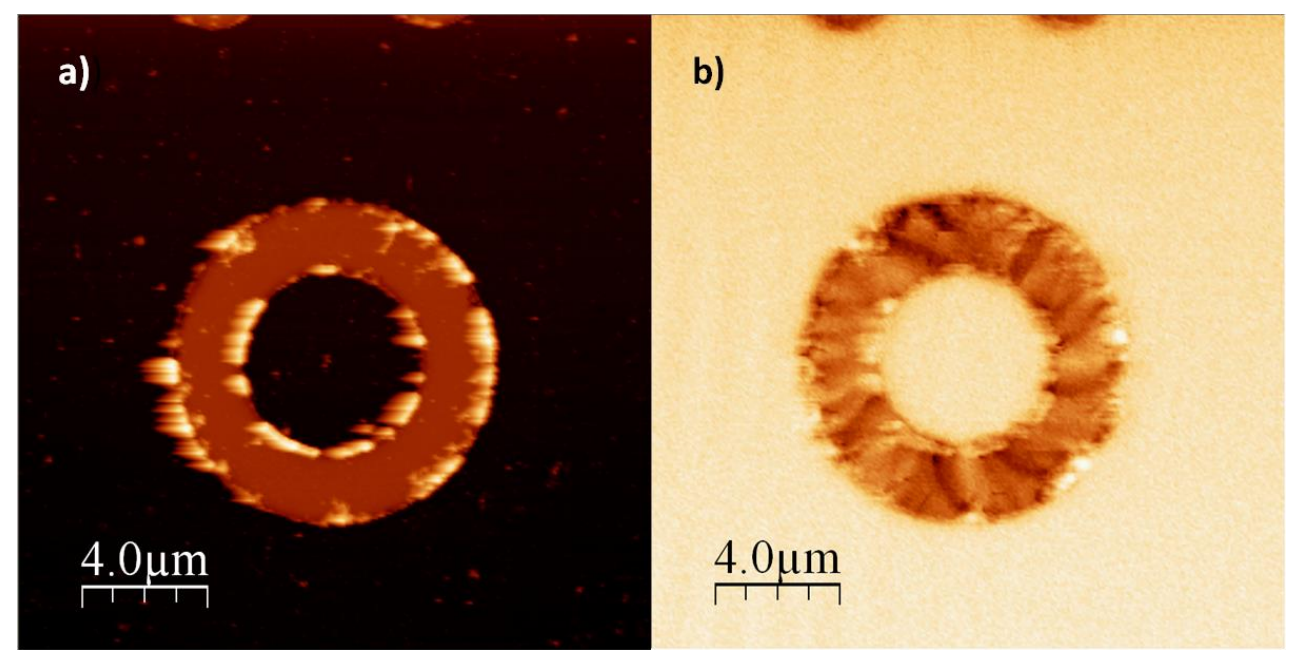

Figura 4-20: Imagens do elemento de anel de CoFeBSi a) imagem topográfica e b) imagem de MFM .

O anel de material de Co visto na Figura 4-21 também apresenta perturbações devidas aos defeitos e impurezas nas bordas do objeto, que também afetam a tomada de dados pela sonda durante a varredura. Como o cobalto tem magnetostricção alta, este é sensível a tensão residual e consequentemente a magnetização local é perturbada. A imagem de MFM revela com pouca resolução uma estrutura magnética de faixas alternadas em sequência, ao longo do anel. Pode se tratar de domínios retangulares compridos na direção radial. Uma possibilidade é que o cobalto com anisotropia cristalina uniaxial e possivelmente com anisotropia induzida pelas tensões nas bordas pode estar definindo uma anisotropia radial, isto faria com que uma sequência de faixas de domínios se formasse ao longo da circunferência do anel. Outra possibilidade é que a magnetização tenda a ter sentido circular, mas com mudanças abruptas ao passar de uma faixa a outra. 


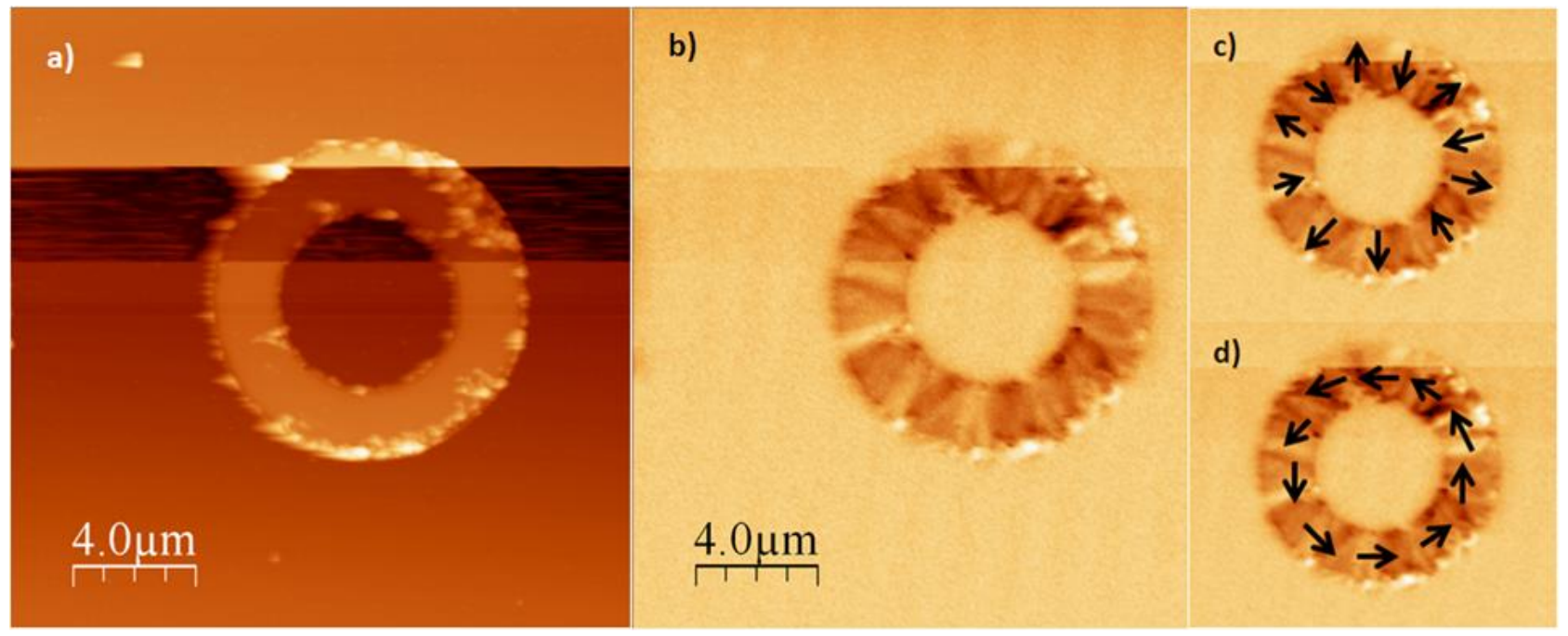

Figura 4-21: Imagens do elemento de anel de Co a) imagem topográfica, b) imagem de MFM, c) possível disposição radial do sentido da magnetização nos domínios e d) possível orientação circular da magnetização a passar de um domínio ao outro.

\section{Elemento triangular}

As imagens de AFM mostram um triangulo equilátero de lados de $10 \mu \mathrm{m}$, as de MFM revelam uma estrutura de três domínios separados por paredes de domínios com disposição de simetria triangular. Nas imagens de MFM pode se ver que as paredes de domínio chegam a se juntar no centro do triângulo e finalizam em cada um de seus vértices.

A amostra de $\mathrm{CoFeSiB}$ é muito mole magneticamente, com anisotropia muito baixa, e a magnetização paralela ao plano da amostra. A estrutura de domínios que tende a se formar é aquele que minimiza o stray-field, diminuindo a quantidade de polos magnéticos livres, produzindo fluxo magnético fechado dentro do objeto e desse modo reduzindo a energia magnetostática. Para poder interpretar as imagens de MFM se faz uso da regra de Van den Berg [50]. Está regra é válida para amostras bidimensionais e magneticamente moles, e ajudam na dedução de sua estrutura de domínios. As regras de Van den Berg são as seguintes:

1) Fazem-se círculos dentro da figura, que devem ser tangenciais a pelo menos dois pontos das bordas do objeto, a linha que une os centros do círculo constitui uma parede de domínio.

2) A magnetização em cada círculo é perpendicular ao raio, onde este encosta na borda do objeto.

3) Se o círculo tem mais do que dois pontos de contato com a borda, seu centro forma a união de paredes.

4) Se os pontos tangenciais são vizinhos, a parede finaliza no centro deste círculo.

5) Se a amostra tem ângulos agudos, a parede se finaliza nos pontos de ângulos agudos. 
Na Figura 4-22 c), é exemplificado o uso das regras acima para um objeto triangular. Comparando esta figura com a imagem de MFM (Figura 4-22b) se identifica as paredes de domínio que se juntam no centro do triângulo e se estendem finalizando nos vértices. Assim, se separa três regiões, onde cada uma é um domínio com sua direção de magnetização paralela ao lado correspondente do triângulo. Pode se ver que a imagem de MFM difere do modelo na curvatura das paredes de domínio, para o $\mathrm{CoFeSiB}$. Isto se deve à perturbação gerada pela ponta sobre amostra magneticamente mole, similarmente ao visto no caso do formato quadrado. Pode se ver também que devido a impurezas localizadas nas bordas do objeto, aparecem também perturbações locais.

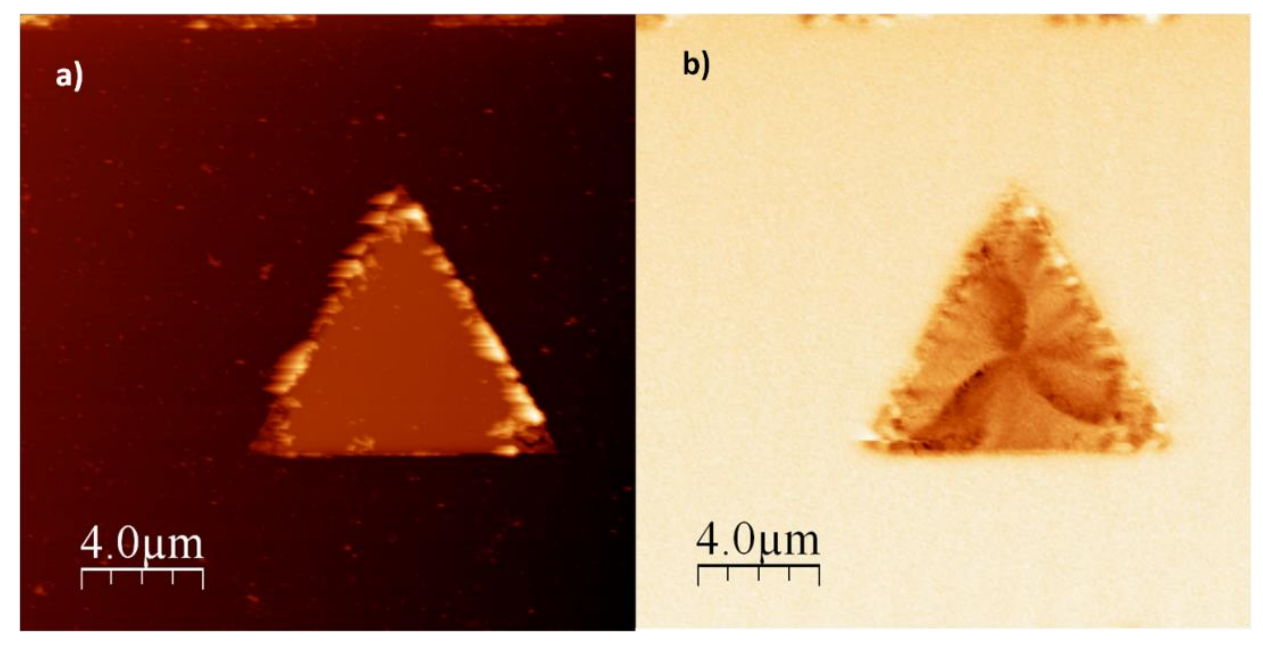

c)

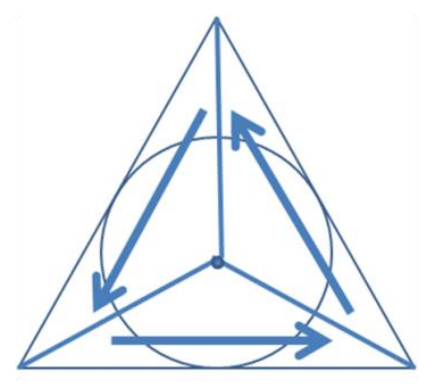

Figura 4-22: Imagens do elemento de triangulo de CoFeBSi a) imagem topográfica, b) imagem de MFM e c) construção de uma estrutura de domínios usando a regra de Van Den Berg.

No caso do elemento triangular de Co, se observa um padrão mais complexo. Neste material se pode ver na Figura 4-23 b) que a imagem de MFM apresenta um padrão do estado de remanência com simetria triangular, e o centro do triangulo continua sendo um centro de união das paredes. Os defeitos presentes na borda e os efeitos magnetostrictivos devido às tensões residuais afetam a estrutura de domínios, assim embora a simetria triangular tenha sido mantida, existem fortes variações na estrutura de domínios nos três vértices. 


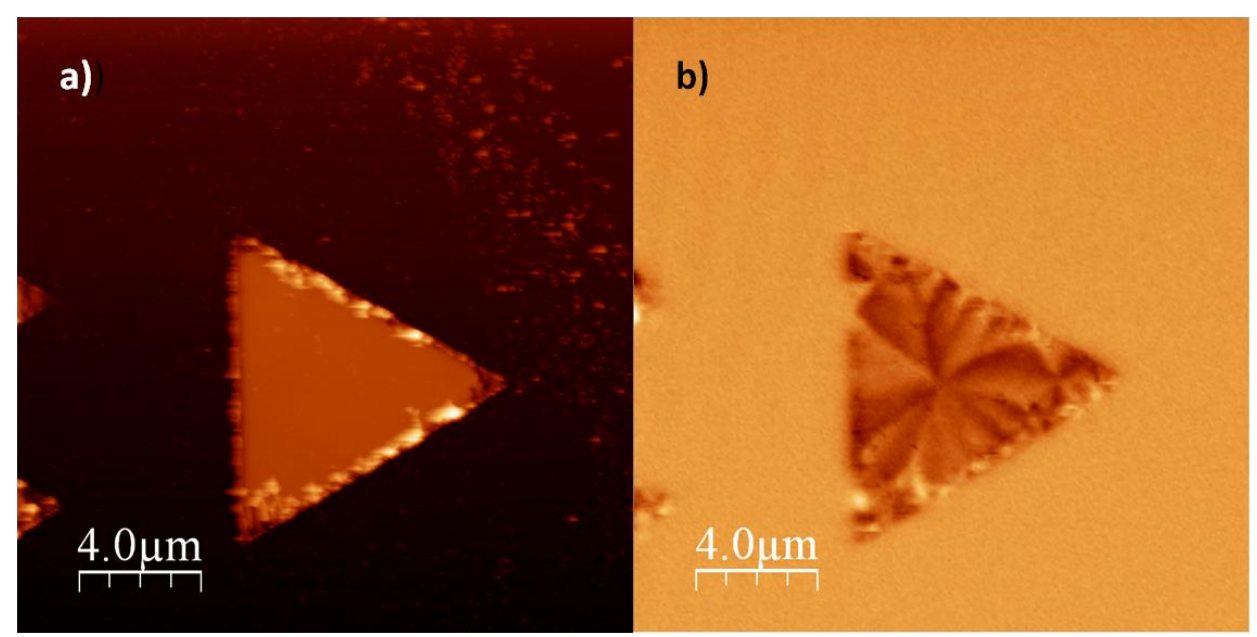

Figura 4-23: Imagens do elemento de triangulo de Co a) imagem topográfica e b) imagem de MFM

\section{Imagem Kerr dos objetos}

Para ajudar na interpretação das imagens de MFM, se obtiveram imagens MOKE feitas pelo microscópio metalográfico, dando uma compreensão direta das estruturas de domínios. Nestas imagens o contraste é devido aos sentidos da componente vertical da magnetização. As Figuras 4-24 (a) e (b) mostram as configurações de remanência nos objetos de interesse. Nas imagens MOKE se visualizam artefatos, que são devido a iluminação não homogênea, à rugosidade da amostra e ao efeito de difração gerado nas regiões das bordas dos objetos.

Assim no caso do quadrado de Co, no seu interior se distingue a estrutura de quatro domínios de fechamento. O triângulo, mostra um contraste invertido na sua metade da figura (lugar de uma parede), e o círculo sugere uma estrutura de dois domínios verticais, com uma possível parede de domínios na sua metade (indicado com linha) ou uma transição gradual como no caso de um estado vórtice. Já no anel não é possível distinguir estrutura devida aos artefatos nas bordas. O processo de desmagnetização usado para deixar os objetos no estado de remanência consistiu em ciclar o campo magnético aplicado, com a sua amplitude sendo progressivamente reduzida a zero. Este procedimento teve muitas repetições, mostrando resultados da configuração de magnetização similares para cada objeto. Então as configurações de magnetização tendem a ser altamente reprodutíveis. No caso do quadrado a aparente não presença de parede de cross-tie pode se dever a baixa resolução da câmera. 

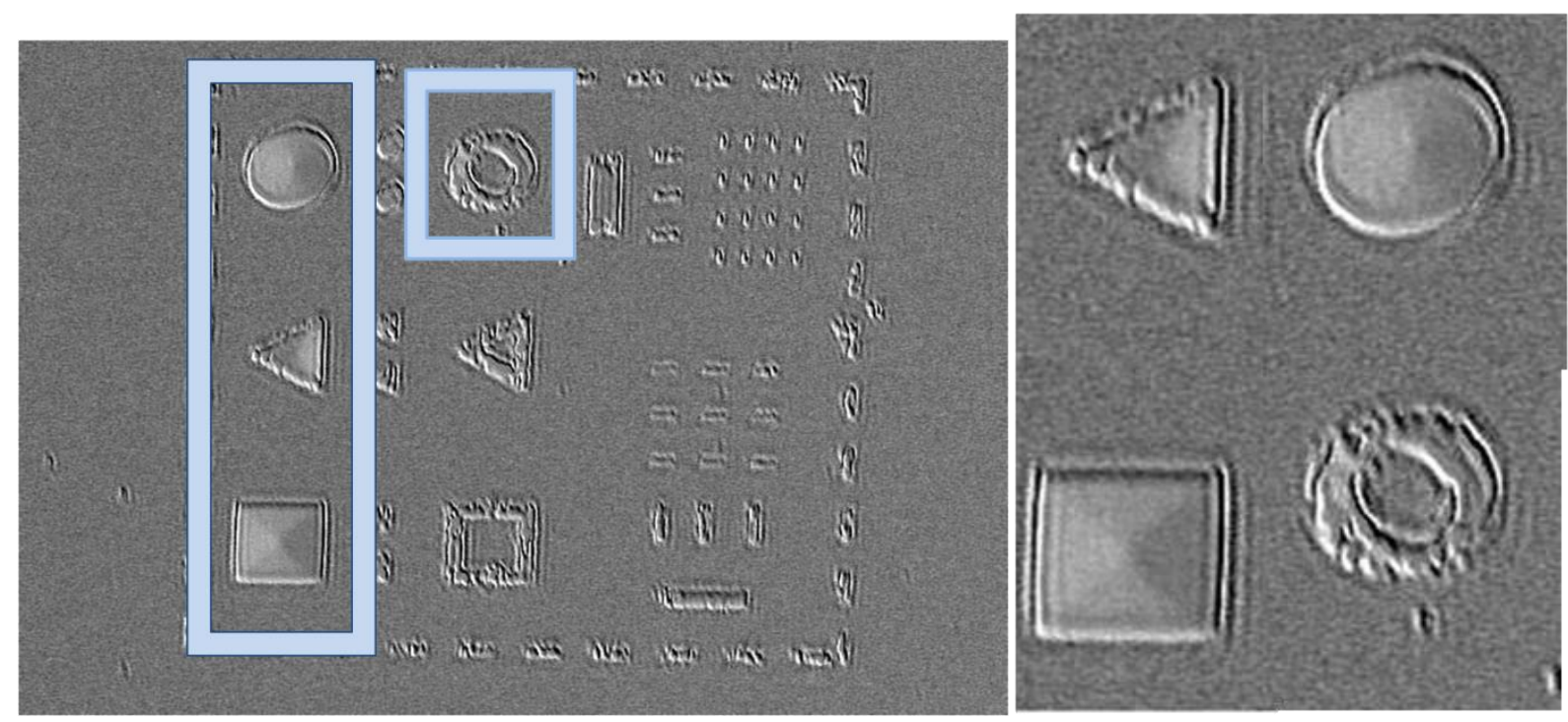

Figura 4-24: Imagens feitas por microscopia Kerr longitudinal, o contraste revela a magnetização a) arranjo de objetos de Co, a linha azul limita os objetos de interesse b) aumento dos objetos de interesse.

\subsection{Resultado das simulações}

Foram realizadas simulações de objetos de diferentes formatos. Estas foram iniciadas, simulando-se objetos quadrados com dimensões de $2.19 \mu \mathrm{mx} 2.19 \mu \mathrm{mx} 60 \mathrm{~nm}$ para o $\mathrm{CoFeSiB}$ e $1.52 \mu \mathrm{mx} 1.52 \mu \mathrm{mx} 38 \mathrm{~nm}$ para o Co, onde t é a espessura.

Os parâmetros de entrada $A, M_{S}$ e $L_{\text {tro }}$ para as propriedades dos materiais foram tomados de [35] e os valores se encontram na Tabela 4.

Tabela 4: Parâmetros magnéticos do Co e CoFeSiB.

\begin{tabular}{|l|c|c|c|}
\hline Material & $\begin{array}{c}A(\mathrm{~J} / \mathrm{m}) \\
\text { (constante de } \\
\text { troca) }\end{array}$ & $\begin{array}{c}M_{S}(\text { emu/cm3) } \\
\text { (magnetização de } \\
\text { saturação) }\end{array}$ & $\begin{array}{c}L_{\text {tro }}(\mathrm{m}) \\
\text { (comprimento de } \\
\text { troca) }\end{array}$ \\
\hline Co & $1.8^{*} 10^{-6}$ & 1400 & $3.8^{*} 10^{-9}$ \\
\hline $\begin{array}{l}\text { CoFeSiB } \\
\text { (magnético mole) }\end{array}$ & $1 * 10^{-6}$ & 550 & $7.3^{*} 10^{-9}$ \\
\hline
\end{tabular}

Para a amostra do Co se escolheu o valor de $M_{s}=1400 \mathrm{emu} / \mathrm{cm}^{3}$ encontrado na literatura para a amostra em bulk [35], embora é sabido que para amostras de filmes finos o valor de $M_{S}$ muda para valores menores do que para o bulk. 
Devido ao fato do tempo de simulação aumentar com o tamanho do objeto simulado, não foi possível simular objetos com as dimensões das amostras de $10 \mu \mathrm{mx} 10 \mu \mathrm{mx} 75 \mathrm{~nm}$, assim as dimensões simuladas foram de $2.19 \mu \mathrm{mX} 2.19 \mu \mathrm{mX} 60 \mathrm{~nm}$ e $1.52 \mu \mathrm{mx} 1.52 \mu \mathrm{mx} 38 \mathrm{~nm}$. Isto se justifica pela seguinte razão, o filme produzido é policristalino com grãos relativamente pequenos e isto remove a dependência com a dimensão externa $\mathrm{z}$ da amostra. Os grãos pequenos possuem anisotropia, mas é aleatoriamente orientada, não gerando uma anisotropia macroscópica significativa, mas majoritariamente efeitos locais. Assim, isto faz com que as características da superfície possam ser simuladas tendo em conta a desordem dos grãos. Se pode conferir a não presença de anisotropia ao ver as medidas das curvas de histereses feitas para o filme de Co. As medidas feitas nas duas direções perpendiculares entre si no plano do filme, são semelhantes. No caso contrário, de presença de anisotropia, nas medidas de filmes finos com VSM, se veriam curvas de histereses com direções preferenciais. Então, a medida que o filme cresceu em espessura, aumentou também a rugosidade e desorientação cristalográfica entre os grãos, fazendo com que o material tenha uma distribuição de direção da anisotropia local. Este efeito pode ser simulado no Mumax3, definindo o tamanho dos grãos e uma distribuição aleatória da direção da anisotropia uniaxial magnetocristalina dos grãos. Em relação à diferença de dimensão de $10 \mu \mathrm{m}$ a $2.19 \mu \mathrm{m}$ ou $1.5 \mu \mathrm{m}$ se espera que não mude o padrão da configuração de domínios [36]. Já que para estas dimensões as estruturas de magnetização tendem a fazer fechamento nas bordas do objeto, conservando a configuração com a mudança do tamanho, em vez de ter magnetização uniforme, que é tendência vista para objeto muito pequenos de tamanho em torno de $10 \mathrm{nmx} 10$ $\mathrm{nm}[36]$.

Nas simulações para o Co se definiu distribuição de anisotropia uniaxial por grão, com tamanho de grão de cerca de $5 \mathrm{~nm}$ e o valor de constante de anisotropia uniaxial magnetocristalina $K_{u 1}=4.1 * 10^{5} \frac{\mathrm{J}}{\mathrm{m}^{3}}$ foi tomada de [17], os mapas vetoriais foram gerados em arquivo do tipo Ovf e visualizados em arquivo jpg com sua escala de cor graças a uma ferramenta de conversão do Mumax3.

A constante de amortecimento de Gilbert, $\alpha$, foi tomada como 0.1 , o valor determina a convergência na solução. O tamanho de célula usada para a simulação foi de $0.75^{*} L_{\text {tro }}$.

Usando estes parâmetros se simularam os objetos para as diferentes geometrias junto com sua simulação de MFM, usando um lift de $120 \mathrm{~nm}$ como feito na tomada de medida de MFM.

Após, as imagens das simulações e as medidas de MFM foram comparadas.

Para o caso do quadrado no $\mathrm{CoFeSiB}$ se tomou uma configuração inicial de dois domínios e se deixou evoluir até o equilíbrio por meio da função relax().

A simulações mostraram que a estrutura de magnetização estável alcançada no objeto quadrado de CoFeSiB foi de quatro domínios de fechamento, como se vê na Figura 4-25 e sua 
imagem de MFM correspondente revela um contraste na região das paredes próprias de uma parede tipo Néel de $90^{\circ}$. Na simulação não é previsto o efeito da ponta sobre a amostra, assim as paredes são retas.

a)

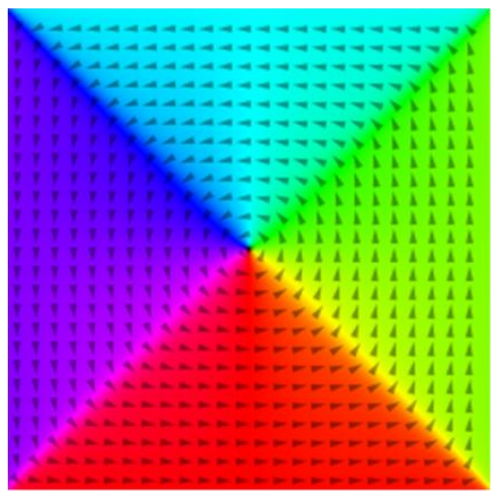

b)

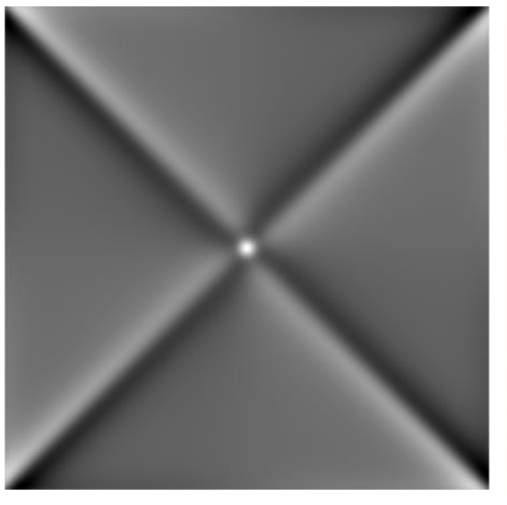

c)

$4.0 \mu \mathrm{m}$

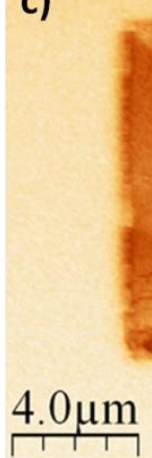

Figura 4-25 a) Imagem de simulação micromagnética de um objeto quadrado de CoFeSiB, os vetores indicam a direção da magnetização, b) a imagem de MFM simulada, correspondente e c) é a imagem de MFM.

No caso do Co, a estrutura evolui até ficar com uma configuração parecida à imagem medida de MFM. A imagem simulada mostra flutuações na orientação da magnetização, como consequência da aleatoriedade orientacional da anisotropia magnetocristalina, isto faz com que as paredes de domínio não fiquem muito bem definidas, mas ajuda a formação e fixação do tipo de estrutura esperada de cross-tie. Assim do lado direito da imagem na figura 4-26 pode se ver a formação de três pontos em sequência de cross-tie. Pode-se ver também a configuração de magnetização local em cada um dos domínios e a presença de paredes de tipo Néel e de cross-tie. Outra característica revelada mostrada pela vetorização da magnetização é que o comportamento da magnetização na superfície resulta ser paralelo ao plano da amostra. Isto se deve à anisotropia de forma que faz alinhar a magnetização paralela a ela, com exceção dos pontos vórtices.

As diferenças mostradas entre a medida de MFM e a simulação podem ser devidas ao fato que os objetos apresentam policristalinidade, com tensões e imperfeições nas bordas da amostra e assim, simular este comportamento resulta ser uma atividade complexa. Por outro lado, apesar dos resultados das simulações para o Co apresentarem certa correspondência com as medidas, as imagens simuladas e as medidas apresentam a mesma disposição de domínios e paredes de tipo Néel e cross-tie. Na Figura 4.26 e 4-27 se podem ver as simulações para o Co em diferentes geometrias retangulares. Nestas simulações, o objetivo foi estudar a formação das paredes de tipo cross-tie, visando compreender as condições para a sua presença. Nestas figuras, vê-se as mudanças de orientação dos vetores de magnetização ao atravessar as paredes e no entorno do cross-tie. As diferenças presentes, como o contraste das imagens MFM, resultam do fato de ter definido grãos pequenos, cada um com sua direção de anisotropia própria. Isto dá uma mudança suave nas regiões das paredes fazendo com que um contraste fraco nas paredes de domínios apareça nas simulações de MFM e não um contraste forte, como visto nas medidas. 
Este problema pode ser resolvido definindo dimensões grandes do objeto. Assim, as imagens simuladas podem ser melhoradas, mostrando mais detalhes. A simulação gerada mostra o campo vetorial das magnetizações locais nos domínios magnéticos, indicando o sentido do fluxo fechado de magnetização. Na amostra quadrada o comportamento das componentes do momento magnético na superfície dos filmes resulta ser paralelo ao plano.

a)

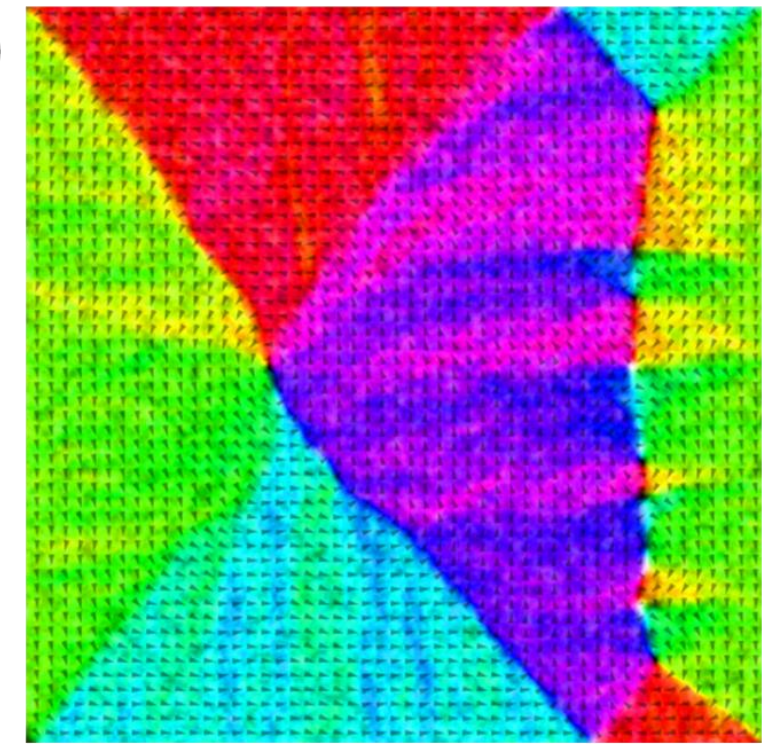

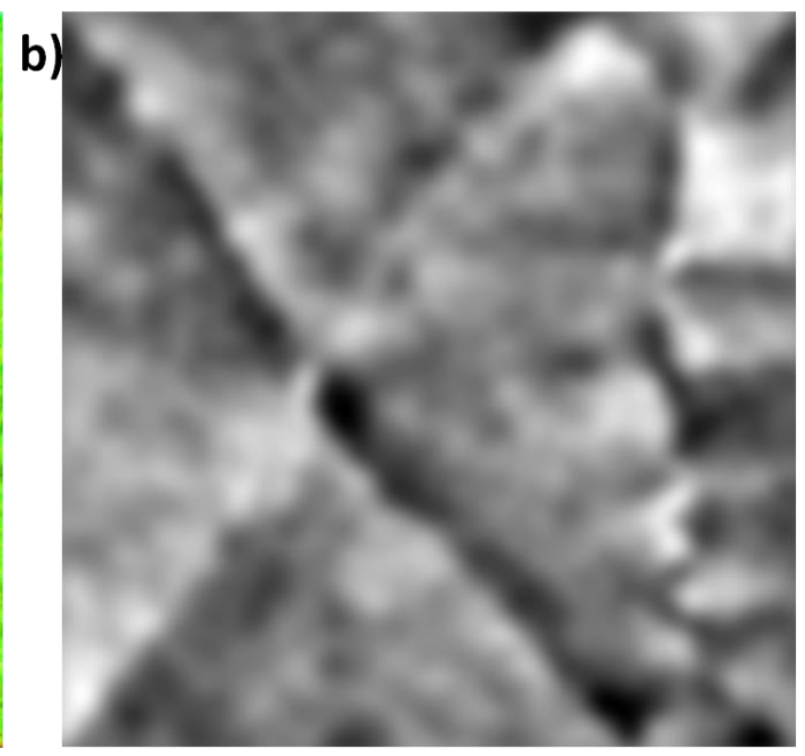

Figura 4-26: (a)Imagem de simulação micromagnética de um objeto quadrado de Co, os vetores indicam a direção da magnetização e (b) a imagem de MFM simulada, correspondente.

Outra característica vista nas simulações das paredes de cross-tie, é que formação destas depende principalmente da espessura do filme e das dimensões do objeto. No caso do elemento quadrado de Co o fato de ter definido anisotropias locais com direções aleatórias ajudou a fixar as paredes de cross-tie. Por outro lado, o efeito de ter definido uma pequena anisotropia uniaxial na direção Y no plano do objeto quadrado, fez com que o número de pontos de cross-tie na parede, aumente como se verá na figura 4-28.

Com o propósito de compreender como as paredes de cross-tie aparecem no Co, se fizeram simulações de objetos retangulares de espessura $t$ para diferentes larguras e comprimentos que mostram cross-tie. Na Figura 4-27 se pode apreciar como muda o tamanho e periodicidade do cross-tie para retângulos de diferentes dimensões com espessura de t, também se mostra sua respectiva imagem de MFM revelando o padrão de cross-tie, este consiste de contrastes alternados claros e escuros. Isto mostra uma relação entre a largura, comprimento do objeto e periodicidade do cross-tie.

Outro ponto importante a ter em conta é a faixa de espessura dentro da qual a formação de cross-tie é possível. Se fizeram simulações de objetos retangulares de $10 L_{\text {tro }} * 40 L_{\text {tro }} * 10 L_{\text {tro }}$ e de $10 L_{\text {tro }} * 30 L_{\text {tro }} * 9 L_{\text {tro }}$ dimensões para o Co, onde $L_{\text {tro }}$ é o comprimento de troca e t é a 
espessura do filme. Escolhem-se dimensões muito menores que as reais pelo custo de tempo da simulação. Os resultados mostraram que para filmes ultrafinos o cross-tie não chega a se formar. Já para espessuras na faixa de $32.3 \mathrm{~nm}$ a $53 \mathrm{~nm}$ a existência de paredes de cross-tie é possível. Assim se tem uma primeira transição de $30.4 \mathrm{~nm}$ a $32.3 \mathrm{~nm}$ de parede de Néel a parede cross-tie e uma segunda transição na faixa de $53 \mathrm{~nm}$ a $57 \mathrm{~nm}$ de parede de cross-tie a parede de Néel como se vê na figura 4-27. Este resultado difere com a medida de espessura no AFM, onde se tem cross-tie para espessura de $75 \mathrm{~nm}$, isto pode ser devido a que o $L_{\text {tro }}$ para o filme resulte ser diferente, já que a magnetização de saturação em filmes é menor em comparação ao caso bulk, isto faria com que o $L_{\text {tro }}$ seja maior que o valor assumido de $L_{\text {tro }}=3.8 \mathrm{~nm}$. Fazendo que a transição de cross-tie a Néel seja acima de $57 \mathrm{~nm}$.

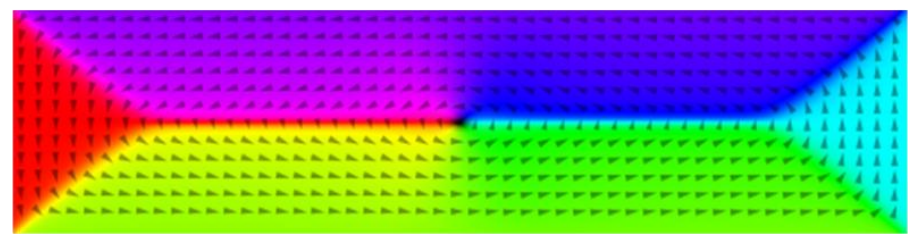

a) 10 Ltro* 40 Ltro*6Ltro

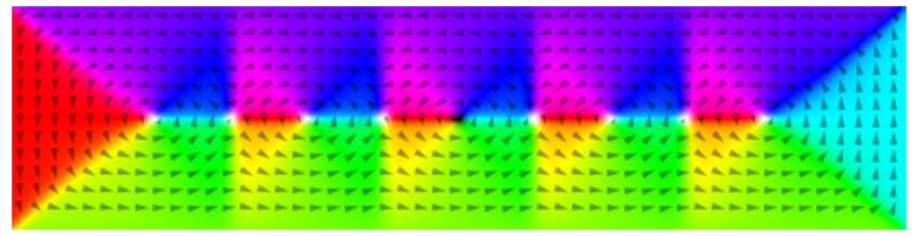

b) 10 Ltro* 40 Ltro*8.5Ltro

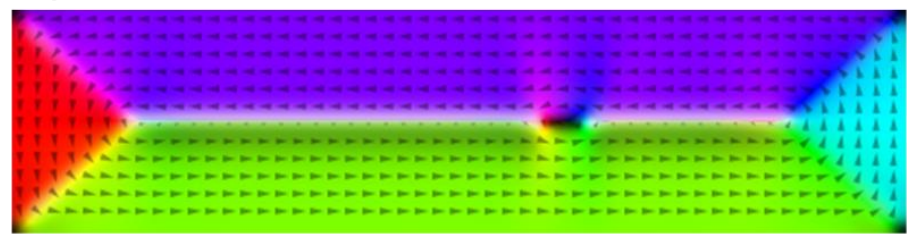

c) 10 Ltro* 40 Ltro*15Ltro

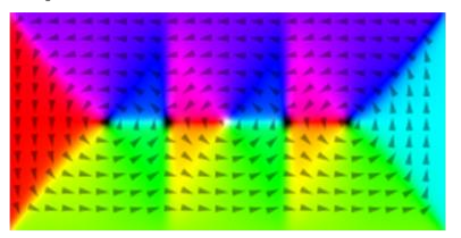

d) 10 Ltro*30Ltro* 9 Ltro

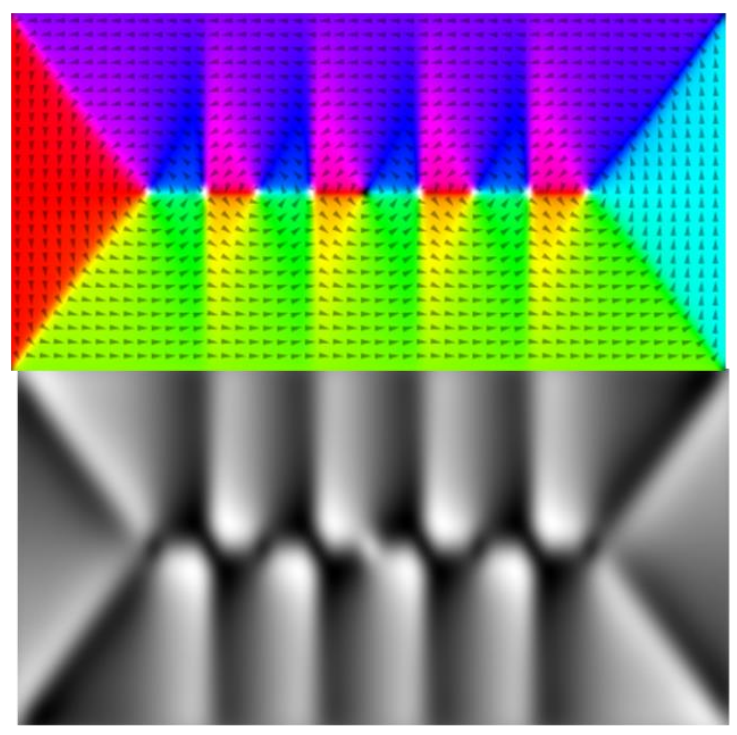

e) 20 Ltro*60Ltro*10Ltro

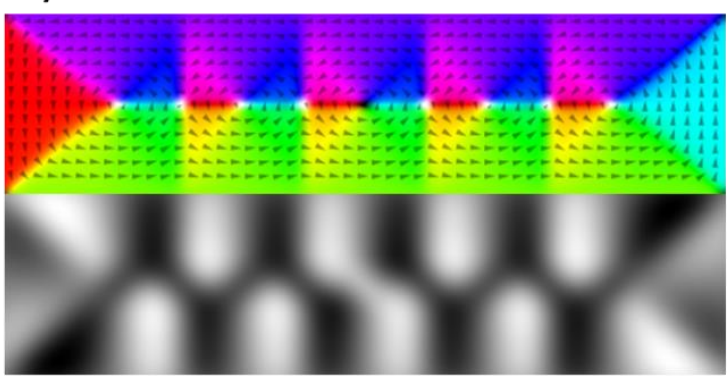

f) 10 Ltro $* 40$ Ltro $* 10$ Ltro

Figura 4-27: Imagens de simulação micromagnética de objetos retangular de Co, os vetores indicam a direção da magnetização, t é a espessura do objeto, em (a),(b),(c), (e) as dimensões são de $10 L_{\text {tro }} * 40 L_{\text {tro }} * \mathrm{t}$ para $\mathrm{t}=6 L_{\text {tro }}, 8.5 L_{\text {tro }}$ e $\mathrm{t}=L_{\text {tro }}$ respectivamente, em (d) de $10 L_{\text {tro }} * 30 L_{\text {tro }} * 9 L_{\text {tro }}$ e em (e) de $20 L_{\text {tro }} * 60 L_{\text {tro }} * 10 L_{\text {tro }}$. e (f) de $10 L_{\text {tro }} * 40 L_{\text {tro }} * 10 L_{\text {tro }}$, (e) e (f) mostram suas respectivas imagens de MFM.

Como foi dito, outra característica da parede de cross-tie, de acordo com os resultados de [36] é mostrada na Figura 4-28. Se vê o comportamento da configuração magnética no objeto 
quadrado para diferentes valores de anisotropias uniaxiais na direção $\mathrm{Y}$ com ka com valores $0.05 K_{u}, 0.1 K_{u}$ e $0.2 K_{u}$; nesta se pode ver o aumento de pontos de cross-tie com o incremento de Ka (constante de anisotropia uniaxial) definido na direção Y. Onde $K_{u}$ é a primeira constante de anisotropia magnetocristalina uniaxial do Co $\left(K_{u}=4.1 * 10^{+5} \mathrm{~J} / \mathrm{m}^{3}\right)$.

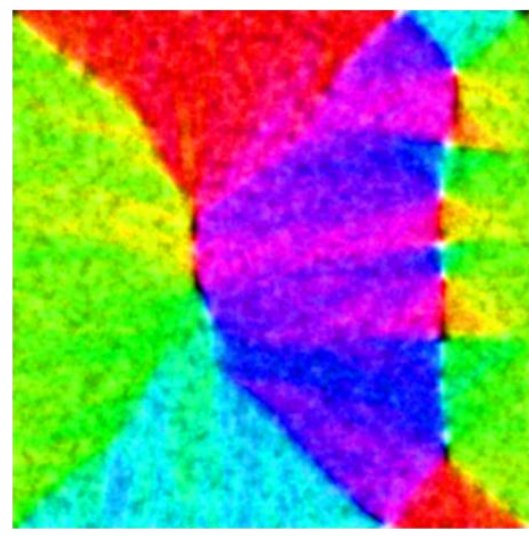

a) $k a=0.05 \mathrm{Ku}$

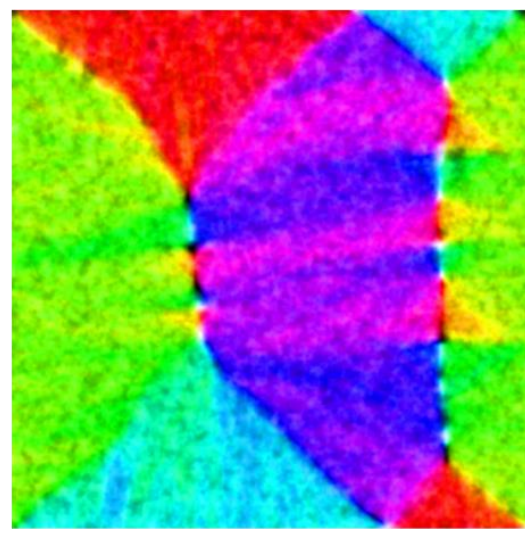

b) $k a=0.1 \mathrm{Ku}$

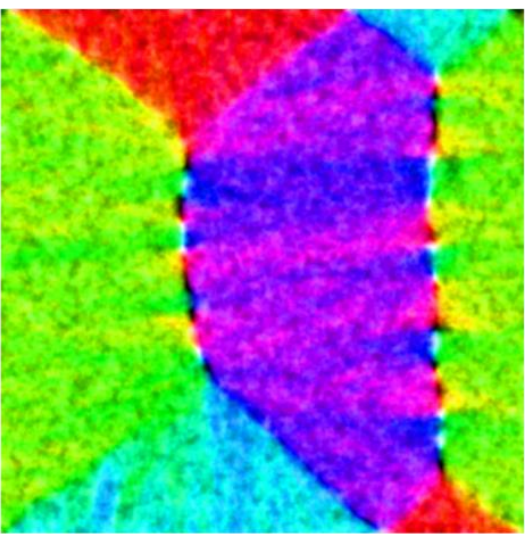

c) $\mathrm{ka}=0.2 \mathrm{Ku}$

Figura 4-28: Imagens de simulação micromagnética de objeto quadrado de Co, para diferentes valores de de $K_{\mathbf{a}}$ (anisotropia uniaxial na direção $\mathbf{Y}$ ).

Em resumo para a espessura usada de $38 \mathrm{~nm}$, se tende a formar paredes de tipo Néel e cross-tie no objeto quadrado. As configurações magnéticas se vêm afetadas possivelmente devido às deformações e inomogenedades durante a deposição, dando lugar a irregularidades nas imagens de MFM que diferem das simulações. Assim a simulação apoia a formação de cross-tie no filme de Co com o comportamento da magnetização paralelo à superfície da amostra. São reveladas também duas transições de tipo de parede, a primeira em torno de $32 \mathrm{~nm}$ e a outra em torno de $57 \mathrm{~nm}$, para um valor usado de comprimento de troca de $L_{\text {tro }}=3.8 \mathrm{~nm}$.

O objeto circular de CoFeSiB visto na Figura 4-29 resulta ser bem simulado mostrando os vetores de magnetização local, com uma estrutura de tipo vórtice em correspondência com a imagem de MFM. A simulação de MFM mostra um sinal forte no centro do disco, onde se tem componentes verticais fortes do stray-field. Mostra também que a magnetização é paralela à superfície da amostra, com exceção da região da borda onde se vê sinal fraco de stray-field, e a não presença de paredes. No caso do material de Co (figura 4-30), a simulação revela como estado final uma estrutura distensionada de um estado vórtice. Se vê que a transição de cor de uma região para outra resulta ser melhor definida que a mudança gradual vista no material magnético mole. Assim esta mudança na direção de magnetização, por exemplo, com um valor em torno de $45^{\circ}$, na transição da cor vermelho para a amarela, pode se ver como se fosse uma parede de Néel separando dois domínios magnéticos. Isto também acontece na região de transição do azul para vermelho como paredes de tipo Néel de cerca de $45^{\circ}$. A deformação ondulada na parede é devida a rugosidade do grão estabelecida. Enquanto à simulação de MFM do Co, este revela stray field distribuído em toda a área da superfície, isso é devido ao tamanho 
de grão definido fazendo com que não resulte possível distinguir um contraste definido de parede.

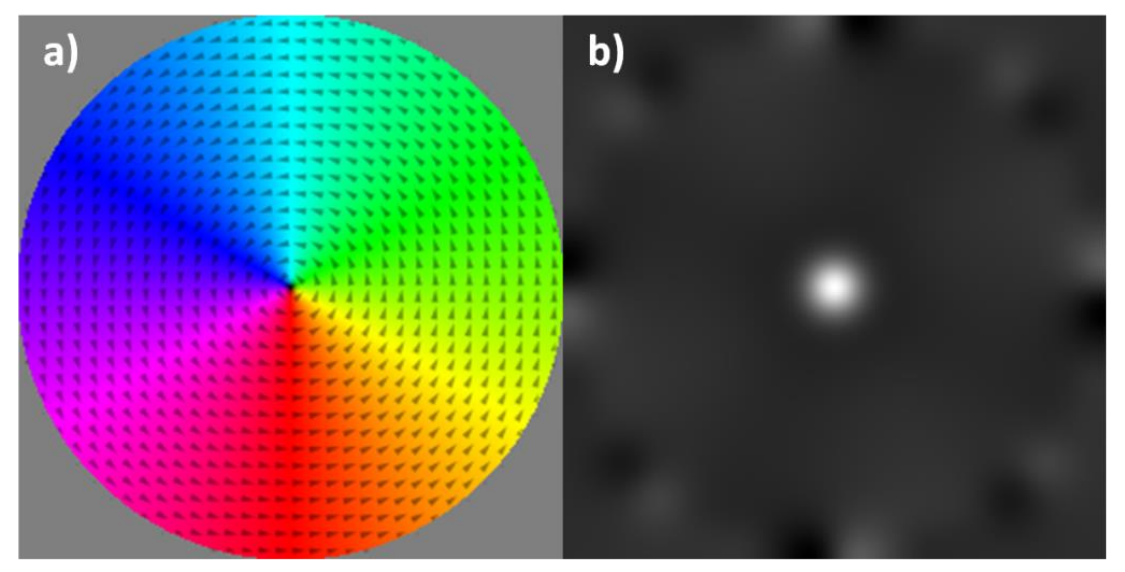

Figura 4-29: (a)Imagem de simulação micromagnética de um objeto de disco de CoFeSiB, os vetores indicam a direção da magnetização e (b) a imagem de MFM correspondente.
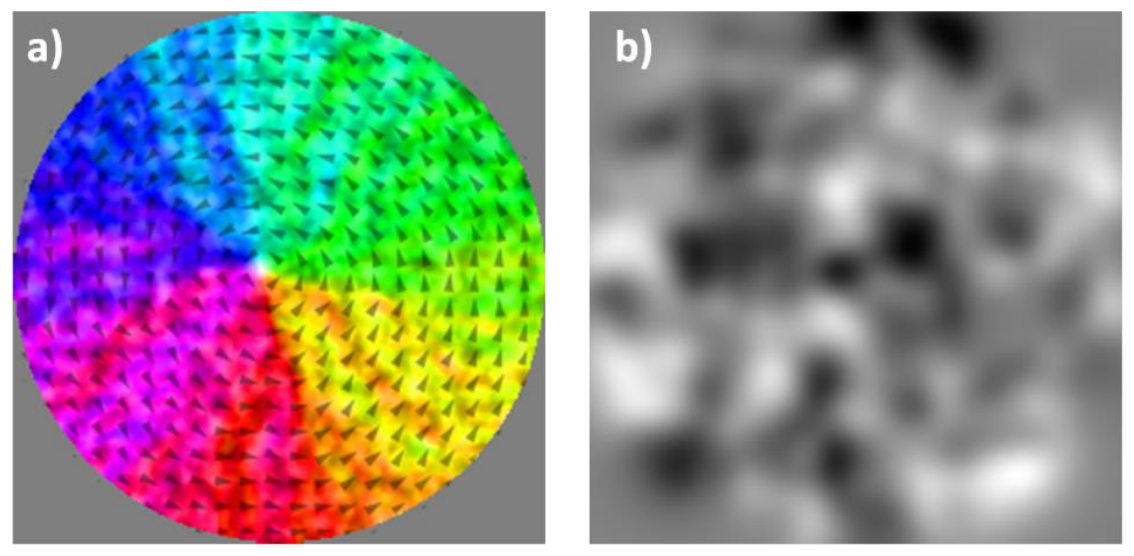

Figura 4-30: (a)Imagem de simulação micromagnética de um objeto de disco de Co, os vetores indicam a direção da magnetização e (b) a imagem de MFM correspondente.

O objeto com formato de triângulo mostrou nas simulações que sua configuração final depende muito de seu estado inicial, a configuração magnética correspondente com a mediada de MFM (figura 4-31) é possível para um estado vórtice inicial. O resultado mostrado na Figura 431 dá uma estrutura simétrica de três domínios triangulares. Em resultados para outras configurações iniciais, a simetria de três dominós não é vista. A simulação tem correspondência com as medidas de MFM, com a diferença de que nas medidas as paredes apresentam uma leve curvatura causada pelo efeito do campo magnético da ponta sobre a amostra. 


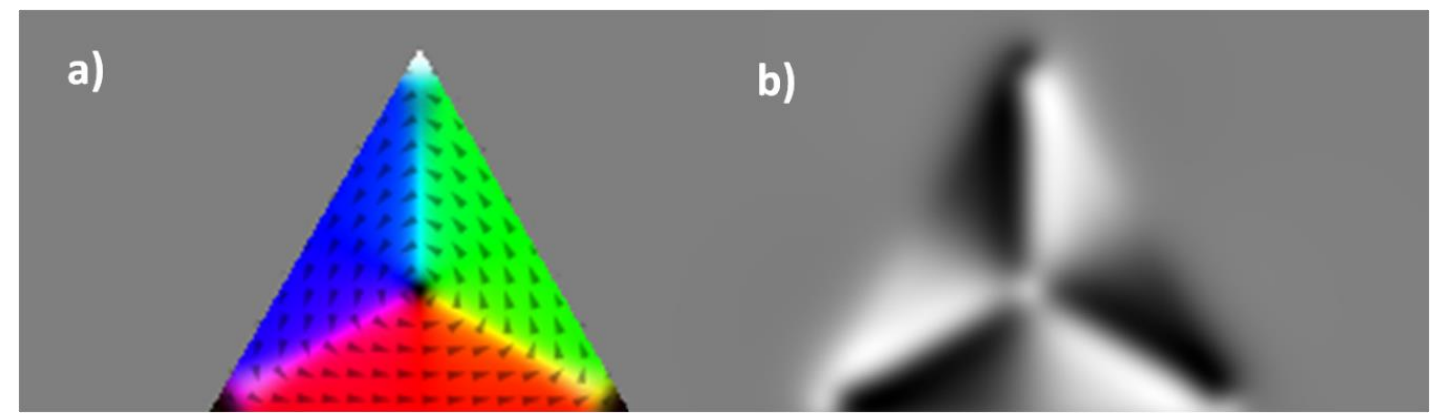

Figura 4-31: : a) Imagem de simulação micromagnética de um objeto triangular de CoFeSiB, os vetores indicam a direção da magnetização e b) a imagem de MFM correspondente.

A simulação para o Co visto na figura 4-32 se fez definindo um estado inicial de tipo vórtice, a estrutura simulada tem características de um estado vórtice complexo, com terminação das paredes em cada vértice do triangulo. $\mathrm{O}$ resultado mostra algumas similaridades com as imagens do MFM, como é a simetria triangular.

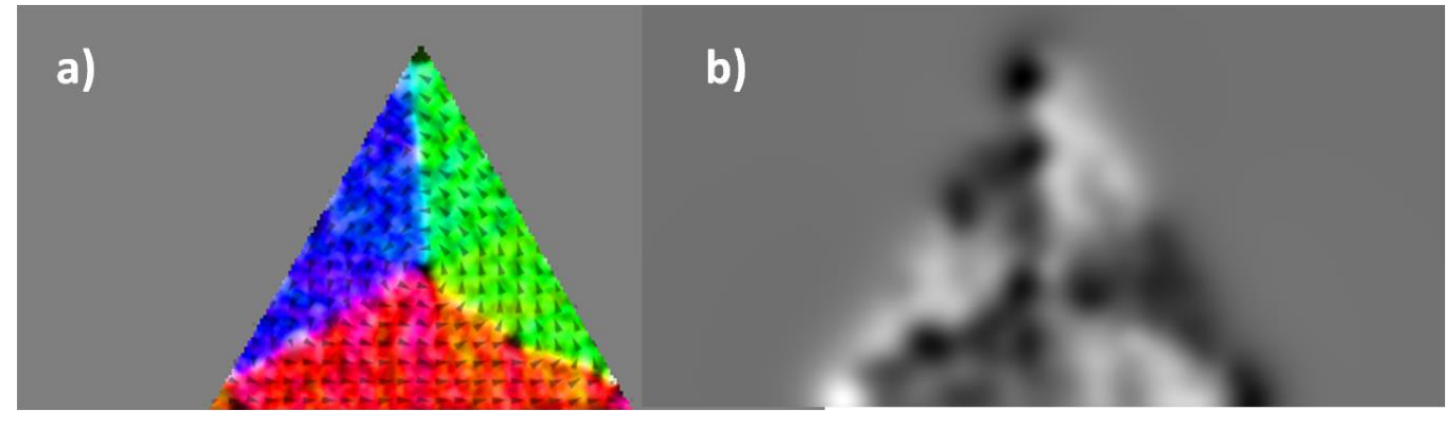

Figura 4-32: (a) Imagem de simulação micromagnética de um objeto triangular de Co, os vetores indicam a direção da magnetização e (b) a imagem de MFM correspondente.

Já para o objeto em formato de anel, as dimensões do anel como a largura deste são determinantes no resultado final. A simulação mostrou que o estado preferível para as dimensões mostradas no AFM foi de um estado vórtice para a amostra de CoFeSiB. Na imagem de MFM, mostra-se que a magnetização fica paralela a superfície. Porém, o sinal magnético é fraco e o contraste é visto só na região da borda interior e exterior, onde há um stray-field mais intenso. 

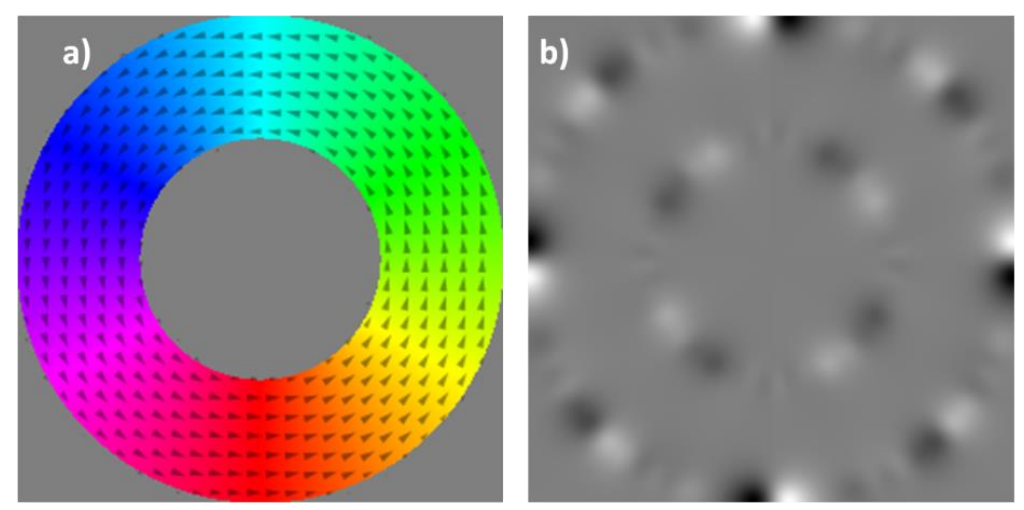

Figura 4-33: a) Imagem de simulação micromagnética de um objeto em formato de anel de CoFeSiB, os vetores indicam a direção da magnetização e b) a imagem de MFM correspondente.
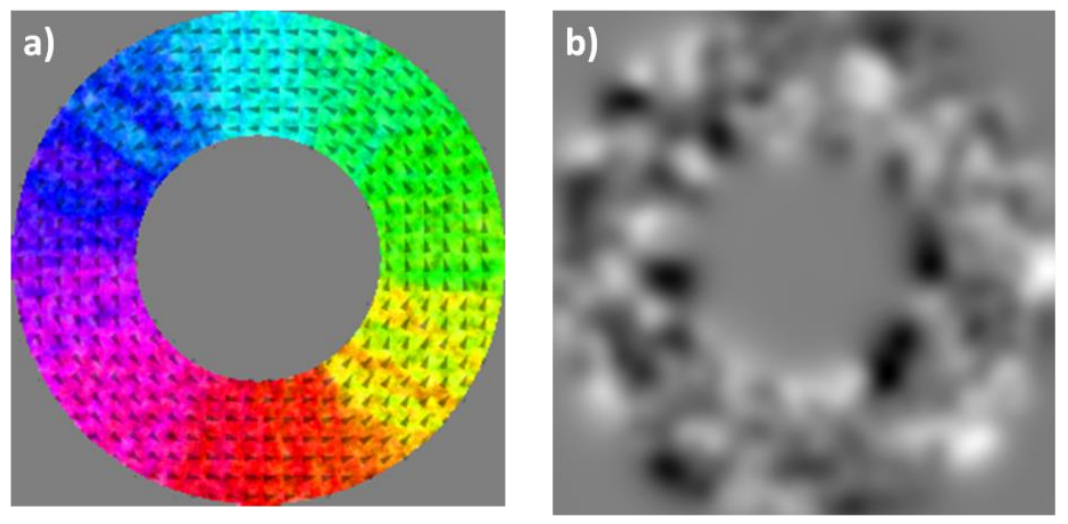

Figura 4-34: a) Imagem de simulação micromagnética de um objeto em formato de anel de Co, os vetores indicam à direção da magnetização e b) a imagem de MFM correspondente.

No caso do Co o estado preferível mostrado pela simulação é um estado vórtice distorcido. Neste a transição de direção de domínio de uma região de cor a outra é mais bem definida, sugerindo formação de parede de domino de Néel entorno de $45^{\circ}$. Isto faz com que se tenha uma sequência de domínios magnéticos ao longo do anel. A medida de AFM sugere também uma sequência de paredes de domínio ao longo do anel. Assim se pode dizer que o objeto tem domínios magnéticos com direção de magnetização a longo do anel. A simulação de MFM mostra contraste de manchas claras e escuras em toda a área da superfície do anel. O strayfield está presente não só nas bordas, mas também em toda a superfície, e assim não se chega a definir bem a presença de paredes de domínio. 


\section{Capítulo 5: Conclusões}

Foram preparados objetos magnéticos de diferentes tamanhos e geometrias. Por meio da litografia se desenhou os objetos e com a técnica do magnetron sputtering se depositou o material de $\mathrm{Co}$ e de $\mathrm{CoFeSiB}$, se controlou os parâmetros de deposição para a conseguir a espessura de cerca de $75 \mathrm{~nm}$ e $55 \mathrm{~nm}$ respetivamente. As amostras foram analisadas nas suas propriedades magnéticas por efeito Kerr magneto-ótico, MFM e VSM; e as características morfológicas por AFM. Por outro lado, se desenvolveu o modo de conseguir curvas de histereses a partir das imagens magneto-óticas, obtidas pelo microscópio metalográfico e também se usou as imagens MOKE e o EBSD para o estudo do aço elétrico Fe6\%Si. Dos resultados obtidos das medidas, quanto às propriedades magnéticas, se partiu para simular as configurações da magnetização no programa Mumax3.

Os objetos grandes obtidos pela litografia por feixe de luz foram estudados no microscópio ótico metalográfico. Os objetos retangulares de tamanho variado indo de $20 \mu \mathrm{m}$ a $100 \mu \mathrm{m}$ mostram configurações magnéticas parecidas entre si na remanência. No caso de $\mathrm{CoFeSiB}$, esta apresentou domínios mais regulares de faixas retas e de fechamento, enquanto que no Co a estrutura foi mais irregular nas paredes de domínios, sua dinâmica com o campo $(\mathrm{H})$ mostrou que este tende a nuclear domínios no sitio dos pontos de pinning seguido de uma inversão de domínios, por deslocamento de parede de domínio de $180^{\circ}$, conforme se aumenta o campo. As amostras com Co também apresentaram um maior campo coercitivo. Para uma boa obtenção de curvas de histereses, em termos de resolução se encontro que os fatores mais importantes a ter em conta são o tipo de lente objetiva, que deve apresentar maior abertura numérica; a estabilidade da fonte luminosa; a capacidade da câmera usada para a digitalização das imagens; e maior tempo de exposição, com média de 16 imagens por estado; visando diminuir o ruído. Junto com isso se determinou os critérios para uma melhor resolução na obtenção da curva. Assim, na escolha da região de interesse se excluiu a região das bordas por mostrar perturbações de difração não desejadas. Depois, faz-se o processo de tratamento de imagens para diminuir as perturbações e maximizar o contraste magneto-ótico do objeto. Se encontrou que para uma boa resolução da curva, os histogramas dos estados saturados devem ficar separados por uma distância maior do que o desvio padrão do ajuste dos histogramas. Os estados intermediários são definidos na proporção direta entre as áreas dos histogramas dos estados saturados. Como diferença frente às técnicas convencionais que oferecem medidas do comportamento global, este resultado torna possível analisar histereses locais, e pode vir a ser de interesse para o estudo de objetos microestructurados.

Graças ao microscópio MOKE e o EBSD se estabeleceu a relação entre as propriedades magnéticas e cristalográficas do aço Fe6\%Si. Assim as imagens MOKE mostraram o formato dos domínios magnéticos em cada grão e continuidade dos domínios nas fronteiras destes e as imagens IPF obtidas pelo EBSD, as orientações cristalográficas de cada grão, encontrando se boa 
concordância com a teoria. Tendo a direções $<100>$ domínios de faixas grandes e ordenadas e as direções próximas a $<111>$ domínios complexos e ramificados.

As medidas de VSM para filmes com espessura de cerca de $55 \mathrm{~nm}$ e de $75 \mathrm{~nm}$, mostraram que não se tem uma direção uniaxial preferencial de magnetização tanto para o $\mathrm{CoFeSiB}$ como para o Co. Isto é devido ao fato que no processo de deposição se obtém uma distribuição aleatória na direção uniaxial de anisotropia de cada grão. Assim as curvas de histereses no mostraram anisotropia uniaxial.

$\mathrm{O}$ resultado das medidas do AFM mostraram que as amostras têm uma baixa rugosidade tanto para o $\mathrm{CoFeSiB}$, como para o Co e espessura de cerca de $55 \mathrm{~nm}$ e $75 \mathrm{~nm}$, respectivamente. Encontrou-se rugosidade nas bordas dos objetos, como resultado do processo de remoção do resiste, que tiveram influência sobre as configurações magnéticas no caso do Co. Isto se deve a que o Co apresenta anisotropia e magnetostricção significativa, diferentemente do CoBFeSi que é um material amorfo e magneticamente mole. Os resultados do MFM mostram as diferentes configurações para as distintas geometrias (quadro, disco, triangulo e anel), tendo correspondência com a teoria no caso do $\mathrm{CoFeSiB}$, enquanto que para o Co mostrou ligeiras diferenças. Observou-se também o efeito de perturbação da ponta do MFM sobre a curvatura das paredes de domínio, no caso do material mole, de CoFeSiB. Foi visto também, a presença de paredes de cross-tie no objeto de formato quadrado, isto é o resultado da interação da ponta com o stray Field associado a uma distribuição de carga magnética.

Foi desenvolvido também um estudo por simulações numéricas das configurações magnéticas vistas nas imagens de MFM. Assim, se obteve que as simulações referentes as amostras de CoFeSiB mostraram boa correlação com as imagens de MFM, com exceção dos defeitos da perturbação produzida pela ponta do MFM. As simulações mostraram também que a magnetização na superfície no material prefere ficar paralela a esta, devido à anisotropia de forma presente em filmes finos. No caso do Co se obteve aproximações e possíveis respostas para as configurações de magnetização vistas nas imagens de MFM, para os casos ideais de estados magnéticos. No caso do formato quadrado se conseguiu simular a formação da parede de cross-tie, vendo que este tipo de parede depende da espessura do filme e das dimensões do objeto. Para conseguir os cross-tie no quadrado se teve que definir na simulação uma distribuição de grãos com direções aleatórias de anisotropia. Se encontrou nas simulações, duas espessuras de transição quanto ao tipo de parede, sendo que na espessura de cerca de $57 \mathrm{~nm}$ passou de parede Néel a Cross-tie e em cerca de $32 \mathrm{~nm}$ passou de parede de cross-tie a Néel. Mas o resultado de $57 \mathrm{~nm}$ não concordou com as medidas de AFM e MFM para o Co, onde se encontrou a presença da parede de cross-tie, acima de $57 \mathrm{~nm}$, ou seja para uma espessura de cerca de $75 \mathrm{~nm}$. Esta incompatibilidade da simulação com as medidas pode ser devida ao uso como parâmetros que definem o comprimento de troca, valores correspondentes ao de amostras em bulk. Assim, se fosse usado valores menores destes parâmetros, próprios de filmes finos, se obteria nas simulações espessuras críticas maiores para o Co que de $57 \mathrm{~nm}$. 


\section{Referências}

[1] Mattia Stella, thesis, Development of a Kerr Microscope for the study of magnetic micro and nanostructures, Politecnico Di Milano, School of Industrial and Information Engineering, 2016/2017.

[2] Jeffrey McCord, Progress in magnetic domain observation by advanced magneto-optical microscopy, Journal of Physics D: Applied Physics 48333001 (43pp), 2015.

[3] Tudu, B., and Tiwari, A., Recent Developments in Perpendicular Magnetic Anisotropy Thin Films for Data Storage Applications, Vacuum 146 (2017) 329-341.

[4] Sagar, R. U., Saleemi, A. S., Shehzard, K., Navale, S. T., Mane, R. S., and Stadler F. J, Nonmagnetic thin films for magnetic field position sensor, Sensors and Actuators A 254 (2017) 8994.

[5] S Swann, Magnetron sputtering, Physics in Technology 19, 67-75, 1988.

[6] D. Georgiana Constantin, Mihai Apreutesei, Magnetron sputtering technique used for coatings deposition; technologies and applications, BRAMAT 2011 Braşov, 24 - 26 (2011)

[7] Krishna Seshan, HANDBOOK OF THIN-FILM DEPOSITION PROCESSES AND TECHNIQUES, Principles, Methods, Equipment and Applications, Norwich, New York, U.S.A (2002).

[8] Mauro Pontes Langhi Junior, Dissertação de mestrado, Estudo do mecanismo de deposição de filmes finos de nitreto de boro assistida por feixe de íons, IF-USP, São Paulo 2009.

[9] Bertellia, T. P., Buenoa, T. E. P., Krohling, A. C., Silva, B. C., Rodríguez-Suárez, R. L., Nascimento, V. P., Paniago, R., Krambrock, K., Larica, C., and Passamani, E. C., Magnetic anisotropy of Co thin films: Playing with the shadowing effect, magnetic field and substrate spinning, Journal of Magnetism and Magnetic Materials 426 636-640, 2017.

[10] Mannan Ali, Tesis for the degree of Doctor, Growth And Study of Magnetostrictive FeSiBC Thin Films For Device Applications, Department of Physic \& Astronomy the University of Sheffield, September (1999).

[11] Qiu, Z. Q. and Bader, S. D., Surface magneto-optic Kerr effect, Review of Scientific Instruments 71, 1243 (2000).

[12] Vavassori, P., Polarization modulation technique for magneto-optical quantitative vector magnetometry, Applied Physics Letters 77, 1605 (2000). 
[13] Frank Homann aus Passau, Dissertation zur Erlangung des Doktorgradesder Naturwissenschaften, Magnetic anisotropies of $(\mathrm{Ga}, \mathrm{Mn})$ As films and nanostructures, der Fakultät Physik der Universität Regensburg, 2010.

[14] Hugo Bonette de Carvalho, Dissertação de mestrado, O Magnetômetro a Efeito Kerr e o filme fino de $\mathrm{Co} / \mathrm{Si}$, Instituto de Física Gleb Wathagin da universidade de Campinas, Fevereiro de 2002.

[15] S. Blundell. Magnetism in Condensed Matter. Oxford University Press (2001).

[16] Kittel, C., "Introdução a Física do Estado Solido", Livros Técnicos e Científicos, Rio de Janeiro, 2006.

[17] Cullity, B. D., and Grahan, C. D., Introduction to Magnetic Materials, John Wiley \& Sons, New Jersey, 2009.

[16] PAIGE, D. M., SZPUNAR, B., and TANNER, B. K., The magnetoscrystalline anisotropy of cobalt, Journal of Magnetism and Magnetic Materials 44 (1984) 239-248.

[18] Kittel, C. "Introdução a Física do Estado Solido", Livros Técnicos e Científicos, Rio de Janeiro, 2006

[17] Cullity, B. D., and Grahan, C. D., Introduction to Magnetic Materials, John Wiley \& Sons, New Jersey, 2009.

[19] Landau, L. D., and Lifsh, E. M., Electrodinámica de lós medios contínuos, Volumen 8 del Curso de Física Teórica, Editorial Reverte, S.A. Encarnación, 86. Barcelona 1981.

[20] Johnson, M. T., Bloemen, P. J., den Broeder, F. J. A. and de Vries, J. J.,“Magnetic anisotropy in metallic multilayers”, Reports on Progress in Physics 59,1409-1458, 1996.

[21] Coey, J. M., Magnetism and magnetic materials. Cambridge University Press, 2010.

[22] Filippov, B. N., Dubovik, M. N., and Zverev, V. V., Numerical studie sof micromagnetic configurations in stripes with in-plane anisotropy and low quality factor, Journal of Magnetismand Magnetic Materials 374 (2015), 600-606.

[23] Michael J. Donahue, Micromagnetic Investigation of Periodic Cross-Tie/Vortex Wall Geometry, Hindawi Publishing Corporation, Advances in Condensed Matter Physics, Volume 2012. Article ID 908692, 8 pages (2012).

[24] Konstantin, L. Metlov., Simple analytical description for the cross-tie domain wall structure, Applied Physics Letters 79, 2609 (2001).

[24] S. Middelhoek, Domain Walls in Thin NiFe Films, J. Appl. Phys. 34, 1054 (1963). 
[25] Konstantin, L. Metlov., Cross-Tie Domain Wall Ground State in Thin Films, Journal of Low Temperature Physics, Vol. 139, Nos. 1/2, April 2005.

[26] Huo, S., Pan, G., Mapps, D. J., and Clegg, W. W., Magnetic force microscopy and micromagnetic study of cross-tie wall structures in Co91Nb6Zr3 amorphous thin films, Applied Physics Letters 79, 2609 (2001).

[27] Fabio Beck, Teses de Doutorado, Dinâmica de paredes de domínio sob o efeito de correntes elétricas, Física da Universidad Federal de Santa Maria, 2013.

[28] Hashimoto, A., and Saito, S., A soft magnetic underlayer with negative uniaxial magnetocrystalline anisotropy for suppression of spike noise and wide adjacent track erasure in perpendicular recording media, Journal of Applied Physics 99, 08 Q907 (2006).

[29] Park, Y. D. , Caballero, J. A., Cabbibo, A., Childress, J. R., Hudspeth, H. D., Schultz, T. J., and Sharifi, F.

,Fabrication of nanometer-sized magnetic structures using e-beam patterned deposition masks, Journal of Applied Physics 81, 4717 (1997).

[30] Maurya, D.K., Sardarinejad, A., and Alameh, K., Recent Developments in R.F. Magnetron Sputtered Thin Films for pH Sensing Applications-An Overview, Coatings 2014, 4, 756-771.

[31] Horcas, I., Fernández, R., Gómez-Rodríguez, J. M., Colchero, J., and Gómez-Herrero, J., WSXM: A software for scanning probe microscopy and a tool for nanotechnology, Review of Scientific Instruments 78, 013705 (2007).

[32] Steffen Porthun, Leon Abelmann and Cock Lodder, Magnetic force microscopy of thin film media for high density magnetic recording, Journal of Magnetism and Magnetic Materials 182 (1998) 238-273.

[33] Edgar David Guarin Castroan, dissertação mestrado, Ánalise das microestruturas magnéticas em filmes de FeNi, UNIVERSIDADE DE BRASÍLIA, INSTITUTO DE FÍSICA BRASÍLIA, BRASIL 2017.

[34] Vansteenkiste, A., Leliaert, J., Dvornik, M., Helsen, M., Garcia-Sanchez, F., and Waeyenberge, B. Van, “The design and verification of mumax3” ,Aip Advances, vol. 4, no. 10, p. $107133,2014$.

[35] Gavin, S. Abo., Yang-Ki Hong, Jihoon Park, Jaejin Lee, Woncheol Lee and Byoung-Chul Choi, Definition of Magnetic Exchange Length, IEEE TRANSACTIONS ON MAGNETICS, VOL. 49, NO. 8, AUGUST 2013.

[36] Charles Kittel, Theory of the Structure of Ferromagnetic Domains in Films and Small Particles, Physical Review Volume 70, numbers 11 and 12, Dec. 1 and 15, 1946. 
[37] IIDA, S., The difference between GILBERT'S and LANDAU-LIFSHITZ'S equations, J. Phys, Chem. Solids. Pergamon Press 1963. Vol. 24. pp. 625-630.

[38] Lukas Novotny and Bert Hecht, Principal of Nano-optics, Cambridge University Press, New York 2006.

[39] Matthew Gallaugher, Nicolas Brodusch, Raynald Gauvin, Richard R. Chromik. Magnetic domain structure and crystallographic orientation of electrical steels revealed by a forescatter detector and electron backscatter diffraction. Ultramicroscopy142 (2014)40-49.

[40] Phway, T. P. P. and Moses, A. J., Magnetostriction trend of non-oriented 6.5\% Si-Fe, J.Magn. Magn. Mater. 320 (20), (2008), 611-613.

[41] Liang, R., Yang, P., and Mao, W., Retaining \{100\} texture from initial columnar grains in 6.5 wt\% Si electrical steels, Journal of Magnetism and Magnetic Materials 441 (2017) 511-516.

[42] Löhndorf, M., Wadas, A., Van den Berg, H. A. M., and Wiesendanger, R., Structure of crosstie wall in thin Co films resolved by magnetic force microscopy, Appl. Phys. Lett. 68, 3635 (1996)

[43] Joisten, H., Lagnier, S., Vaudaine, M. H., Vieux-Rochaz, L., and Porteseil, J. L., A magnetic force microscopy and Kerr effect study of magnetic domains and cross-tie walls in magnetoresistive NiFe shapes, Journal of Magnetism and Magnetic Materials 233 (2001) 230235.

[44] Saenz, J. J., Garcia, N., and Slonczewski, J. C., Theory of magnetic imaging by force microscopy, Applied Physics Letters 53, 1449 (1988).

[45] Hopster, H., Magnetic Microscopy of Nanostructures, Springer-Verlag Berlin, 2005, pp246

[46] Handbook of Magnetism and Advanced Magnetic Materials. Edited by Helmut Kronmüller and Stuart Parkin. Volume 2: Micromagnetism. Mathias Kläui, Magnetization Configurations and Reversal in Small Magnetic Elements, pp 11-13. (2007).

[47] Vaz, C. A. F., Lopez-Diaz, L., Kläui, M., Bland, J. A. C., Monchesky, T.L., Unguris, J. and Cui, Z., Observation of a geometrically constrained domain wall in epitaxial FCC Co small disks, Journal of Magnetism and Magnetic Materials 272-276 (2004) 1674-1675.

[48] Vaz, C. A. F., Athanasiou, C. and Bland, J. A. C., Energetics of magnetic ring and disk elements: Uniform versus vortex state, Physical Review B 73, 054411 (2006).

[49] Handbook of Magnetism and Advanced Magnetic Materials. Edited by Helmut Kronmüller and Stuart Parkin. Volume 2: Micromagnetism. Mathias Kläui, Magnetization Configurations and Reversal in Small Magnetic Elements, pp 13-15. (2007). 
[50] HUBERT, A., and SCHÄFER, R., Magnetic Domains: The Analysis of Magnetic Microstructures, Springer-Verlag, Berlin, 1998. 